\title{
WED-SQL: uma linguagem declarativa intermediária com apoio transacional para a modelagem e implementação de Sistemas de Informação Cientes de Processos.
}

\author{
Bruno Padilha
}

DisSERTAÇÃO APRESENTADA

$\mathrm{AO}$

Instituto DE MATEMÁtica e EstatísticA

DA

Universidade DE SÃo PAUlo

PARA

OBTENÇÃO DO TÍTULO

$\mathrm{DE}$

Mestre EM CiênCIAS

\author{
Programa: Ciência da Computação \\ Orientador: Prof. Dr. João Eduardo Ferreira \\ Coorientador: Prof. Dr. Calton Pu
}

Durante o desenvolvimento deste trabalho o autor recebeu auxílio financeiro do NIH-USA, da FAPESP e do CNPQ 
São Paulo, julho de 2018 


\section{WED-SQL: uma linguagem declarativa intermediária com apoio transacional para a modelagem e implementação de Sistemas de Informação Cientes de Processos.}

Esta é a versão original da dissertação elaborada pelo candidato Bruno Padilha, tal como submetida à Comissão Julgadora. 


\section{Resumo}

\section{PADILHA, B. WED-SQL: uma linguagem declarativa intermediária com apoio transacional para a modelagem e implementação de Sistemas de Informação}

Cientes de Processos.. Dissertação (Mestrado) - Instituto de Matemática e Estatística, Universidade de São Paulo, São Paulo, 2018.

Os Sistemas de Informação Cientes de Processo (PAIS), os quais incluem os Sistemas de Gerenciamento de Processo de Negócio (BPM) e os Sistemas Gerenciadores de Workflows, tem evoluído continuamente para atender às demandas por sistemas cada vez mais complexos tanto no domínio de processos de negócio quanto no campo dos processos científicos. Não obstante, as abordagens tradicionais ainda são incapazes de prover uma integração simples e direta entre a modelagem e a implementação de tais sistemas. As abordagens formais (e.g. Álgebras de Processos e Redes de Petri) são suficientes para a especificação de sistemas que possam ser formalmente verificados, no entanto sua implementação é difícil e não padronizada. A notação BPMN, largamente empregada como ferramenta de modelagem de processos de negócio, apesar de simples e funcional, não aborda de forma criteriosa aspectos importantes de implementação. Por outro lado, WS-BPEL é uma linguagem desenvolvida apenas para controle de execução de processos de negócio, negligenciando a modelagem. Além do mais, nenhuma dessas abordagens é suficientemente adequada para tratar estratégias adaptativas, as quais implicam em mudanças estruturais recorrentes no sistema de software. Nesse contexto, com base na abordagem WED-flow, este trabalho apresenta a WED-SQL: uma linguagem intermediária declarativa, específica de domínio (DSL), e com apoio transacional para a modelagem e implementação de PAIS.

Palavras-chave: WED-flow, WED-SQL, Workflow, Sistemas de Informação Cientes de Processos, Transações de Longa Duração, Processos de Negócio. 


\section{Abstract}

PADILHA, B. WED-SQL: an intermediate transactional based declarative language for modeling and implementation of Process-Aware Information Systems. Master's dissertation - Institute of Mathematics and Statistics, University of São Paulo, São Paulo, 2018.

Process-Aware Information Systems (PAIS), which include Business Process Management (BPM) systems and Workflow Management systems, have been evolving to fulfill the requirements of increasingly complex business and scientific applications. In spite of all efforts, traditional approaches still struggle to provide a seamless integration between the structural design and implementation of such systems. Formal approaches (e.g. Process Algebras and Petri Net) are sufficient to specify systems that can be formally verifiable, albeit unwieldy to implement. The widespread BPMN notation is remarkably effective and a easy to use tool for modeling despite setting aside implementation aspects. On the other hand, the WS-BPEL is a language for execution control of business process that lacks support for modeling. Furthermore, none of these approaches are ideal to handle adaptive strategies that result in recurrent application structural changes. In this context, based on the WEDflow approach, we present WED-SQL: a transactional based, domain-specific, intermediate declarative language for modeling and implementation of PAIS.

Keywords: WED-flow, WED-SQL, Workflow, PAIS, Long Lived Transactions, Business Process. 


\section{Sumário}

1 Introdução 1

2 Fundamentos $\quad 5$

2.1 A abordagem WED-flow . . . . . . . . . . . . . . . 5

2.1 Definições .......................... 6

2.2 PostgreSQL: Banco de Dados Relacional . . . . . . . . . . . . . . 9

2.3 Linguagens de Programação . . . . . . . . . . . . . . . . . . . 10

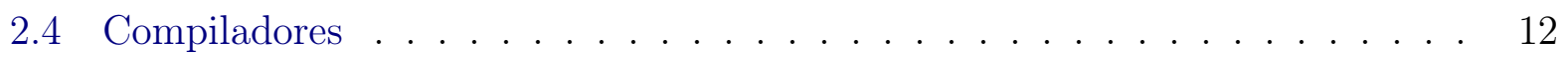

2.4.1 Compiladores \& Interpretadores . . . . . . . . . . . . . . . . 13

2.4.2 Estrutura Básica de um Compilador . . . . . . . . . . . . . . 13

2.4.3 Ferramentas auxiliares .................. 16

2.5 Conclusão . . . . . . . . . . . . . . . . . . . . . 17

3 Trabalhos Relacionados $\quad 19$

3.1 Abordagens Orientadas a Processos . . . . . . . . . . . . . . . . . . 19

3.2 Abordagens Orientadas a Eventos . . . . . . . . . . . . . . . . 21

3.3 Abordagens Orientadas a Dados . . . . . . . . . . . . . . . . . 21

3.4 Conclusão . . . . . . . . . . . . . . . . . . . . . . . 22

4 WED-Engine: Ambiente Transacional de Execução e Gerenciamento de 
4.1 Arquitetura . . . . . . . . . . . . . . . . . . . . 23

4.2 Modelo de dados . . . . . . . . . . . . . . . . . . . . . . . 24

4.3 Algoritmos de Controle Transacional . . . . . . . . . . . . . . . . 25

4.4 Implementado WED-workers . . . . . . . . . . . . . . . . . . . . . . . 29

4.5 Sistema de Notificações . . . . . . . . . . . . . . . . . . . . 30

4.6 Protocolo de Comunicação . . . . . . . . . . . . . . . . . . . . . . . . . . 31

4.7 Isolamento Transacional e Paralelismo f . . . . . . . . . . . . . . . . . 32

4.8 Executando as WED-transitions . . . . . . . . . . . . . . . . . . . . 34

4.8.1 Stored Procedure Vs. WED-Workers . . . . . . . . . . . . . . 34

4.9 Conclusão . . . . . . . . . . . . . . . . . . . . . . . . 37

5 WED-SQL: Uma linguagem intermediária de implementação 39

5.1 Por que utilizar WED-SQL ao invés de SQL ? . . . . . . . . . . . . . 41

5.2 WED-SQL: Sintaxe e Operações . . . . . . . . . . . . . . . . . . 42

5.2 .1 Operações de Definição . . . . . . . . . . . . . . . . . . . . . 42

5.2.2 Operações de Gerenciamento . . . . . . . . . . . . . . . . . 44

5.3 Descrição Formal . . . . . . . . . . . . . . . . . . . . . . . . 46

5.4 Interpretador de Comandos . . . . . . . . . . . . . . . . 49

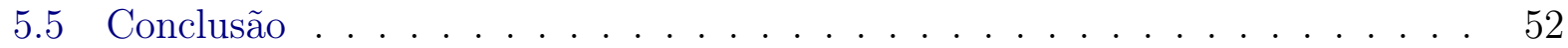

6 Modelagem e Implementação $\quad 53$

6.1 Exemplo: Agência de Viagens . . . . . . . . . . . . . . . . . . 53

6.1 .1 Identificando os Eventos . . . . . . . . . . . . . . 55

6.1.2 Identificando as Atividades . . . . . . . . . . . . . 56 
6.1 .3 Parametrizando Eventos . . . . . . . . . . . . . . . 57

6.1.4 Capturando Eventos . . . . . . . . . . . . . . . . . . . . 59

6.1 .5 WED-SQL . . . . . . . . . . . . . . . . . 62

6.1.6 Implementando as WED-transitions . . . . . . . . . . . . . . . 63

6.1.7 Execução \& Análise de Resultados . . . . . . . . . . . . . . . . . 65

6.2 Estendendo o Exemplo . . . . . . . . . . . . . . . . . . . . 70

6.2 .1 Implementação em WED-SQL . . . . . . . . . . . . . . . . . . . . 74

6.3 Conclusão . . . . . . . . . . . . . . . . . . . . . . . 76

7 Conclusão

Referências Bibliográficas 


\section{Capítulo 1}

\section{Introdução}

A crescente evolução das tecnologias da informação ao longo das últimas décadas ampliou extensamente a capacidade de comunicação tanto entre pessoas quanto entre computadores, tornando a disseminação do conhecimento cada vez mais rápida, abrangente e expressiva. Como consequência, a rapidez com que grandes companhias precisam reagir a mudanças de comportamento e novas tendências a fim de manter seus produtos ou serviços relevantes, resulta em modelos de processo de negócio muito mais dinâmicos e que evoluem significativamente no decorrer do tempo. Os sistemas de software que implementam esses processos de negócio modernos precisam ser flexíveis, suscetíveis a mudanças estruturais e prover mecanismos que simplifiquem a incorporação de novas regras de negócio e minimizem seu custo de manutenção. De modo mais abrangente, vamos adotar o termo Process-Aware Information Systems [15] (PAIS) para nos referir à toda infraestrutura de sistemas de software para gerenciamento de Processos de Negócio (BPM) [51], Processos Científicos, Worflows [56] e aplicações similares. PAIS são sistemas de software que gerenciam e executam processos segundo regras e modelos explicitamente definidos.

As abordagens clássicas para modelagem e implementação de PAIS [28], tais como Business Process Model and Notation (BPMN)[38],[55], Web Services Business Process Execution Language [37] (WS-BPEL), Redes de Petri [31] e as Álgebras de Processos [5] são apropriadas para especificar modelos estáticos, nos quais o fluxo da operação, ou seja, os possíveis caminhos a serem seguidos e seus resultados possam ser pré-definidos e sofram poucas mudanças durante o ciclo de vida do sistema. Isso ocorre uma vez que algumas dessas abordagens são específicas para modelagem, enquanto que outras são exclusivas para implementação. Por exemplo, as abordagens formais (e.g. Álgebras de Processos e Redes de Petri) são suficientes para a especificação de sistemas que possam ser formalmente verificados, no entanto sua implementação é difícil e não padronizada. A notação BPMN, largamente empregada como ferramenta de modelagem de processos de negócio, apesar de simples e funcional não aborda 
de forma criteriosa aspectos importantes de implementação. Por outro lado, WS-BPEL é uma linguagem desenvolvida apenas para controle de execução de processos de negócio, negligenciando a modelagem.

Dada a crescente demanda por modelos dinâmicos a adaptativos para os PAIS atuais, nenhuma das abordagens citadas é suficientemente adequada para especificá-los por não fornecerem uma solução completa que aborde tanto os aspectos abstratos da modelagem quanto os aspectos concretos da implementação. Um desalinhamento entre o modelo e a implementação pode inviabilizar a construção de tais sistemas, cuja evolução incremental depende significativamente de um bom acoplamento e flexibilidade equivalente de ambos aspectos. Por exemplo, uma técnica comumente empregada no desenvolvimento de PAIS é modelar os processos com BPMN e efetuar o controle de execução com WS-BPEL. Conforme discutido em [52], esse mapeamento não é direto e nem formalmente especificado, o que muitas vezes impossibilita manter as duas abordagens em sincronia para sistemas mais complexos. Esse descompasso deteriora a qualidade do código e compromete a manutenibilidade do sistema, além de impor severas limitações à capacidade de adaptação a reestruturações nas regras de negócio.

Para tentar suprir essa necessidade por abordagens mais dinâmicas e flexíveis, diversos modelos alternativos para a modelagem e implementação de PAIS foram propostos nas últimas décadas. Especificamente na área de banco de dados, com o advento do conceito de transação e a introdução do modelo ACID [23] no início dos anos 80, os sistemas gerenciadores de bancos de dados relacionais (SGBDR) passam a contar com apoio à recuperação de falhas. Embora esse modelo transacional clássico ainda atenda às necessidades de recuperação de falhas de muitos sistemas de informação modernos, ele já não é suficiente para atender a demanda de sistemas mais avançados, especialmente sistemas que tratam com transações de longa duração [16]. Sendo assim, diversos sistemas transacionais avançados [17] foram propostos posteriormente.

Outro avanço significativo na área de bancos de dados foi a introdução do conceito Evento-Condição-Ação (ECA, do inglês Event-Condition-Action) com o advento dos Bancos de Dados Ativos (BDA) [14]. Os BDA são um aperfeiçoamentos dos SGBD tradicionais com a incorporação de triggers, funções agregadas, restrições de integridade assim como outras funcionalidades que habilitaram os SGBD a efetuarem um gerenciamento primitivo de workflows. Sumariamente, por meio de um conjunto de regras (ou condições) e ações que pré-especificadas, pode-se definir como o BDA deve reagir à modificações nos dados armazenados. Além disso, uma outra abordagem, baseada em restrições, foi proposto por [54] especificamente para modelar workflows dinâmicos, para os quais não é possível inferir todo seu controle de fluxo com precisão em tempo de modelagem. Nessa abordagem, a ordem em que as atividades de um workflow devem ser executadas é definida implicitamente a partir de um conjunto de restrições declaradas previamente. Desse modo, qualquer ordem 
de execução que não viole as restrições é uma ordem válida. Embora promissora, e a despeito de permitir a construção de modelos mais flexíveis, os próprios autores afirmam a existência de problemas severos de desempenho na implementação de modelos extensos utilizando essa abordagem.

Uma característica comum a todo sistema baseado em processos é a produção de dados resultantes das relações interprocessos. Embora negligenciada pela maioria das abordagens, projetos que integram análise de dados à fase de modelagem de um PAIS são intrinsecamente mais flexíveis do que projetos que a desprezam. Com auxílio desses dados, é possível capturar o comportamento dos processos de modo mais detalhado e preciso, não apenas simplificando a incorporação de modificações estruturais ao sistema, como também reduzindo a complexidade da deteç̧ão de falhas. Nesse contexto, em [19] é proposta uma abordagem alternativa para a modelagem e implementação de PAIS denominada WED-flow, a qual introduz o conceito de estados de dados como força motriz do gerenciamento de processos.

Há três conceitos fundamentais que podem ser identificados em um PAIS: workflow, ou fluxo de trabalho; event flow, ou fluxo de eventos; data flow, ou fluxo de dados. A abordagem WED-flow considera que esses três conceitos são igualmente importantes, e que combiná-los é uma estratégia eficiente para a construção de modelos suficientemente flexíveis que atendam às necessidades dos PAIS atuais. Nessa abordagem, o fluxo de trabalho é modelado de modo implícito por meio de gatilhos que capturam eventos e disparam a execução dos processos. Os eventos são parametrizados como estados de dados, que por sua vez são a única via de comunicação entre processos. Desse modo, pode-se dizer que, na abordagem WED-flow, os processos consomem e também produzem estados de dados. Definir o fluxo de trabalho de um PAIS de modo implícito simplifica seu desenvolvimento incremental e adaptativo, uma vez que elimina-se estruturas rígidas de controle que dificultam e encarecem a evolução do sistema ao longo do tempo. Além disso, na abordagem WED-flow ${ }^{1}$ todo relacionamento entre processos é precisamente definido como uma sequência temporal de estados dados, e toda execução de processo é uma transação ACID. Essas duas propriedades facilitam a identificação de comportamentos errôneos no sistema e favorecem substancialmente a recuperação de falhas.

As definições formais e propriedades matemáticas da abordagem WED-flow permitem construir modelos de PAIS que, além de precisamente definidos, contem com a flexibilidade estrutural exigida pelas aplicações modernas. No entanto, por mais que essas definições e propriedades sejam suficientes para a modelagem e especificação de um sistema, a abordagem não provê mecanismos ou ferramentas de implementação. Desse modo, para que esses

\footnotetext{
${ }^{1}$ É importante notar que, no restante deste texto, o termo WED-flow será utilizado tanto para mencionar a abordagem WED-flow como para referir-se a exemplos de sistemas modelados e implementados segundo essa abordagem. Nesse último caso, o termo WED-flow será precedido de um pronome masculino (e.g. esse WED-flow, o WED-flow, um WED-flow e etc ...).
} 
modelos sejam implementados de maneira eficiente, com apoio adequado a sua evolução incremental e amparados por propriedades transacionais, este trabalho propõe-se não somente a fornecer um arcabouço transacional para a implementação de WED-flows, como também a linguagem de especificação WED-SQL: uma linguagem específica de domínio declarativa [21], de sintaxe similar a linguagem SQL, mas construída para representar as abstrações da WED-flow de modo natural e intuitivo. Por meio dessas duas ferramentas, espera-se difundir a abordagem WED-flow como abordagem alternativa para o desenvolvimento de PAIS robustos, flexíveis, confiáveis e que atendam aos requisitos dos processos de negócio e científicos contemporâneos.

O restante deste trabalho está organizado da seguinte forma. No capítulo 2 serão apresentados os fundamentos e conceitos envolvidos na elaboração das ferramentas aqui propostas. O capítulo 3 discute, de um ponto de vista técnico e histórico, os trabalhos relacionados à abordagem WED-flow. No capítulo 4 será apresentado em detalhes o ambiente de execução de WED-flow, incluindo detalhes de funcionamento e do processo de construção. O capítulo 5 apresenta formalmente a linguagem WED-SQL, descrevendo sua gramática livre de contexto e a sintaxe dos comandos. No capítulo 6 apresentamos, por meio de um exemplo prático, as técnicas de modelagem e implementação de um PAIS segundo a abordagem WED-flow. O capítulo 7 conclui o trabalho. 


\section{Capítulo 2}

\section{Fundamentos}

Neste capítulos serão apresentados os conceitos e fundamentos necessários para a melhor compreensão das ferramentas propostas neste trabalho.

\subsection{A abordagem WED-flow}

Assim como toda tecnologia tende a evoluir com o passar do tempo, os PAIS não fogem à regra. Outrora modelados como uma estrutura estática, com propósitos e objetivos precisamente definidos previamente, em que a inclusão de novas regras ou o tratamento de exceções causadas por uma execução não prevista de uma sequência de processos são eventos raros, já não é o paradigma apropriado nem para a modelagem e nem para a implementação dos PAIS contemporâneos. Por exemplo, as empresas atualmente precisam perceber tendências e reagir muito mais rápido a mudanças para se manterem competitivas em um mercado com níveis de concorrência sem precedentes. Para isso, é fundamental que seus processos de negócio, assim como suas operações, estejam amparados por um modelo que apoie evolução do modo mais eficiente possível. O mesmo princípio aplica-se aos processos científicos, em que novas descobertas e resultados frequentemente implicam em mudanças, muitas vezes abruptas, no modelo de pesquisa.

A abordagem WED-flow propõe-se a solucionar esse problema por meio de um caminho ainda pouco explorado na área de BPM: uma modelagem baseada em estados de dados que disparem transações ao satisfazerem determinadas condições. Desse modo, modificar ou adicionar nova regras de negócios a um projeto WED-flow, o que efetivamente implica na criação de novos processos, é uma simples questão de definir novas condições associadas a novas transações. Esse paradigma captura a verdadeira essência dos modelos de processos 
de negócio dinâmicos, possibilitando a evolução incremental de um sistema em praticamente todas as fases do projeto. Tanto a deteç̧ão quanto o tratamento de exceções são amplamente amparados por propriedades transacionais avançadas, o que simplifica a integração ao sistema mesmo em tempo de execução.

Sem perda de generalidade, um PAIS modelado e implementado segundo a abordagem WED-flow será doravante denominado apenas como um WED-flow, embora, em muitas ocasiões esse sistema de software pode ser composto de múltiplos WED-flows.

\subsubsection{Definições}

Formalmente, a WED-flow [19] é composta das seguintes definições e propriedades:

\section{Definição 1: WED-attribute}

Os WED-attributes podem ser definidos de maneira similar a um atributo em um banco de dados relacional, ou seja, é a propriedade representada por uma coluna em uma tabela. São utilizados para definir os estados de dados de um WED-flow.

\section{Definição 2: WED-state}

Dados $a_{1}, a_{2}, \ldots, a_{n}$ como os WED-attributes de um dado WED-flow, considere a tupla $\mathcal{A}=\left\langle a_{1}, a_{2}, \ldots, a_{n}\right\rangle$. Assim, define-se um WED-state como a tupla $\left\langle v_{1}, v_{2}, \ldots, v_{n}\right\rangle$, em que $v_{i}$ corresponde ao $i$-ésimo atributo de $\mathcal{A}$, para $1 \leq i \leq n$. Desse modo, $\mathcal{S}=\left\{\left\langle v_{1}, v_{2}, \ldots, v_{n}\right\rangle \mid\right.$ $\left.\forall i \in[1 ; n], v_{i} \in \operatorname{dominio}\left(a_{i}\right)\right\}$ é o conjunto de todos os WED-states possíveis de um determinado WED-flow.

\section{Definição 3: WED-condition}

Dado um WED-flow, uma WED-condition é um predicado definido sobre o conjunto de WED-attributes $\mathcal{A}$. Desse modo, sendo $\mathcal{C}$ o conjunto das WED-conditions, pode-se dizer que, para um dado WED-state $s \in S$ e uma WED-condition $c \in C$, s satisfaz $c$ se o valor dos atributos de $s$ tornam $c$ verdadeira. 


\section{Definição 4: WED-transition}

Uma WED-transition $t$ é uma função $t: S \rightarrow S$, ou seja, $t$ recebe um WED-state como entrada e devolve um WED-state como saída. Cada WED-transition pode estar ainda associada a um conjunto $\mathcal{U}_{t}=\left\langle u_{1}, u_{2}, \ldots, u_{m}\right\rangle$, tal que $u_{i} \in \mathcal{A}$ (para $1 \leq i \leq m \leq n$ ), o qual restringe quais WED-attributes do WED-state recebido por $t$ podem ser atualizados. $T$ é o conjunto das WED-transitions de um dado WED-flow.

\section{Definição 5: WED-trigger}

Um WED-trigger $g$ é definido como a tupla $g=\langle c, t\rangle$ em que $c \in C$ e $t \in T$, ou seja, $g$ associa uma WED-condition a uma WED-transition. Quando um WED-state $s$ satisfaz $c$, $g$ é responsável por disparar $t$. $G$ é o conjunto dos WED-triggers definidos para um dado WED-flow.

\section{Definição 6: WED-flow}

De acordo com as definições anteriores, um WED-flow é definido pela tripla $\left\langle G, c_{i}, c_{f}\right\rangle$, em que $c_{i}, c_{f} \in C$. As WED-conditions $c_{i}$ e $c_{f}$ definem respectivamente um conjunto de WED-states iniciais válidos e um conjunto de WED-states finais para este WED-flow. Em outras palavras, um WED-flow é uma composição de WED-transitions, as quais são disparadas pelos WED-triggers quando um WED-state satisfaz sua WED-condition associada. Desse modo, cada WED-transition produz um WED-state, o qual pode ocasionar o disparo de novas WED-transitions.

\section{Definição 7: História de execução de uma instância}

O conjunto de todas as WED-transitions executadas para uma instância de um WEDflow, juntamente com os respectivos WED-states gerados até que se atinja WED-state final, recebe o nome de história de execução. Essa historia de execução é composta de uma sequência de registros representados pela trípla $\left\langle s_{c}, t, s_{o}\right\rangle$, da qual:

- $s_{c} \in S$ é o WED-state que satisfez a WED-condition associada a $t$;

- $t \in T$ é a WED-transition executada;

- $s_{o} \in S$ é o WED-state gerado por $t$. 
O estado de dado atual de uma instância é o WED-state representado por $s_{o}$ do último registro de seu histórico. Caso esse WED-state seja um estado final válido, essa instância terminou com sucesso.

Vale salientar que, de acordo com essa definição, $s_{c}$ pode não ser igual a $s_{i}$. Isso ocorre uma vez que $s_{c}$ pode iniciar mais de uma WED-transition que serão executadas em paralelo. Uma vez que toda WED-transition sempre atualiza o estado atual da instância, $s_{c}=s_{i}$ apenas quando nenhuma outra WED-transition terminar durante a execução de $t$.

\section{Definição 8: WED-state transação-consistente}

Dada uma instância $i$ de um WED-flow $f=\left\langle G_{f}, c_{i f}, c_{f_{f}}\right\rangle$, um WED-state $s \in S$ de $i$ é dito transação-consistente se vale uma das seguintes condições:

- $\exists\left\langle c_{f}, t_{f}\right\rangle \in G_{f}$ tal que $s$ satisfaz $c_{f}$, ou seja, $s$ implica no disparo de $t_{f}$;

- $s$ não implica no disparo de nenhuma WED-trigger $t \in G_{f}$, mas existe ao menos uma WED-transition executando em $i$. Nesse caso, $s$ não será o ultimo estado gerado em $i$.

O WED-state inicial de uma instância precisa, necessariamente, ser um estado transaçãoconsistente. Caso contrário, a menos que esse estado inicial seja um estado final, essa instância sequer seria inicializada.

\section{Definição 8: WED-state inconsistente}

Um WED-state é inconsistente caso não seja final ou transação-consistente. Um estado inconsistente é gerado quando ocorre uma das seguintes situações em uma dada instância:

- Uma WED-transition aborta sua execução devido a alguma falha ou mesmo de modo deliberado por um usuário do sistema;

- Um erro de modelagem do WED-flow.

Quando um estado inconsistente é gerado em uma instância, sua execução é interrompida e o WED-flow inicia o processo de recuperação dessa instância. No entanto, a descrição detalhada desses processos de recuperação de instâncias inconsistentes está além do escopo desse trabalho. 


\subsection{PostgreSQL: Banco de Dados Relacional}

O PostgreSQL [24] é um sistema gerenciador de banco de dados relacional(SGBDR) de código aberto, amplamente utilizado por grandes empresas, universidades e agências governamentais. Devido à sua vasta documentação e a algumas de suas propriedades, por exemplo, permitir que seus usuários adicionem novos tipos de dados e novas estruturas de controle por meio da escrita de módulos adicionais utilizando múltiplas linguagens de programação, possibilitar o controle de concorrência entre transações concomitantes de modo explícito, acesso às suas estruturas de dados internas de controle, criação de processos em segundo plano dentre outras propriedades, esse SGBDR foi escolhido como base de implementação do arcabouço de controle e execução WED-flow denominado WED-Engine, o qual será discutido em detalhes no capítulo 4. As principais estruturas de controle fornecidadas pelo PostgreSQL e empregadas no desenvolvimento do WED-Engine são as Stored Procedures [17], os Database Triggers [17] e os Background Workers [24].

Em banco de dados, Stored Procedures são funções que ficam armazenadas e cuja execução é controlada pelo SGBDR. Essas funções são úteis, por exemplo, quando algum processamento precisa ser feito sobre os dados resultantes de uma consulta que é executada por várias aplicações, não só simplificando a manutenção do código dessa função como também potencialmente reduzindo a quantidade de dados em uma transferência, diminuindo o custo de comunicação.

Database Trigger é uma funcionalidade dos SGBDR que permite associar a execução de uma Stored Procedure à ocorrência de um evento de inserção, remoção ou atualização de dados em uma tabela específica. Com isso, é possível analisar uma nova entrada de dados, ou alguma modificação, antes de armazená-la definitivamente e executar uma sequência de operações apropriadas a tal evento. Por exemplo, ao criar-se uma nova instância em um WED-flow, é preciso fazer uma série de verificações e validações antes que a mesma possa ser inicializada, disparando as WED-triggers conforme necessário (de acordo com o Algoritmo 1 do capítulo de Fundamentos).

Background Workers, ou Processos em Segundo Plano, é uma funcionalidade do PostgreSQL que permite a um usuário escrever um programa, utilizando a linguagem de programação C, que será executado em segundo plano pelo PostgreSQL como um novo processo do sistema operacional. Esses processos são versáteis, além de convenientes para executar tarefas de monitoramento transacional e detecção de falhas, uma vez que executam de modo paralelo e são gerenciados pelo SGBDR. Esses processos em segundo plano foram empregados na WED-Engine para gerenciar as WED-transitions, ou seja, garantir que uma execução não ultrapasse seu tempo limite assim como restaurar a execução das instâncias caso o PostgreSQL seja reiniciado. 
Os SGBDR precisam armazenar metadados sobre as estruturas de tabelas, índices, transações, funções e etc. Esses dados são armazenados em tabelas especiais denominadas Catálogos de Sistema. Em particular, o PostgreSQL também armazena nesses catálogos muito dos seus dados sobre estruturas internas de controle, utilizando-os como referência para suas operações. Esse modelo recebe o nome de Catalog-driven operation, ou operação baseada em catálogos. Além disso, os usuários do PostgreSQL acessam, dadas as devidas permissões, essas informações como tabelas ordinárias, simplificando tanto o desenvolvimento de módulos adicionais como também a modificação do comportamento do SGBDR em geral. Essa propriedade é fundamental para garantir um funcionamento adequado do WED-Engine, principalmente para o gerenciamento transacional.

Outra peculiaridade do PostgreSQL é permitir a adição de novos tipos de dados e estruturas de controle por meio de módulos escritos por usuários utilizando múltiplas linguagens de programação. A mais simples delas, denominada $p g S Q L$, é uma extensão da linguagem SQL com a inclusão de elementos procedurais. Esses módulos também podem ser escrito utilizando a linguagem $\mathrm{C}$, o que possibilita obter tanto um controle mais refinado sobre as estruturas de dados quanto o máximo desempenho dentre as demais linguagens que podem ser utilizadas. Embora os procedimentos escritos em ambas linguagens executem mais rapidamente do que procedimentos escritos nas demais linguagens, para algumas situações elas podem não ser totalmente adequadas, seja pela expressividade limitada da pgSQL ou devido à complexidade de detalhes da linguagem $\mathrm{C}$ para implementar lógicas de programação de maior complexidade. Por esses motivos, o PostgreSQL também aceita código escrito em algumas linguagens procedurais, como Python, Perl, TCL ou até mesmo Java. Devido à dinamicidade da abordagem WED-flow, a linguagem Python é a mais apropriada e foi a escolhida para implementar o WED-Engine, recorrendo-se a linguagem C apenas quando estritamente necessário. Além disso, consultas SQL são amplamente utilizadas na manipulação dos dados.

\subsection{Linguagens de Programação}

Formalmente, uma Linguagem de Programação (LP) é um conjunto de palavras definidas sobre um alfabeto de símbolos e um conjunto de regras que definem as estruturas e sequências de palavras válidas para essa linguagem. Dizemos que uma sequência de palavras aceita por uma LP é uma expressão, ou sequência de palavras, válida. Desse modo, podemos definir um Programa de Computador como uma sequência de expressões válidas para uma determinada LP, as quais especificam uma série de operações a serem executadas por um computador. Normalmente, a sintaxe de uma LP, ou seja, o conjunto de regras que definem suas expressões válidas, é expressa por meio de uma Gramática Livre de Contexto 
Uma abordagem amplamente difundida para o projeto de uma LP é especificar sua sintaxe por meio de uma gramática livre de contexto (ou CFG, do inglês Context-free Grammar. Uma CFG é uma descrição formal de uma linguagem por meio de um conjunto finito de regras de produção ou substituição. Por sua vez, cada regra de produção é formada por símbolos terminais e símbolos não terminais, na qual há um símbolo não terminal mais a esquerda seguido de uma ou mais regras de produção. Por exemplo, a CFG representada na figura 2.1 reconhece a linguagem das expressões aritméticas que contenham os operadores ,$+{ }^{*}$ e parenteses. Nessa gramática temos os símbolos não terminais $E, F$ e $T$ e os simbolos terminais,$+^{*}$, ), (, <numero $>$, em que <numero $>$ pode ser definido como uma sequência não vazia de algarismos decimais. Além disso, o símbolo não terminal mais à esquerda da primeira regra, o símbolo $E$ nesse exemplo, é também chamado Símbolo Inicial, o qual define o ponto de entrada da avaliação da CFG. Desse modo, para avaliar se uma expressão aritmética é aceita pela linguagem representada por essa CFG, partindo do símbolo E, devemos aplicar as regras de substituição recursivamente até que tenhamos apenas símbolos terminais. Por exemplo, a figura 2.2 ilustra uma sequência de substituições para avaliar a expressão "2 $+3 * 4$ ".

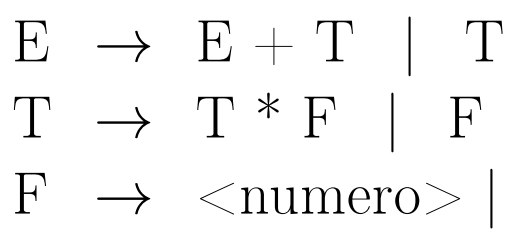

Figura 2.1: CFG para reconhecer expressões aritméticas que contenham apenas os operadores + ou *

$$
\begin{aligned}
E & \Longrightarrow E+T \\
& \stackrel{T \rightarrow T * F}{\longrightarrow} E+T * F \\
& \stackrel{F \rightarrow<\text { numero }>}{\longrightarrow} E+T *<\text { numero }> \\
& \stackrel{T \rightarrow F}{\longrightarrow} E+F *<\text { numero }> \\
& \stackrel{F \rightarrow<\text { numero }>}{\longrightarrow} E+<\text { numero }>*<\text { numero }> \\
& \stackrel{E \rightarrow T}{\longrightarrow} T+<\text { numero }>*<\text { numero }> \\
& \stackrel{T \rightarrow F}{\longrightarrow} F+<\text { numero }>*<\text { numero }> \\
& \stackrel{F \rightarrow<\text { numero }>}{\longrightarrow}<\text { numero }>+<\text { numero }>*<\text { numero }> \\
& \Rightarrow 2+3 * 4
\end{aligned}
$$

Figura 2.2: Avaliando a expressão $2+3 * 4$ com a $C F G$ da figura 2.1

Especificar uma LP por meio de uma CFG é uma técnica que, além de simplificar o projeto de implementação de software capazes de reconhecerem essa linguagem, também define regras formais que são menos dependentes da tecnologia utilizada para a implementação de 
tais softwares, tornando a linguagem sintaticamente mais robusta e menos propensa a conter inconsistências léxicas, ou seja, tanto sua estrutura quanto seu conjunto de palavras podem ser melhor definidos por meio de uma CFG. No entanto, a vasta maioria das linguagens de programação comerciais (e.g. Java, Python, $\mathrm{C}++$ ) não são livres de contexto, ou seja, essas linguagens apesar de em geral possuírem uma CFG que as especificam parcialmente, dependem também de uma análise semântica para serem interpretadas corretamente. Por exemplo, na linguagem Python os blocos de código que definem o escopo de uma função ou de uma operação de laço são definidos apenas por meio da indentação do código. Desse modo, um programa interpretador de Python precisa conhecer o contexto no qual se insere cada expressão a fim de poder avaliá-la corretamente, o que não pode ser feito apenas por meio de uma CFG. Por outro lado, a especificação da linguagem WED-SQL proposta neste trabalho é livre de contexto, ou seja, a linguagem WED-SQL é especificada em sua totalidade por meio de uma CFG (capítulo 5, código 5.2).

\subsection{Compiladores}

Historicamente, os circuitos integrados que compõem os microprocessadores são construídos para processar sinais digitais com base no sistema binário de numeração. Por consequência, os programas executáveis em computadores digitais são conjuntos de instruções primitivas descritas em linguagem binária, também conhecida como Linguagem de Máquina. Por mais que essa padronização simplifique a construção de microprocessadores e outros circuitos afim, escrever programas em linguagem de máquina torna-se rapidamente uma tarefa árdua, trabalhosa e propensa a erros após algumas dezenas de linhas de código. Desse modo, os programas de computador são majoritariamente escritos, a menos de casos muito específicos, em linguagens de programação mais sofisticadas e com maior poder de abstração. Em relação à linguagem de máquina, linguagens de programação como Python, Java ou até mesmo C são conhecidas como Linguagens de Alto Nivel. No entanto, antes que programas escritos em linguagens de alto nível possam ser executados é preciso traduzi-los para linguagem de máquina. Esse processo de tradução, denominado Compilação [2], é executado por programas específicos conhecidos coletivamente por Compiladores [4].

Escrever um programa utilizando uma linguagem de alto nível traz benefícios importantes. Por exemplo, programas são escritos mais rapidamente uma vez que linguagens de alto nível são construídas para representar estruturas de dados e operações sobre as mesmas de modo mais natural e intuitivo. Além disso, usualmente esses programas são consideravelmente mais curtos do que se fossem escritos em linguagem de máquina, o que os torna mais fáceis de ler e menos suscetíveis a conter erros. Durante o processo de compilação, os compiladores são capazes de detectar erros em linguagens de alto nível que outrora passa- 
riam despercebidos em programas escritos diretamente em linguagem de máquina. Outra grande vantagens de linguagens compiladas é a capacidade dos compiladores em abstrair detalhes de arquitetura de diferentes fabricantes de microprocessadores. Por exemplo, um mesmo programa escrito em linguagem $\mathrm{C}$ pode ser compilado para executar em um chip de arquitetura $\mathrm{ARM}^{1}$ ou em um chip de arquitetura Intel x86. Uma desvantagem de programas compilados é que o código de máquina gerado automaticamente por um compilador pode executar mais lentamente do que um código equivalente escrito diretamente em linguagem de máquina. No entanto, como resultado de inúmeras pesquisas e processos de otimização, o código gerado pelos compiladores atuais para a maioria das linguagens de programação mais populares tem eficiência suficientemente satisfatória, e em alguns casos (e.g GCC para a linguagem C) muito próxima da eficiência máxima que se poderia extrair de um dado microprocessador.

\subsubsection{Compiladores \& Interpretadores}

Sucintamente, compiladores podem ser descritos como programas de computador que recebem como entrada um programa escrito em linguagem de alto nível e produz como saída o mesmo programa em código de máquina, também conhecido como Código Objeto. Por sua vez, os interpretadores são programas que, assim como os compiladores, também recebem como entrada um programa escrito em linguagem de alto nível. No entanto, em vez de gerar código de máquina um interpretador avalia cada sentença de sua entrada e executa uma ação correspondente. Em outras palavras, um compilador precisa necessariamente analisar todo o código que recebe como entrada antes de gerar o código de máquina correspondente em sua saída, enquanto que um interpretador avalia a sua entrada sentença a sentença, capaz de fazê-lo de modo interativo.A despeito dessa diferença entre os modos de operação de um compilador e de um interpretador, ambos compartilham a mesma estrutura básica quanto ao processo de interpretação da linguagem de alto nível que recebem como entrada.

\subsubsection{Estrutura Básica de um Compilador}

A compilação de um programa escrito em linguagem de alto nível é uma tarefa complexa que comumente é subdividida em uma sequência de fases menores e bem definidas. Genericamente, podemos identificar as seguintes fases ou etapas:

- Análise Léxica: Nesta etapa inicial do processo de compilação o texto de entrada,

\footnotetext{
${ }^{1}$ ARM ou Advanced RISC Machine é um conjunto de arquiteturas RISC para microprocessadores desenvolvidas pela empresa ARM Holdings. Em contraste, as arquiteturas Intel x86 ou AMD64 são consideradas arquiteturas CISC. Veja [25] para maiores detalhes.
} 
ou seja, um programa escrito em linguagem de alto nível, é lido e fragmentado em símbolos ou tokens. Esses símbolos representam as palavras reservadas da linguagem (e.g. as palavras for, float, struct em C), os nomes de variáveis, números, operadores aritméticos e etc. Essa etapa também é denominada tokenização.

- Análise Sintática:Nessa fase, são utilizados os tokens produzidos na análise léxica e também a CFG que define as regras de produção dessa linguagem (veja seção 2.3). Os tokens são consumidos um a um e agrupados em uma estrutura de dados denominada Árvore Sintática (ou Parse Tree). Essa árvore é construída de acordo com a expansão das regras de produção da CFG. A figura 2.4 ilustra um exemplo de uma Parse tree para a CFG 2.1 e a expressão aritmética $2+3 * 4$. Essa fase também é denominada Parsing.

- Verificação de Tipos: Nessa fase, a árvore sintática construída na fase anterior é analisada para verificar se os tipos das variáveis, estruturas de dados e ponteiros foram empregados corretamente no programa que está sendo compilado.

- Geração de Código Intermediário: A partir da árvore sintática, é gerado um código de máquina intermediário que ainda será modificado e otimizado para a arquitetura alvo. Nomes de variáveis e chamadas de funções serão traduzidos para endereços de memória e registradores.

- Alocação de Registradores: Nessa etapa, endereços de registradores disponíveis no processador da máquina para o qual o código será compilado serão atribuídos às variáveis desse programa com base no código intermediário gerado na etapa anterior.

- Montagem e Vinculação: Finalmente, o código de máquina intermediário será convertido em código de máquina binário resultando em um ou mais programas objeto, dependendo do código fonte de entrada. Em seguida, serão determinados os endereços de memória para funções, variáveis e estruturas de dados estáticas e os objetos serão combinados em um único programa executável.

Vale notar que, usualmente, as etapas de análise léxica e sintática ocorrem de modo alternado, ou seja, um analisador sintático, ou parser, consome os tokens produzidos pelo analisador léxico, ou lexer, sob demanda. Assim, toda expressão válida é avaliada imediatamente após a produção dos tokens que a compõe, otimizando assim a detecção de diversos erros de sintaxe. A figura 2.3 ilustra a interação lexer-parser para avaliar a expressão $2+3^{*} 4$ sob a CFG 2.1. Inicialmente, o lexer recebe como entrada a expressão que será avaliada mas não a analisa imediatamente uma vez que é o parser quem requisita ao lexer para produzir um token. Ao encontrar um número, o lexer produzirá um token cujo valor é o próprio número. Ao encontrar um sinal + ou ${ }^{*}$, serão produzidos respectivamente os tokens 
"P_SIGN"e "M_SIGN". Uma vez produzidos tokens o suficiente para formar uma expressão válida segundo a CFG 2.1, o parser poderá incrementar uma árvore sintática (fig. 2.4) ou ainda avaliar a expressão e produzir o resultado diretamente. Essa interação repete-se até que toda a entrada seja consumida pelo lexer.

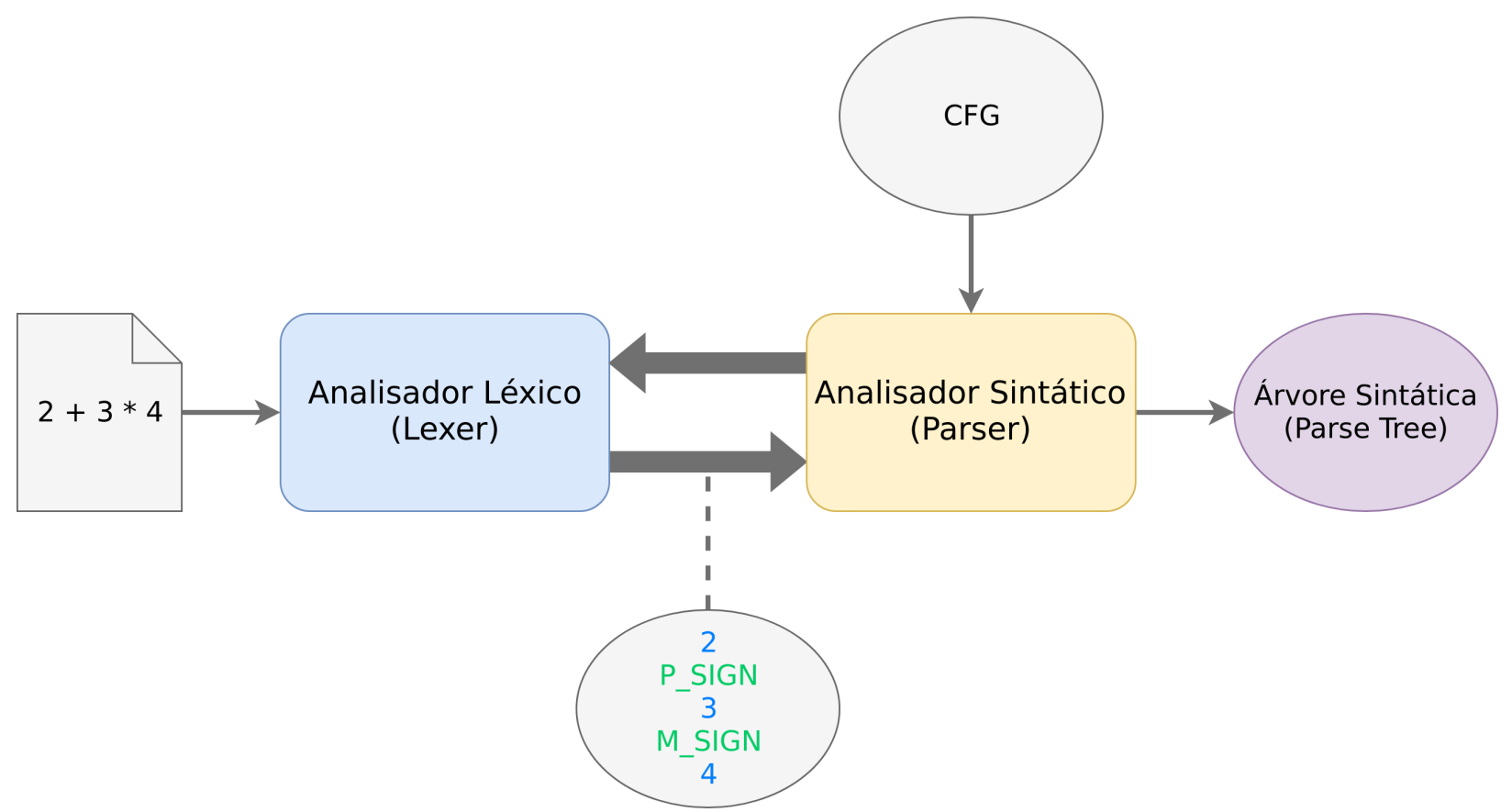

Figura 2.3: Análise léxica e sintática da expressão $2+3 * 4$ utilizando a CFG 2.1

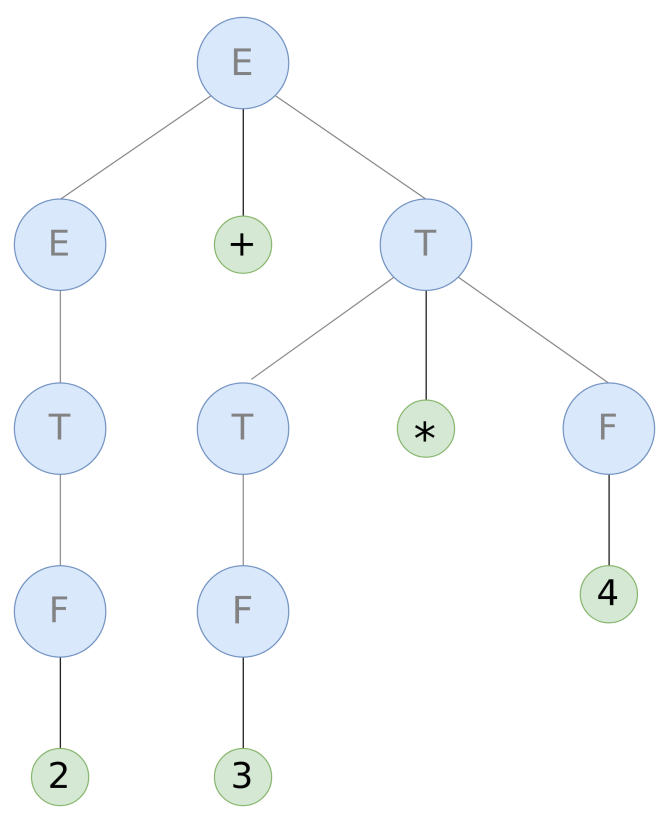

(a) Parse tree Completa

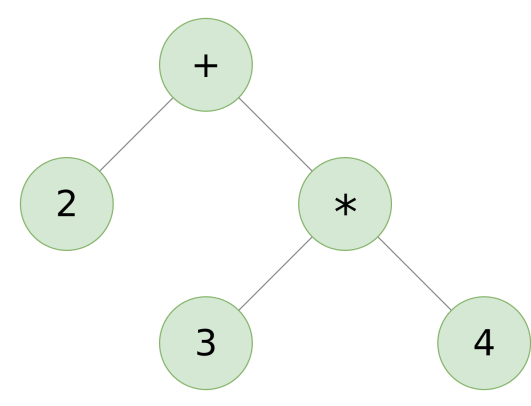

(b) Parse tree Simplificada

Figura 2.4: Parse tree para a expressao $2+3 * 4$

No escopo deste trabalho estamos interessados em construir um interpretador capaz de traduzir operações da linguagem WED-SQL em comandos SQL. Para tal, é suficiente que esse software restrinja-se a executar as etapas de análises léxica e sintática segundo a 
CFG para WED-SQL que será apresentada nos próximos capítulos, já que a compilação e a execução do código SQL gerado ficará a cargo de um SGBDR.

\subsubsection{Ferramentas auxiliares}

O projeto de um compilador ou um interpretador para uma determinada linguagem de programação é uma tarefa sistêmica e pragmática que, de modo geral, pouco depende de peculiaridades ou de paradigmas específicos dessa linguagem. Sendo assim, ao longo dos anos, foram propostas diversas ferramentas para auxiliar a construção de compiladores, notavelmente para as etapas de reconhecimento da linguagem, ou seja, para as etapas de análises léxica e sintática. Três dessas ferramentas que merecem destaque são: GNU Flex[27], GNU Bison[27][12] e ANTLR[42], [43], [41].

Primeiramente, GNU Flex é um gerador de analisadores léxicos que, apesar de funcionar como uma ferramenta autônoma, foi concebido para trabalhar em conjunto com o $G N U$ Bison, cujo funcionamento depende de uma ferramenta como o GNU Flex. Já o ANTLR incorpora as funcionalidades de análise léxica e sintática em uma única ferramenta. No entanto, a principal diferença entre GNU Bison e ANTLR é o tipo de parser gerado. Por padrão, o GNU Bison gera pasers do tipo $L A L R(1)$ (do inglês One token look-ahead, left to right, rightmost derivation), enquanto que o $A N T L R$ gera parsers do tipo $L L\left(^{*}\right)$ (do inglês Left to right, Leftmost derivation, arbitrary look-ahead) [4], [2].

Um parser do tipo LALR(1) é capaz de visualizar o próximo token que ainda não foi processado (o número 1 entre parênteses indica que até 1 token adiante pode ser consultado), os tokens são avaliados da esquerda para a direita e a árvore sintática é construída segundo sua derivação mais a direita. A ordem em que os símbolos não terminais nas regras de produção de uma CFG são expandidos determina o modo como a respectiva árvore sintática é construída. Quando o parser expande primeiro o símbolo não terminal mais à direita das regras de produção, dizemos que a árvore sintática representa a derivação mais a direita para a expressão avaliada. Caso o parser expanda primeiro o símbolo não terminal mais à esquerda, a árvore sintática representa a derivação mais a esquerda. Por sua vez, um parser do tipo LL(*) é um parser que processa os tokens da esquerda para a direita mas que, diferentemente de um parser LALR, constrói uma árvore sintática segundo uma derivação mais a esquerda. Além disso, um parser do tipo LL(*) é capaz de analisar um número arbitrário de tokens que ainda não foram processados.

Outra diferença entre esses dois tipos de parsers é que um parser do tipo LALR constrói a árvore sintática das folhas para a raiz (bottom-up), enquanto que um parser LL o faz da raiz para as folhas (top-down). Isso faz com que parser LALR sejam capazes de processar CFGs 
que sejam esquerda-recursivas, ou seja, CFG que contenham regras de produção do tipo "E -> E | ... ". Já em um parser LL, o qual não apenas constrói a árvore sintática da raiz para as folhas mas também utiliza para tal a derivação mais a esquerda, não conseguiria resolver uma regra de produção desse tipo pois ficaria preso em uma recursão infinita. Por outro lado, construir um parser por meio do ANTLR é mais fácil do que utilizar a combinação $G N U$ Flex $\mathscr{E}$ Bison desde que a CFG que deseja-se implementar não seja esquerda-recursiva. Nesse caso, como o código gerado pelo ANTLR é muito mais próximo da CFG, ou seja, é gerada uma função para cada regra de produção, encontrar erros na CFG torna-se uma tarefa muito mais fácil. Além disso, para utilizar o GNU Bison é preciso ter conhecimentos avançados de $\mathrm{C}, \mathrm{C}++$ ou Java, enquanto que o ANTLR aceita diversas outras linguagens mais dinâmicas e baseadas em outros paradigmas de programação (e.g. Python, Java, C++, Ruby dentre outras). Do ponto de vista de complexidade computacional, ambas ferramentas são capazes de gerar parsers da ordem de $\mathrm{O}(\mathrm{n})$.

\subsection{Conclusão}

Neste capítulo, foram apresentados os fundamentos das tecnologias principais utilizadas tanto para construção do WED-Engine, o ambiente de execução e controle transacional de WED-flows, quanto para a linguagem de modelagem e especificação WED-SQL. A CFG construída neste trabalho para gerar a linguagem WED-SQL não é esquerda-recursiva e, desse modo, pode ser implementada com o ANTLR. Por questões de cronograma, a fim de viabilizar o uso das ferramentas desenvolvidas neste trabalho por outros trabalhos de pesquisa desenvolvidos em paralelo, a implementação do interpretador de WED-SQL apresentada neste trabalho foi feita manualmente e não contempla o uso da ferramenta $A N T L R$, a qual será empregada já na próxima revisão da WED-SQL. 


\section{Capítulo 3}

\section{Trabalhos Relacionados}

Sistemas gerenciadores de processos de negócio, assim como sistemas gerenciadores de processos científicos, são tradicionalmente construídos segundo abordagens de controle de fluxo (workflow), abordagens baseadas em eventos (event-driven) ou abordagens orientadas a dados (data-flow). Historicamente, os sistemas de informação orientados a processos trouxeram avanços significativos à solução de problemas de controle de fluxo na coordenação de tarefas atômicas. Por meio do isolamento e do gerenciamento de eventos, os sistemas baseados em eventos são de suma importância na resolução dos mais diversos desafios de comunicação presentes em sistemas complexos. Já os sistemas orientados a dados são especialmente relevantes na implementação de modelos de negócio nos quais a execução de atividades é feita por meio de instâncias de dados estruturados coordenadas por um sistema de transição rotulado. No restante deste capítulo, serão discutidos os resultados mais importantes dessas três abordagens, as principais linguagens de especificação e ou execução desenvolvidas para os modelos propostos em cada abordagem, assim como um dos principais desafios a ser superados para melhorar o gerenciamento de dependências em PAIS.

\subsection{Abordagens Orientadas a Processos}

Em relação às abordagens orientadas a processos, o primeiro grupo de resultados surgiu na década de 70 oriundo da necessidade de se representar, simular e gerenciar processos de negócio, o que culminou na criação dos sistemas gerenciadores de workflow [56] e também da Coalizão de Gerenciamento de Workflows [53] (WfMC, do inglês Workflow Management Coalition). Em [13] e [26], os autores enfatizam a importância dos worflows para contemplar as perspectivas funcional, comportamental, informacional e organizacional dos processos. 
O conceito de Gerenciamento de Processos de Negócio (BPM, do inglês Business Process Management [51], [15] estendem esses primeiros resultados em termos de modelagem de processos ao adicionar métodos e técnicas de caracterização e análise de processos. O segundo grupo de resultados está relacionado ao estudo dos padrões de workflow [1], os quais identificam os principais padrões de controle de fluxo de modo a generalizar e abstrair algumas características comuns das interações entre processos. O terceiro grupo de resultados aborda a representação formal de processos, como os modelos orientados a grafos [28], as redes de Petri [31] e as álgebras de processos [5]. Essas representações formais foram propostas com a finalidade de propiciar propriedades de controle de fluxo que viabilizassem a verificação formal de sistemas gerenciadores de worflow. No entanto, esses resultados, a despeito da incontestabilidade de seus avanços e de sua importância, não fornecem o apoio adequado para abordagens de controle de eventos e de estados de dados.

Amplamente adotada na indústria de tecnologia, a linguagem de execução de processos WS-BPEL [36] surgiu como uma ferramenta de implementação de sistemas orientados a processos. Estruturalmente representada em arquivo XML, é uma linguagem de natureza procedural desenvolvida para orquestrar a execução de processos de negócio implementados por meio de web services. Assim como em linguagens de programação imperativas, WSBPEL implementa variáveis, estruturas de controle de fluxo (if, else), laços e primitivas para especificar os principais padrões de workflow identificados em [1]. Alternativamente, a linguagem YAWL [8] é uma linguagem de execução de workflow com base em Petri NET que, apesar de sua natureza gráfica, possui uma semântica formalmente bem definida, além de, assim como em WS-BPEL, implementar os principais padrões de workflow. Em [8], os autores propõem uma metodologia para traduzir processos WS-BPEL para workflows YAWL e, com isso, viabilizar a verificação formal de processos WS-BPEL. Outra linguagem de destaque nesse contexto é a BPMN [38]. Ela oferece uma notação simples e intuitiva e tornou-se uma linguagem popular para a modelagem de processos de negócio ao ampliar a capacidade de comunicação entre especialistas de negócio, programadores e clientes. No entanto, a BPMN não possui especificação formal, além de uma estrutura de implementação incipiente que a torna inviável como uma solução completa para o desenvolvimento de PAIS. Comumente, projetos BPMN são mapeados para a linguagem de execução WS-BPEL, ainda que não haja uma correspondência direta entre ambas linguagens [52].

Embora populares, essas linguagens não foram concebidas para atender ao nível de flexibilidade exigido por PAIS modernos. A alta dinamicidade presente nos modelos de negócio atual demanda sistemas capazes de incorporar altas taxas de mudanças com agilidade e eficiência. A natureza imperativa das linguagens apresentadas anteriormente as restringe ao desenvolvimento de PAIS razoavelmente estáticos, os quais, muitas vezes, ficam aquém das requisitos das aplicações contemporâneas. Em [54], os autores discutem como uma abordagem declarativa baseada no conceito de restrições poderia suprir essa demanda por mais 
flexibilidade. Nesse contexto, ao invés de especificar-se um sistema em termos de uma sequencia de passos de execução pré-definida, declara-se um conjunto de restrições para definir implicitamente quais ordens de execução são válidas. Para isso, os mesmos propõe a utilização de um arcabouço denominado DECLARE [44], o qual utiliza a linguagem YAWL para a execução de processos e as linguagens baseadas em restrições DecSerFlow [50] e ConDec [30] para especificação e modelagem.

\subsection{Abordagens Orientadas a Eventos}

No que diz respeito às abordagens baseadas em eventos, tanto as metodologias de orientação a eventos [3] quanto a modelagem de eventos [29] desenvolveram mecanismos para a ordenação de eventos por meio de dependências temporais. Essas abordagens estão estreitamente relacionadas ao feito histórico da comunidade de banco de dados que propôs o conceito de Evento-Condição-Ação (ECA, do inglês Event-Condition-Action) [14]. Em [9] e [11], os autores empregaram o conceito ECA para gerenciar tipos de eventos em BPM. Mais precisamente, sistemas de banco de dados ativos (ou reativos) implementam o conceito ECA para reagir à modificações nos dados. No âmbito dos processos de negócio, regras ECA podem ser utilizadas para capturar diversos tipos de eventos de interesse. Em [10], os autores apresentam a linguagem XCHANGE, uma linguagem baseada em regras ECA para a composição de serviços Web. Essas abordagens estabeleceram estratégias amplamente difundidas para a modelagem e implementação de eventos em BPM.

Na linguagem XCHANGE, eventos são representados como estruturas de dados XML, enquanto que os processos de negócio são implementados por meio de serviços Web. O controle de fluxo é expresso por meio de regras ECA que definem o comportamento do sistema, ou seja, o fluxo de execução de uma instância é determinado em tempo de execução de acordo com a ocorrência de uma sequência de eventos. Essa linguagem também simplifica o tratamento de exceções, uma vez que as mesmas podem ser convenientemente representadas como eventos utilizando regras ECA. Não obstante, a captura e a representação de eventos não são suficientes para prover um apoio suficientemente adequado à implementação de tarefas complexas em PAIS.

\subsection{Abordagens Orientadas a Dados}

Com amparo da abordagem de orientação a dados, em [32], [34] e [33] os autores apresentam o conceito de ciclo de vida de estruturas de dados para ordenar dependências de 
atividades em cenários complexos, e.g. linha de montagem de automóveis, além de proporem o arcabouço COREPRO para a modelagem de grandes estruturas de processos orientados a dados. Nessa abordagem, o especialista de negócio descreve o comportamento dinâmico de um objeto, representado por uma estrutura de dados, como seu ciclo de vida. De fato, o ciclo de vida de um objeto determina como os processos que modificam a estrutura de dados que o representa devem ser encadeados. No COREPRO, os ciclos de vida dos objetos são mapeados para um sistema de transição de estados acionado pelos processos que modificam os objetos.

O conceito de artefatos de negócio [35], [6] e [22] foi introduzido a fim de prover unidades atômicas que agrupem dados auto contidos e indivisíveis dos processos para modelos com ciclo de vida complexo. Em [7], é apresentado um modelo formal para validar as propriedades de um ciclo de vida. Ainda assim, apesar de seus resultados relevantes, no conceito de ciclo de vida não é possível representar estados de dados de modo explicito.

\subsection{Conclusão}

Sucintamente, as três abordagem apresentadas produziram resultados práticos e teóricos significativos para o desenvolvimento de sistemas BPM e de workflow científico. No entanto, todas essas abordagem clássicas possuem deficiências decorrentes da falta de integração dos conceitos de Processos, Eventos e Dados. Essas deficiências manifestam-se mais fortemente em domínios de aplicação mais complexos. Em contraste, a abordagem WED-flow é fundamentada no conceito de que dados, eventos e processos são igualmente importantes para o desenvolvimento de PAIS inerentemente complexos. Além disso, na WED-flow o gerenciamento de processos de negócio é tratado como um modelo transacional avançado [47]. Esse aspecto, menosprezado nas demais abordagens, faz com que a abordagem WED-flow seja extremamente robusta e versátil no tratamento de exceções, tornando-a convenientemente eficaz para a implementação de estratégias sofisticadas de recuperação([19]), e adaptação ([46]). Ao integrar os paradigmas de orientação a processos, eventos, fluxo de dados e transações, a abordagem WED-flow não somente preenche essa lacuna deixada pelas abordagens tradicionais como também simplifica tanto a modelagem quanto a implementação de processos de negócio intrinsecamente sofisticados. 


\section{Capítulo 4}

\section{WED-Engine: Ambiente Transacional de Execução e Gerenciamento de WED-flow}

O WED-Engine é um ambiente transacional de execução e gerenciamento de WED-flow desenvolvido para oferecer apoio transacional à implementação de projetos WED-flow. Sua implementação é baseada na extensão das funcionalidades do SGBDR PostgreSQL por meio da incorporação de novas estruturas de dados e mecanismos de controle transacional requeridas pela abordagem WED-flow, tornado-o capaz de executar WED-flows representados em código SQL. No restante deste capítulo, serão apresentados os detalhes de implementação, os principais algoritmos implementados assim como as demais tecnologias e ferramentas auxiliares empregadas no desenvolvimento do WED-Engine. Ao decorrer de cada tópico, serão discutidas as vantagens, desvantagens e as consequências das principais decisões estruturais adotadas durante o desenvolvimento deste software.

\subsection{Arquitetura}

A arquitetura de composição de serviços (SOA, do inglês System Oriented Architecture) é uma configuração naturalmente adotada na implementação de PAIS [48]. Não coincidentemente, o WED-Engine foi projetado utilizando essa mesma arquitetura, em que cada WEDtransition é implementada por meio de um serviço auxiliar. Sendo assim, a coordenação de execução das instâncias de um WED-flow ocorre por meio de uma composição de serviços, na qual cada WED-transition será executada de forma atômica em uma única transação. Desse modo, a historia de execução de uma instância será uma composição específica de serviços que a levou de seu estado de dados inicial para seu estado de dados final. Esses 
serviços responsáveis por executar as WED-transitions são denominados WED-Workers.

As principais vantagens que essa arquitetura traz ao WED-Engine são:

- Permitir sua implementação em um ambiente heterogêneo, uma vez que cada serviço responsável por executar uma WED-transition pode ser implementado utilizando-se diferentes linguagens ou tecnologias;

- Favorecer sua escalabilidade horizontal, dado que os serviço podem ser distribuídos diretamente em locais distintos;

- Aumentar a confiabilidade do sistema, uma vez que é possível distribuir as tarefas entre serviços semelhantes, de acordo com sua disponibilidade.

A seguir, serão apresentados os principais algoritmos implementados pelo WED-Engine, seu modelo de dados, assim como detalhes de funcionamento.

\subsection{Modelo de dados}

O diagrama Entidade-Relacionamento da figura 4.1 representa o modelo de dados empregado no WED-Engine. Assim como as demais linguagens e diagramas clássicos de especificação de modelo de negócio, esse diagrama não captura de modo explícito a evolução temporal dos WED-flows, uma vez que tratam-se de sistemas dinâmicos. Por exemplo, os atributos da entidade WED-state são WED-attributes, os quais podem ser adicionados durante a execução do WED-flow. Além disso, também não é possível representar a ocorrência de um novo estado de dados. De qualquer modo, é uma boa representação de como o WEDEngine utiliza os elementos da abordagem WED-flow.

Vale ressaltar que o relacionamento Composição, definido entre as entidades Instância e WED-state, indica que uma instância é uma composição de WED-states. Por consequência, o relacionamento Possui, entre Instância e História, indica que cada instância possui um histórico de execução, que nada mais é do que a ordenação temporal da ocorrência dos estados de dados pertencentes à instância. Também é importante notar que o relacionamento Dispara ocorre apenas no momento em que um WED-state satisfaz uma WED-condition.

A entidade Journal tem papel fundamental em um mecanismo de recuperação de falhas que será explicado adiante. 


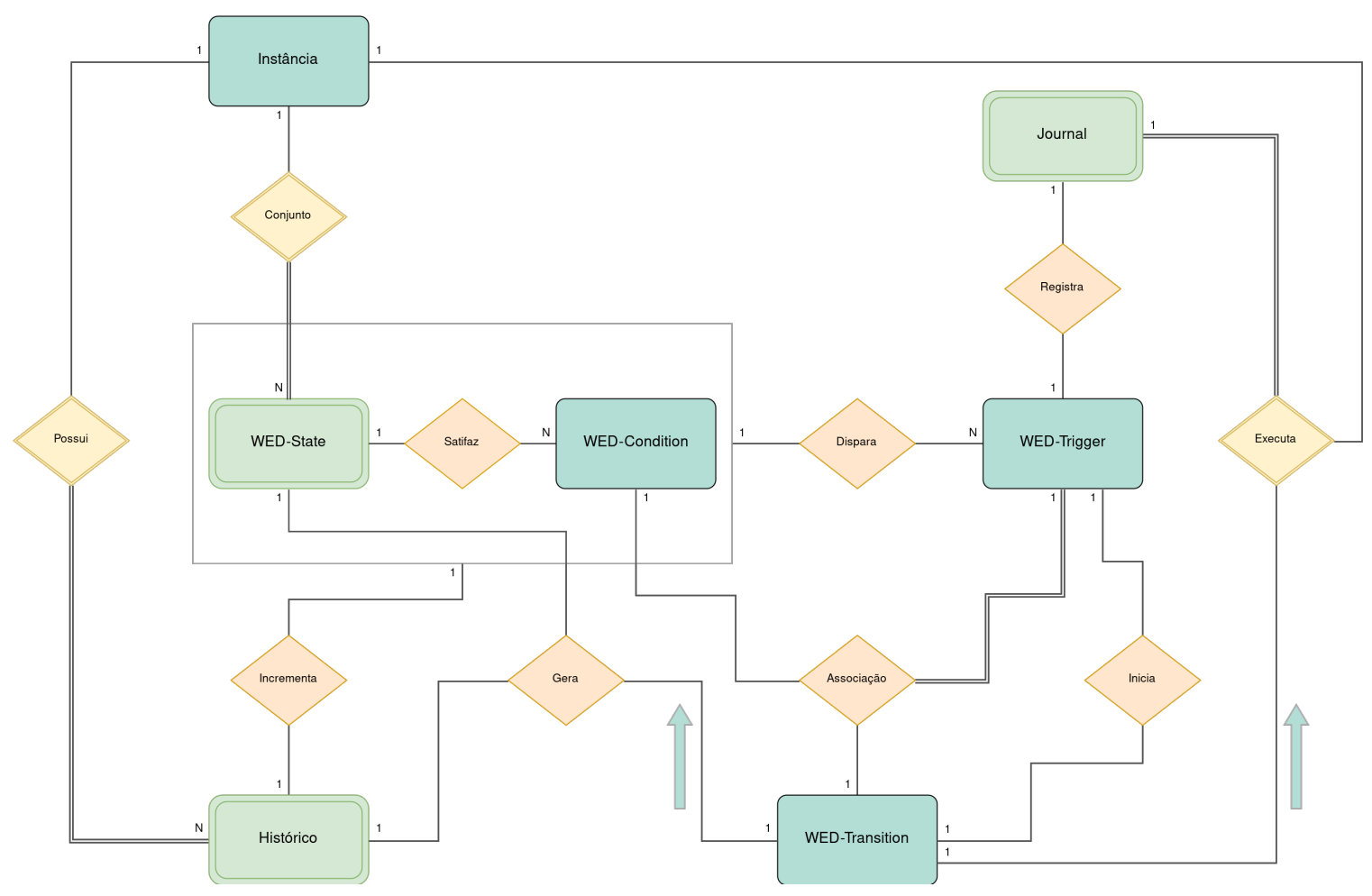

Figura 4.1: Modelo de dados do WED-Engine

\subsection{Algoritmos de Controle Transacional}

O WED-Engine delega a execução das WED-transitions para um conjunto de WEDWorkers. Devido a esse fato, há dois algoritmos principais executados pelo WED-Engine. O algoritmo 1 controla a execução das instâncias de um WED-flow, já o algoritmo 2 implementa de protocolo de comunicação entre o WED-Engine e os WED-Workers.

Estados de dados em um WED-flow são gerados em duas situações: ao inicializar-se uma nova instância ou quando uma WED-transition finaliza com sucesso sua execução. Em ambos os casos, o WED-Engine executa o algoritmo 1, que recebe como entrada uma instância e devolve o valor TRUE para uma transação bem sucedida ou FALSE, caso a transação seja abortada. Desse modo, toda a execução do algoritmo 1 ocorre de forma atômica, ou seja, está encapsulada em uma única transação. No caso em que essa transação falha, todas as alterações feitas até o momento serão revertidas e a instância voltará ao estado em que se encontrava imediatamente antes do início dessa transação.

Ao receber uma instância $i$, o algoritmo 1 inicia sua execução criando uma lista $L$ (linha 1) para armazenar todas as possíveis WED-transitions que serão inicializadas pelas WED-triggers que sejam eventualmente disparadas por $s$, seu estado atual de $i$. Em seguida, cada WED-trigger definida para esse WED-flow (linhas 3 a 12) será avaliada comparando-se suas WED-conditions com o estado $s$. Para cada WED-condition satisfeita por $s$, sua WEDtransition associada será adicionada à lista $L$. Caso $s$ seja um WED-state final, o símbolo 


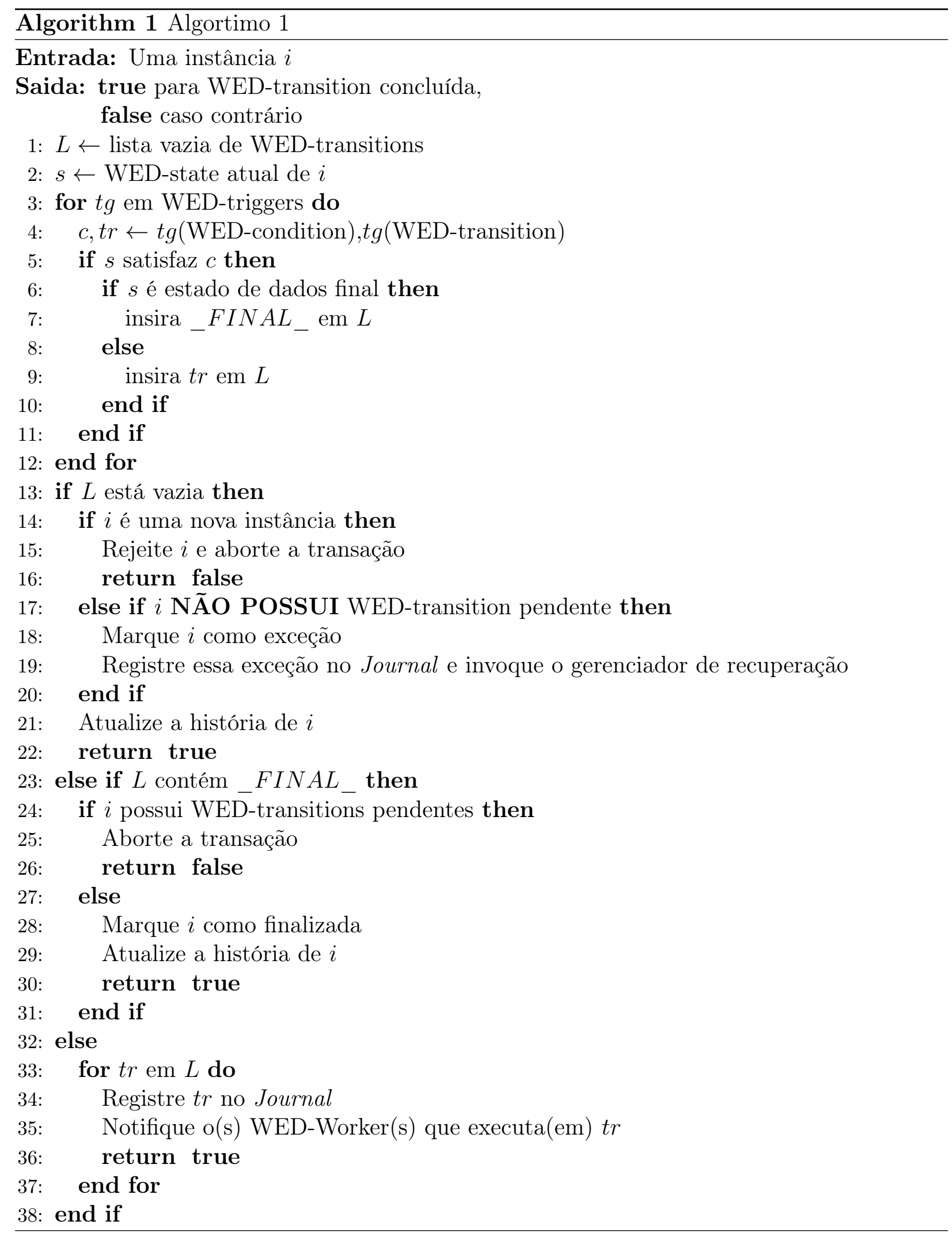


_ FINAL_ será adicionado a $L$. O próximo passo é avaliar $L$ (linhas 13 a 38), que pode conter ou não o símbolo _ FINAL_ou estar vazia.

Se $L$ estiver vazia (linhas 13 a 22), então $s$ não disparou nenhuma WED-trigger. Caso $s$ seja o estado inicial de $i$, a transação será abortada e $i$ não será inicializada. Então é preciso verificar se há alguma outra WED-transition executando para a instância $i$ (linha 17), pois se não houver, $s$ é um estado de exceção, $i$ será suspensa e o gerenciador de recuperação será informado. Caso contrário, $s$ é transação-consistente, a história de execução de $i$ é atualizada e a transação termina com sucesso.

Se $L$ contiver o símbolo _FINAL_ e $i$ possuir WED-transitions que estão executando, a transação é abortada. Essa situação indica que há erros na modelagem do projeto. Caso contrário, a instância $i$ será finalizada e a transação termina com sucesso.

Se $L$ não é vazia e não contém _ FINAL_, os disparos das WED-transitions em $L$ são registrados no Journal e seus respectivos WED-Workers serão notificados. Assim, a transação termina com sucesso.

Nessa primeira versão do WED-Engine, a comunicação com os WED-Workers é realizada seguindo o padrão de comunicação Publish-Subscribe para envio de mensagens. Nesse modelo, quem publica uma mensagem não está nem ciente da quantidade de ouvintes e nem se, de fato, há algum serviço ouvindo. De maneira análoga a uma transmissão de rádio, o WED-Engine cria uma "estação" para cada tipo de WED-transition e os WED-Workers sintonizam em suas estações de interesse. No contexto da abordagem WED-flow, essa técnica simplifica a escalabilidade do sistema quando comparada com a tradicional arquitetura cliente-servidor, por exemplo, ao permitir que novos WED-Workers possam ser adicionados dinamicamente, mesmo que temporariamente, e de modo conveniente a um sistema que esteja congestionado.

O conjunto de WED-Workers que executam as WED-transitions de um dado WED-flow podem executar em máquinas fisicamente distintas, comunicando-se com o WED-Engine por uma rede de computadores. Essas redes podem eventualmente enfrentar problemas de instabilidade, fazendo com que algumas mensagens não cheguem a seu destino. Assim, para lidar com esse tipo de falha e minimizar o número de instâncias que entrem em estado de exceção devido à WED-transitions que não finalizam dentro de seu tempo limite de execução preestabelecido, o WED-Engine utiliza um sistema de journaling para registrar todas as WED-transitions que devem ser executadas. Esse Journal, de forma semelhante à empregada nos sistemas de arquivos mais avançados, é um log circular para registrar operações que devem ser executadas, até que sejam concluídas. Isso permite que os WEDWorkers possam ser configurados para regularmente atuar de modo ativo e perguntar ao WED-Engine se existe alguma WED-transition pendente de ser executada, de acordo com 
o algoritmo 2 .

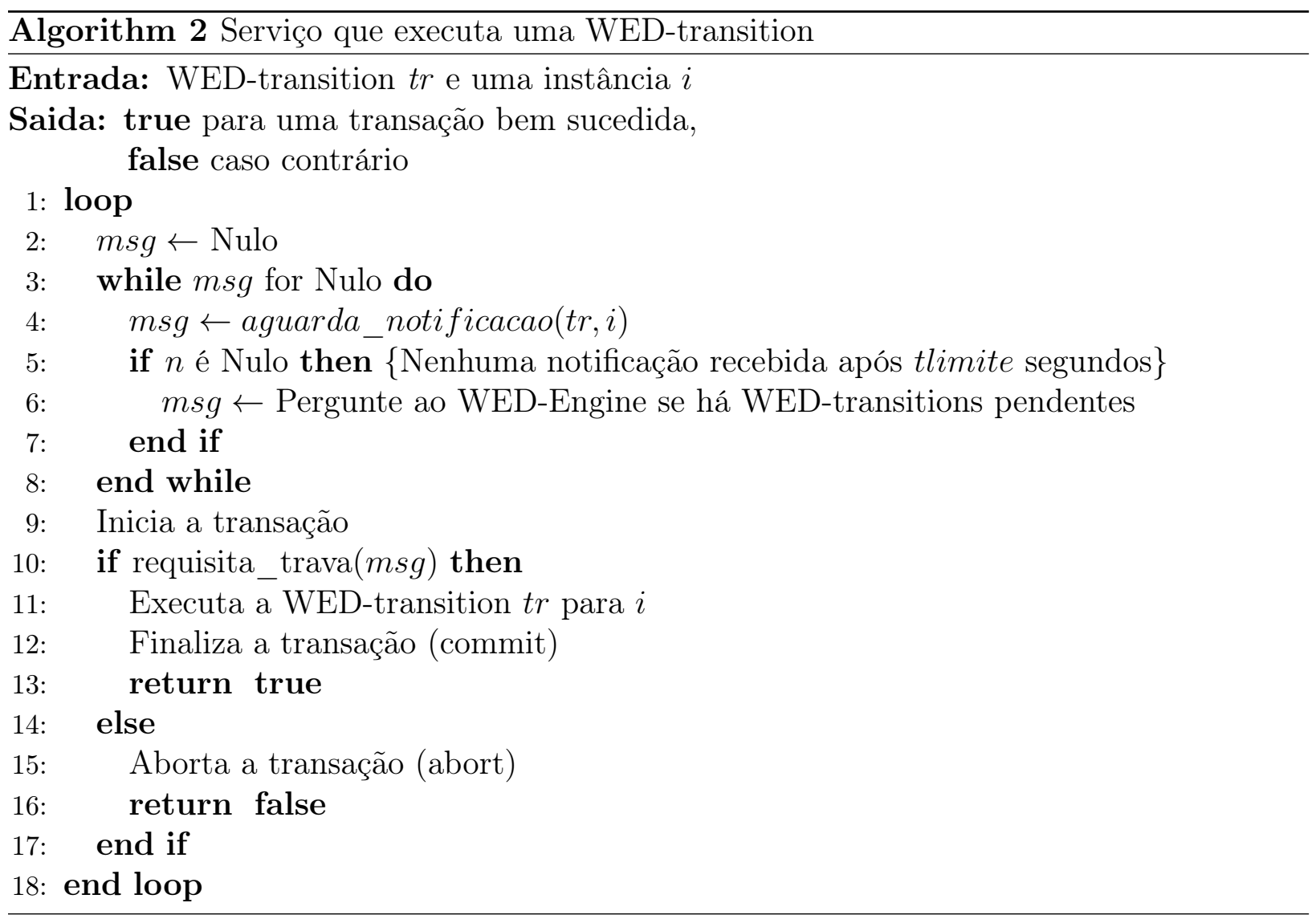

O algoritmo 2, implementado pelos WED-Workers, recebe como entrada uma WEDtransition e a instância para a qual a mesma será executada. Esse algoritmo prevê ainda a utilização do parâmetro tlimite para indicar quanto tempo o serviço deve esperar por uma mensagem antes de perguntar ao WED-Engine se existe alguma tarefa pendente.

Assim, um serviço genérico fica aguardando por uma mensagem $m s g$, advinda do WEDEngine, a qual contém: a WED-transition $\operatorname{tr}$ que deve ser executada, a instância $i$ e seu WEDstate atual $s$. Após esperar essa mensagem por um tempo máximo definido por tlimite, o serviço pergunta ao WED-Engine se existe alguma tarefa pendente. Caso não exista, ele volta a esperar por uma nova mensagem (linhas 3 a 8 ).

Ao receber uma mensagem, o WED-Worker inicia a transação. No entanto, como podem haver múltiplos WED-Workers interessados em executar a mesma WED-transition, é preciso antes adquirir uma trava para garantir acesso exclusivo à execução da respectiva tarefa (linha 10). Caso essa trava seja obtida, a WED-transition será executada e a transação finalizada com sucesso. Caso contrário, a transação é abortada. 


\subsection{Implementado WED-workers}

Dado que os WED-Workers são externos ao RDBMS, eles podem ser implementados utilizando qualquer linguagem de programação que possa conectar-se com o PostgreSQL, bastando para isso implementar o algoritmo 2. A fim de facilitar o seu desenvolvimento, o WEDEngine acompanha uma implementação de referência de um WED-Worker que fornece todos os mecanismos necessários de autenticação e controle de execução das WED-transitions. Por meio dessa referência, o desenvolvedor necessita somente implementar o procedimento que será executado para realizar a WED-transition, o qual deverá retornar como resultado um novo estado de dados. A interface desse modelo, desenvolvido em Python, está ilustrada na figura 4.2 .

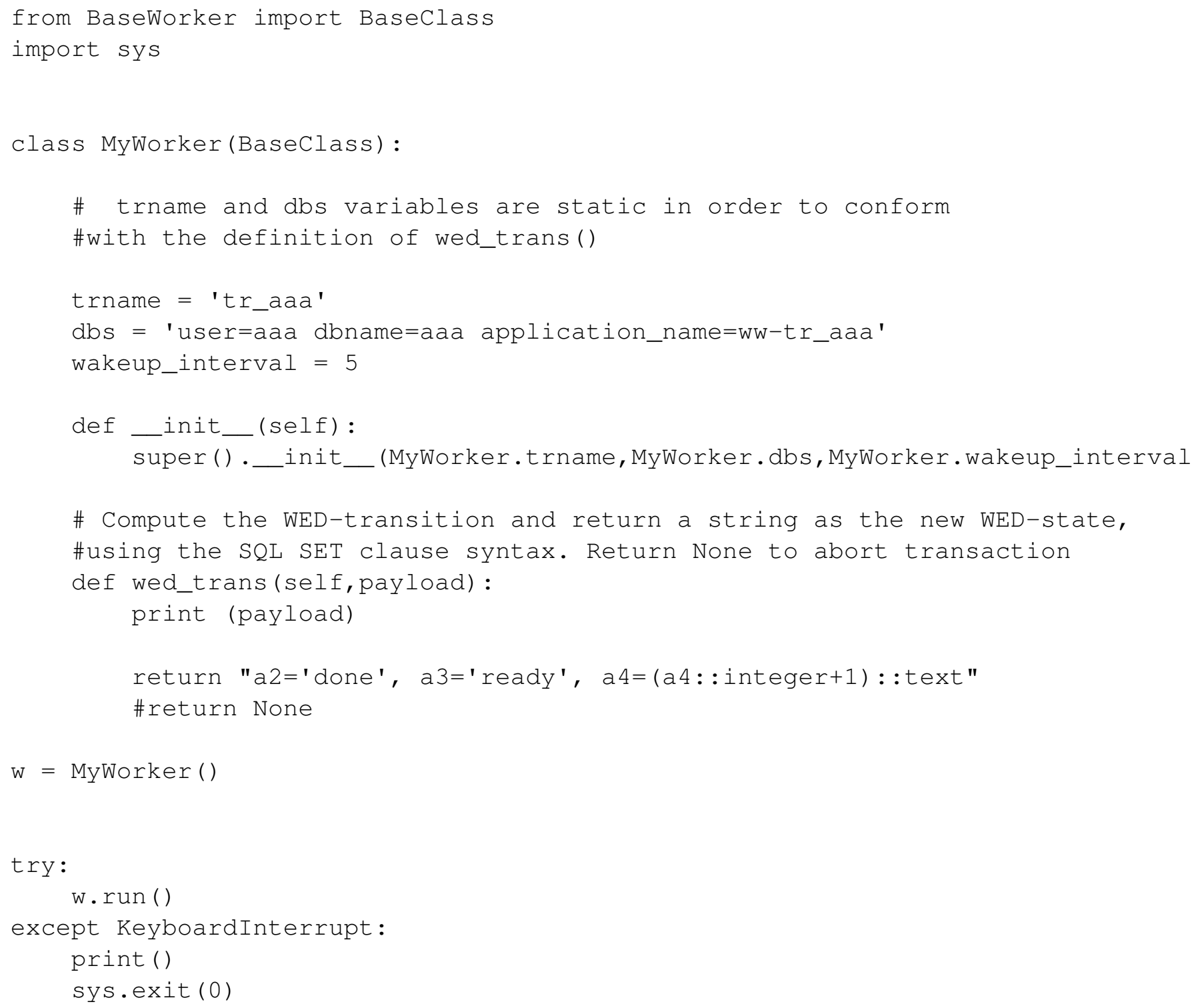

Figura 4.2: Implementação de um WED-Worker em Python

De acordo com a figura 4.2, o primeiro passo para implementar WED-Worker é im- 
portar a classe abstrata BaseClass. Em seguida deve-se definir os seguintes parâmetros de comunicação com o WED-Engine:

- trname: é o nome da WED-transition que esse serviço irá executar. Esse nome deve ser o mesmo definido no WED-flow;

- $d b s$ : é uma cadeia de caracteres contendo os parâmetros de conexão com o PostgreSQL;

- wakeup_interval: define quanto tempo esse serviço espera passivamente por uma notificação advinda do WED-Engine antes de enviar uma requisição por tarefas pendentes (de acordo com o algoritmo 2);

Logo após, é preciso implementar o método abstrato wed_trans(self,payload), que é a função que contém a lógica de negócio da WED-transition especificada pelo parâmetro trname. Esse método recebe como parâmetro a mensagem enviada pelo WED-Engine, contendo o WED-state atual da instância para a qual a WED-transition será executada, assim como seu tempo limite de execução, e devolve um novo WED-state.

\subsection{Sistema de Notificações}

Sistemas computacionais orientados a eventos são sistemas que reagem à ocorrência de determinados eventos de interesse. Para isso, tais sistemas geralmente implementam seus próprios mecanismos de detecção de eventos. Dado que sistemas orientados a eventos de dados usualmente baseiam suas operações em um banco de dados, a detecção de eventos é feita consultando-se os dados diretamente no banco por meio de uma técnica denominada polling. Essa técnica resume-se a realizar uma consulta ao banco de dados, continuamente, de modo síncrono e com uma frequência pré-definida. Em geral, essas consultas são construídas especialmente para cada tipo de evento a ser detectado.

Ao empregar a técnica de polling em um sistema sensível ao tempo de resposta, é preciso considerar que, além de existir um custo associado a execução de cada consulta ao banco de dados, é fundamental estimar o intervalo de ocorrência dos eventos a fim de não comprometer-se a eficiência do sistema. Quando não é possível estimar a frequência de ocorrência desses eventos, as consultas devem ser executadas com o menor intervalo de tempo possível, o que potencialmente acarreta em desperdício de energia e de recursos computacionais, além de sobrecarregar o sistema. No caso do WED-Engine, os WED-Workers não precisam consultar o banco de dados para detectar eventos de dados. Isso é possível utilizando-se um mecanismo de notificação do PostgreSQL denominado Asynchronous Notifications. 
Por meio das Notificações Assíncronas, ou Asynchronous Notifications, o PostgreSQL consegue notificar um cliente, no caso um WED-Worker, da ocorrência de um evento. Para tal, o comando NOTIFY é utilizado internamente no WED-Engine para criar-se um canal de comunicação exclusivo para informar o disparo de cada WED-trigger. Desse modo, cada WED-Worker registra-se em seu canal de interesse utilizando o comando LISTEN. A principal vantagem dessa técnica sobre a técnica de polling é que os WED-Workers são notificados imediatamente da ocorrência de um evento. Além disso é possível suspender a execução de um WED-Worker enquanto não houver novas mensagens, e com isso liberar recursos computacionais e economizar energia.

Conforme dito anteriormente, os WED-Workers podem ser configurados para consultar o WED-Engine de modo ativo, periodicamente a cada intervalo de tempo pré-definido, a fim de mitigar possíveis perdas de mensagens, seja por erro de transmissão na rede de computadores ou por indisponibilidade temporária do próprio WED-Engine. Com isso, pode-se dizer que o WED-Engine combina as duas técnicas apresentadas, buscando não só minimizar seu tempo de resposta na ocorrência de eventos de interesse como também ser capaz de recuperar-se o mais rapidamente possível na ocorrência de falhas de comunição.

\subsection{Protocolo de Comunicação}

Após receber uma mensagem e antes de iniciar a execução de uma WED-transition em uma determinada instância de um WED-flow, cada WED-Workers precisa registrar no WEDEngine que a tarefa que será executada. Esse registro é feito obtendo-se uma trava exclusiva de execução para a respectiva tarefa. Essa trava é utilizada não apenas para identificar as transações, e com isso garantir que sua execução não ultrapasse o tempo limite definido para a WED-transition, como também para resolver possíveis conflitos entre WED-Workers que tentem executar simultaneamente a mesma tarefa.

O PostgreSQL oferece alguns mecanismos de travas explícitas para aplicações que requerem um controle mais refinado sobre o acesso concorrente a dados no banco. Essas travas, que podem ser subdivididas em travas a nível de tabelas e travas a nível de linhas em tabelas, são automaticamente adquiridas para operações nativas do SGBDR. O WED-Engine, no entanto, utiliza de modo explícito apenas travas a nível de linhas.

O modo mais comumente utilizado quando deseja-se obter acesso exclusivo a uma linha em uma tabela é utilizar a expressão FOR UPDATE no final de um comando SELECT em SQL. Desse modo, uma transação será bloqueada ao tentar modificar uma linha travada por outra transação até que a trava seja liberada, ou seja, até que a transação anterior termine. É possível ainda fazer com que uma transação não espere para acessar um dado 
bloqueado. Para isso, basta utilizar o comando NOWAIT após FOR UPDATE para indicar que a transação deve abortar sua execução caso não consiga obter acesso exclusivo aos dados de interesse.

Uma alternativa ao modelo de travas anterior são as travas semânticas, ou Advisory Locks. Essas travas operam em nível semântico, ou seja, são úteis apenas quando possuem algum significado semântico na aplicação. Em outras palavras, os dados não serão realmente bloqueados e o PostgreSQL não garantirá sua utilização correta, o que ficará a cargo da aplicação. Os WED-Workers utilizam as travas semânticas para informar ao WED-Engine qual tarefa será executada, identificando-as univocamente por meio do identificador da instância e pelo nome da WED-transition. Assim, quando o WED-Engine envia uma mensagem em um canal de comunicação, avisando um conjunto de WED-Workers da ocorrência de um determinado evento, apenas um deles irá executar a WED-transition, enquanto que os demais ficarão suspensos esperando por novas mensagens.

Apesar de utilizar as travas semânticas na implementação do WED-Engine, ambas as soluções poderiam ser utilizadas a menos de um detalhe de implementação do próprio PostgreSQL: as informações sobre as travas do tipo FOR UPDATE são armazenadas apenas em disco e não em memória RAM, consequentemente não aparecendo nos catálogos de sistema. Por outro lado, é possível obter as mesma informações sobre as Advisory Locks diretamente dos catálogos de sistema, simplificando o controle transacional das WED-transitions e sem perda de desempenho.

\subsection{Isolamento Transacional e Paralelismo}

O PostgreSQL mantém a integridade dos dados acessados por transações concorrentes por meio de um modelo de concorrência denominado $M V C C$ (do inglês, Multiversion Concurrency Control), ou Controle de Concorrência Multiversão. Nesse modelo, cada transação enxerga uma nova versão do banco de dados que não contém dados gerados por transações concorrentes não finalizadas, ou seja, dados não persistidos por transações simultâneas não são compartilhados. Além disso, operações de leitura sobre os dados não conflitam com operações de escrita, minimizando a contenção de travas.

O padrão ISO/ANSI SQL define quatro níveis de isolamento transacional: Read Uncommitted, Read Committed, Repeatable Read e Serializable. Embora o PostgreSQL implemente apenas os três últimos níveis, isso não viola o padrão, que dita apenas quais são os requisitos mínimos de cada nível.

No nível de isolamento Read Committed, que é o nível padrão para executar WED- 
transitions, uma transação irá enxergar alterações nos dados geradas por uma transação concorrente que finaliza com sucesso. Por exemplo, duas execuções consecutivas de um comando SELECT dentro da mesma transação podem devolver conjuntos de dados distintos. Esse fenômeno é conhecido como nonrepeatable read, ou leitura que não se repete. De acordo com a abordagem WED-flow, esse fenômeno não atrapalha a execução de WED-transitions concomitantes, uma vez que não é necessário que o estado de dados que as inicia mantenhase inalterado durante sua execução. O projetista de um WED-flow deve estar ciente de que tal situação pode ocorrer e prever os possíveis efeitos colaterais.

Ao contrário do nível anterior, no nível Repetable Read, uma transação ativa não enxerga tuplas modificadas por transações concorrentes que finalizem previamente. Em caso de conflito, apenas uma transação finaliza e as outras são abortadas. Ainda assim, o padrão permite que ocorra um fenômeno chamado de phantom read, no qual um conjunto de tuplas que satisfaça uma determinada condição difira em duas execuções da mesma consulta na mesma transação. No PostgreSQL, esse fenômeno não ocorre.

O último e mais restritivo nível de isolamento é o Serializable. De acordo com o padrão, um conjunto de transações concorrentes executando nesse nível deve produzir o mesmo resultado da execução sequencial em alguma ordem. Sendo assim, nenhum dos fenômenos mencionados anteriormente ocorre. No PostgreSQL, esse nível de isolamento funciona exatamente como o Repeatable Read, a menos da introdução de um mecanismo para detectar anomalias que poderiam levar a um resultado não condizente com todas as possíveis execuções em série de um conjunto de transações.

No WED-Engine, as WED-transitions podem ser executadas em paralelo para uma mesma instância até o momento final no qual o WED-state atual precisará ser atualizado. Nesse momento, cada transação precisará obter uma trava de acesso exclusivo para atualizar a instância, e operações concomitantes serão serializadas. Todavia, dado que o tempo médio de espera entre transações que eventualmente tentem atualizar uma instância simultaneamente é ínfimo, o que implica em baixa probabilidade de colisão, é razoável que uma transação que seja bloqueada espere um pequeno intervalo de tempo antes de abortar sua execução. Não obstante, pode ocorrer de um WED-Worker segurar essa trava por um tempo maior do que o necessário para finalizar sua execução, atrasando a execução de transações concorrentes. Além disso, caso um WED-Worker perca a conexão com o WED-Engine durante sua execução, essa transação será automaticamente abortada. 


\subsection{Executando as WED-transitions}

De acordo com [19], a execução de uma nova instância de um dado WED-flow inicia-se com a criação de um estado de dados inicial e termina, após a geração de uma sequência de estados de dados intermediários, com a produção de um estado de dados final. Esses estados de dados, salvo o estado inicial, são criados por meio da execução das WED-transitions. Em outras palavras, podemos dizer que uma instância é uma sequência de estados de dados gerados a partir da execução da respectiva sequência de WED-transitions.

Por ser fortemente baseada no conceito de transação [23], a abordagem WED-flow determina que a transição entre estados de dados seja aquiescente às propriedades ACID. Isso significa que, toda operação sobre WED-attributes que produz um novo WED-state deve ser executada atomicamente. A geração de estados de dados de modo atômico impede que eventuais execuções parciais de WED-transitions possam resultar na criação de estados de dados não esperados (exceções), que por sua vez poderiam, por exemplo, acarretar na ativação indevida de uma ou mais WED-triggers ou de um deadlock, comprometendo assim a consistência do modelo. Desse modo, dizemos que a execução de uma WED-transition T, a qual inicia com o estado de dados Di que a disparou e termina produzindo um novo estado de dados Df, é uma transação ACID que leva Di a Df.

Na linguagem WED-SQL, a sintaxe para declarar uma WED-transition, conforme descrita no capitulo 5, requer que sejam informados seu nome e se a mesma é um procedimento armazenado no SGBDR. Procedimentos armazenados, do inglês Stored Procedures, são funções definidas pelo usuário, geralmente contendo alguma regra de negócio, que ficam armazenadas e são executadas pelo próprio SGDB. Entretanto, caso a WED-transition não seja declarada como um procedimento armazenado, então tanto sua definição quanto sua execução serão externas ao SGBDR e encapsuladas por uma estrutura especial chamada de WED-worker. Note que, em ambos os casos, a especificação do código que realmente executa a WED-transition está fora do escopo da WED-SQL e deve ser implementada previamente à execução do WED-flow. Uma vez que ambas as estratégias de implementação possuem vantagens e desvantagens, que variam de acordo com o domínio de aplicação das tarefas do sistema, fica a cargo do projetista de um WED-flow definir qual estratégia será adotada para cada WED-transition.

\subsubsection{Stored Procedure Vs. WED-Workers}

Os Procedimentos Armazenados (PA), tradicionalmente presentes na maioria dos SGBDRs, podem ser definidos como uma funcionalidade de otimização de consultas. Essa funcionalidade permite que funções definidas por usuários, as quais agrupem conjuntos de consultas 
SQL que executem em uma mesma transação, sejam não somente armazenadas mas também executadas pelo próprio SGBDR. Desse modo, uma vez que o SGBDR conhece as operações que serão executadas em cada procedimento armazenado, ele será capaz de otimizar sua execução, por exemplo, pré-compilando as consultas SQL envolvidas assim como précomputando seus planos de execução, tarefas que outrora seriam realizadas toda vez que essas consultas fossem executadas. Vale notar que é comum que os SGBDRs estendam a linguagem SQL padrão por meio da inclusão de comandos condicionais e ou de repetição com o intuito de tornar os PA mais expressivos. Essa extensão da SQL, no entanto, não é padronizada e cada SGBDR possui seu próprio dialeto. O PostgreSQL, por exemplo, permite que outras linguagens de programação, como C, Python e Perl (dentre outras) possam ser utilizadas para implementar os Procedimentos Armazenados [24].

Uma prática comum em desenvolvimento de PAIS é transformar a lógica de negócio de certos processos em Procedimentos Armazenados. Essa transformação torna-se especialmente vantajosa para processos cuja operação dependa ou da execução de consultas complexas ou da leitura de um grande volume de dados do SGBDR. Considere uma consulta complexa quando os dados requisitados envolvam a junção de diversas tabelas, ou seja, tenha um alto grau de relacionamento, ou ainda consultas compostas de múltiplas sub-consultas. Nesse caso, o SGBDR será capaz de otimizar essas consultas, conforme mencionado anteriormente, caso sejam implementadas como Procedimentos Armazenados. Processos cuja lógica de negócio resume-se a verificação de diversas informações em um banco de dados são mais eficientes quando implementados como P.A., uma vez que, por estarem mais próximos dos dados, praticamente eliminam a latência envolvida na transmissão dos dados. Além disso, já que toda manipulação de dados ocorre no interior do SGBDR, ganha-se em segurança.

Quando empregados adequadamente, os PA podem melhorar significativamente o desempenho de um sistema. No entanto, há situações nas quais seu uso pode trazer complicações que superem seus benefícios. Por exemplo, os PA, em geral, executam na mesma máquina que o SGBDR, compartilhando recursos computacionais como CPU, memória, acesso a disco, etc. Desse modo, processos implementados como PA que abusem da utilização de um ou mais desses recursos podem comprometer o desempenho do SGBDR, comprometendo sua capacidade de atender a requisições, aumentando seu tempo de resposta e, consequentemente, prejudicando o desempenho do sistema como um todo.

Um outro exemplo de emprego inadequado de uso de P.A. é na implementação de processos cuja execução necessite, necessariamente, ser atômica, ou seja, execute como uma transação, e demande interação com usuário em tempo de execução. Uma vez que os PA são executados pelo SGBD de modo autônomo, a comunicação com usuários torna-se complexa, dependendo de mecanismos internos do sistema operacional como memória compartilhada, sockets ou algum outro mecanismo de intercomunicação de processos, além de uma possível camada extra de software que gerencie tais mecanismos a fim de intermediar a comunicação. 
Além da possibilidade de implementar as WED-transitions como PA, o WED-Engine WED-SQL também permite implementá-las de modo que sua execução seja externa ao SGBDR, mas sem abrir mão do controle de concorrência e das funcionalidades do SGBDR. Para tal, o WED-Engine informa às WED-transitions externas de que sua execução foi habilitada, expondo-as aos respectivos eventos de dados que as ativem e armazenando os novos estados de dados gerados no SGBDR. As regras de como essa comunicação deve ocorrer compõe um protocolo de comunicação, explicado em detalhes no capítulo 4.6. A fim de abstrair o protocolo de comunicação, prover um ambiente transacional de execução, além de fornecer uma estrutura homogênea de implementação, as WED-transitions externas são implementadas por meio de uma estrutura especial denominada WED-worker. De modo genérico, os WED-workers encapsulam a implementação das WED-transitions de modo a viabilizar sua execução parcialmente fora do SGDBR enquanto mantém as mesmas propriedades transacionais dos PA.

A principal motivação que justifica a utilização dos WED-workers é expandir a escalabilidade e prover heterogeneidade do WED-Engine WED-SQL. Desse modo, executar WEDtransitions na mesma máquina em que o WED-Engine WED-SQL, independentemente de serem implementadas como P.A. ou na forma de WED-workers, pode comprometer a capacidade do sistema em processar instâncias em paralelo. Além do mais, os WED-workers podem ser implementados utilizando qualquer linguagem de programação capaz de se comunicar com o PostgreSQL, possibilitando sua execução em ambientes heterogêneos.

WED-transitions que dependam de interação com usuário também são mais facilmente implementadas por meio de WED-workers. Ao contrário de uma WED-transition implementada como um PA, que inicia imediatamente após a ocorrência de um evento de dados de seu interesse, o WED-Engine apenas habilita a execução de um WED-worker. Em outras palavras, o WED-worker é notificado que a WED-condition associada à WED-transition que o mesmo implementa foi satisfeita. Desse modo, o WED-worker passa a ser o responsável por inicializar a transação com o WED-Engine. Essa inversão de controle proporciona mais autonomia e um controle mais fino na execução das WED-transitions, que agora, ao contrário dos PA, que executam em segundo plano, operam em primeiro plano. Isso aumenta a versatilidade do sistema ao simplificar sua integração com a interface de outros sistemas ou com interfaces de interação com o usuário.

Ao longo do desenvolvimento de um sistema WED-flow, o projetista pode implementar as WED-transitions: seja por meio de procedimentos armazenados ou utilizando WEDworkers. Ele deve ter sempre em mente, no entanto, que existe um compromisso entre desempenho e escalabilidade vertical do WED-Engine WED-SQL. Por se tratar de uma abordagem flexível, que incentiva a modelagem de sistemas que evoluam de modo incremental, o projetista pode explorar os limites das escalabilidades dinamicamente, seja de acordo com os recursos computacionais disponíveis em um dado momento ou seja de acordo com a de- 
manda do sistema, ao alternar entre os modos de execução das WED-transitions, inclusive em tempo de execução. O WED-Engine também inclui algoritmos de controle de concorrência para possibilitar que múltiplos WED-workers implementem a mesma WED-transition, e com isso aumentar a vazão em sistemas de alta demanda. No próximo capítulo, discutiremos em detalhes o funcionamento dos WED-workers, os mecanismos do controle de concorrência do WED-Engine, assim como os pormenores da comunicação entre ambos.

\subsection{Conclusão}

O WED-Engine é um ambiente transacional de execução e gerenciamento de WED-flow desenvolvido para oferecer apoio transacional à implementação de projetos WED-flow. Desse modo, a principal contribuição dessa ferramenta é implementar os fundamentos do WEDflow e prover toda a estrutura necessária de controle de fluxo, o que inclui o gerenciamento transacional, detecção automática e apoio ao tratamento de exceções, detecção de estados de dados e o disparo das WED-triggers, transição entre WED-states, assim como o controle de concorrência entre operações que podem ser executadas em paralelo. Além disso, a integridade dos dados é garantida por meio das propriedades ACID. Essa ferramenta funciona efetivamente como uma camada de abstração entre a estrutura de controle e a especificação de um WED-flow. Conjuntamente com a linguagem WED-SQL, seu principal objetivo é fornecer a confiabilidade, a escalabilidade e a flexibilidade demandada pelos PAIS modernos. 
38 WED-ENGINE: AMBIENTE TRANSACIONAL DE EXECUÇÃO E GERENCIAMENTO DE WED-FLOW 


\section{Capítulo 5}

\section{WED-SQL: Uma linguagem}

\section{intermediária de implementação}

Avanços recorrentes na indústria de microeletrônica resultantes não somente de estudos e pesquisas em materiais, mas também do refinamento dos processos de fabricação, dentre outros fatores, permitem que sejam construídos computadores com poder de processamento e capacidade de armazenamento cada vez maiores. De fato, no ano de 1975, Gordon Moore previu que a quantidade de transistores presentes nos circuitos integrados dobraria a cada dois anos. Essa previsão, conhecida popularmente como "Lei de Moore", ainda se sustenta nos dias atuais.

Embora não exista propriamente uma lei ou previsão que estime o crescimento dos sistemas de software, seja em tamanho de código ou em complexidade, é irrefutável que a evolução dos computadores viabiliza a construção de sistemas cada vez maiores e mais complexos. Por consequência, modelar um sistema em termos de abstrações tornou-se prática comum e amplamente estudada na área de desenvolvimento de software. Abstrações, quando utilizadas como uma técnica de desenvolvimento, ajudam a gerenciar a complexidade do sistema, uma vez que possibilitam organizar melhor as ideias e, com isso, simplificam a modelagem ao permitir que entidades do mundo real sejam representadas de modo mais natural e, muitas vezes, mais intuitivo.

Um exemplo de abstração amplamente empregada no desenvolvimento de sistemas é a Programação Orientada a Objetos (POO). Nesse paradigma de programação, um programa é definido em termos de objetos e dos relacionamentos entre os mesmos. Os objetos, por sua vez, são Abstrações cujo objetivo é agrupar código e dados referentes a execução de alguma tarefa específica em uma entidade cuja exposição de suas funcionalidades ocorre por meio de 
métodos e atributos de acesso. Outro exemplo de abstração, extensamente difundido na área de bancos de dados, é o modelo relacional de dados. Nesse modelo, os dados são organizados em relações ou tabelas, que por sua vez são constituídas por um ou mais atributos, também chamados de registros. Por ser fundamentado na álgebra relacional, a qual define diversas operações sobre conjuntos, consultas sobre esses dados são declaradas por meio de predicados compatíveis com predicados de lógica de primeira ordem.

Na construção de um sistema de software, para que modelos abstratos sejam eficientemente implementados é fundamental adotar uma linguagem de programação que apoie adequadamente tais abstrações, ou na qual seja possível representá-las de modo natural e conveniente. Por mais que uma boa modelagem seja a essência de um sistema bem projetado, robusto, escalável, de custo de manutenção reduzido e fácil de estender, implementá-lo por meio de uma linguagem de programação não adequada pode tornar a tarefa árdua e excessivamente complexa. Desse modo, inúmeras linguagem de programação surgiram ao longo dos anos com o intuito de apoiar novos modelos de programação ou modelos de estruturação de dados. Por exemplo, as linguagens Smalltalk, $\mathrm{C}++$ e Java foram desenvolvidas especialmente para representar o paradigma de orientação a objetos, enquanto que a linguagem declarativa SQL foi criada para a manipulação de dados no Modelo Relacional. Não obstante, há problemas cujo domínio da aplicação é melhor representado por um modelo alternativo de computação, o qual em geral demanda níveis de abstração não contemplados em linguagens de programação de uso geral. Nesses casos, o problema pode ser modelado de modo elegante e eficiente por meio da construção de uma linguagem de programação de domínio específico, uma minilinguagem elaborada especificamente para manipular uma abstração e que possa ser traduzida para alguma linguagem de programação de escopo mais abrangente.

Segundo [21], uma Linguagem de Domínio Específico (DSL, do inglês Domain-Specific Language) é uma linguagem de programação de expressividade limitada e com foco em um domínio particular. As DSL são ferramentas poderosas de modelagem, elas ajudam a expressar melhor o modelo em termos de código ao conceder aos desenvolvedores a liberdade de especificar o sistema utilizando um nível de abstração adequado ao domínio da aplicação. Com isso, é possível produzir um código mais expressivo, mais enxuto e, portanto, menos propenso a erros. Uma DSL que capture fielmente a semântica do modelo aumenta a comunicabilidade do código do sistema, facilitando assim a compreensão do que está sendo implementado por especialistas de negócio que não necessariamente sejam programadores. Além disso, segundo [45], um resultado consistente proveniente de estudos de padrões de erros no desenvolvimento de software é que a proporção de erros de programação por centenas de linhas de código executável varia muito pouco de linguagem para linguagem. Logo, espera-se que códigos concisos contenham menos erros de programação.

Assim como as demais abordagens para a modelagem e implementação de PAIS discutida no capítulo 3, a abordagem WED-flow pode ser compreendida como uma DSL para 
representar tanto os elementos concretos quanto conceitos abstratos presentes na concepção de um PAIS. No entanto, a notação matemática proposta em [19] descreve os elementos da abordagem WED-flow de modo abstrato e não contempla todas as operações necessárias para implementar-se um WED-flow por meio do WED-Engine. Desse modo, o desenvolvimento da WED-SQL como uma linguagem intermediária para a especificação de WED-flows não somente viabiliza como também simplifica o emprego da abordagem WED-flow no desenvolvimento de PAIS. Além disso, a linguagem WED-SQL é uma DSL no escopo da abordagem WED-flow.

\subsection{Por que utilizar WED-SQL ao invés de SQL ?}

A principal proposta deste trabalho é construir um arcabouço transacional que seja capaz de executar um WED-flow a partir de uma descrição formal dos elementos do mesmo. Conceitualmente, a abordagem WED-flow tem por base aspectos conceituais que incluem parte dos fundamentos do Modelo Relacional [17], os quais permitem construir, de modo conveniente, um ambiente de execução de WED-flows integrado ao SGBDR PostgreSQL. Uma consequência dessa interação é permitir que um WED-flow seja não somente declarado para executar nesse ambiente mas também gerenciado por meio da linguagem SQL.

Não obstante, WED-flow é um modelo transacional avançado que se apresenta como um modelo computacional alternativo para a modelagem e implementação de PAIS. Logo, a linguagem SQL não oferece o nível de abstração necessário para que os desenvolvedores possam explorar a modelagem de um WED-flow de modo natural e intuitivo, exigindo dos mesmos conhecimentos minuciosos de SQL para elaborar consultas de código extenso e de difícil compreensão. Por exemplo, os códigos 5.1 e 5.2 ilustram respectivamente a tradução de uma operação em WED-SQL para um código SQL equivalente.

Assim, como contribuição complementar ao ambiente de execução WED-Engine, este trabalho também propõem uma linguagem de programação para a implementação e gerenciamento WED-flow denominada WED-SQL: uma DSL declarativa, de sintaxe similar à SQL mas que captura a semântica do modelo WED-flow de modo claro, simples e preciso.

LIST FIRED WED-TRANSITIONS FOR <Wid>;

Código 5.1: Exemplo de código WED-SQL para listar as WED-transitions ativas para a instância identificada por $<$ wid $>$

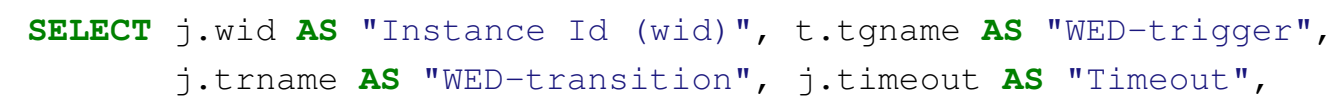




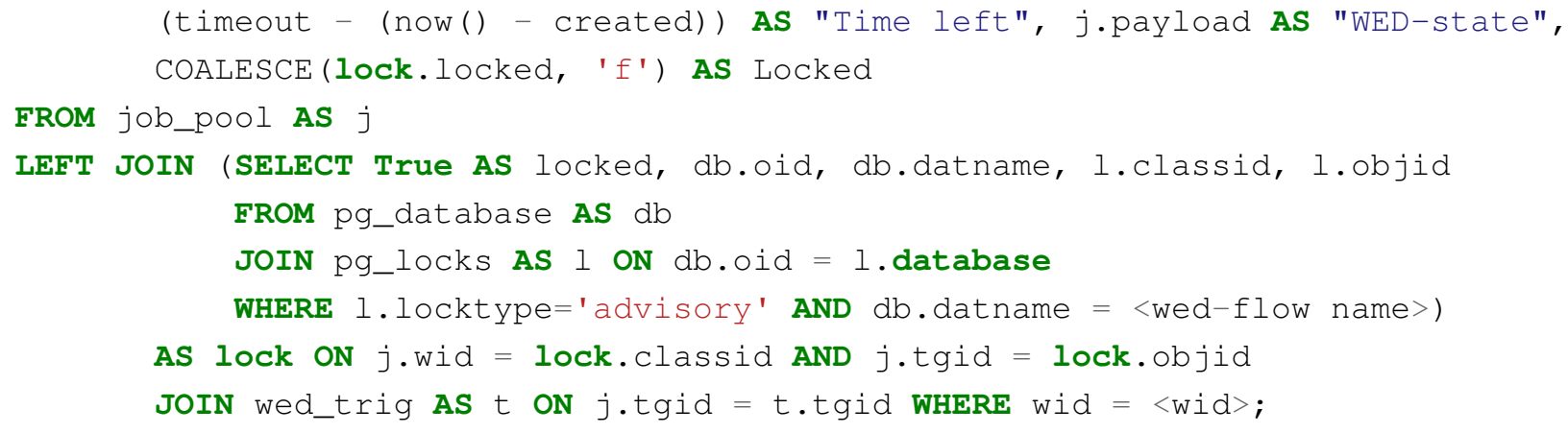

Código 5.2: Código em SQL equivalente ao código 5.1

\subsection{WED-SQL: Sintaxe e Operações}

As operações definidas na linguagem WED-SQL podem ser classificadas como operações de definição e operações de gerenciamento dos elementos da WED-flow. As operações de definição são utilizadas para declarar os elementos como, por exemplo, WED-attributes, WED-conditions e etc, que irão compor um WED-flow. Já as operações de gerenciamento sao empregadas, por exemplo, na visualização do elementos declarados, na criação de novas instancias e no acompanhamento do processamento das transações. Os comandos atualmente disponíveis em WED-SQL são os seguintes:

\subsubsection{Operações de Definição}

\section{CREATE WED-FLOW <nome $>$}

Esse comando cria um novo WED-flow, identificado por $<$ nome $>$. Efetivamente, o ambiente de execução inicializará uma nova base de dados contendo toda a metaestrutura de dados e de controle transacional necessárias para receber as definições subsequentes dos elementos que pertencerão a esse WED-flow. Note que, o ambiente de execução é capaz de gerenciar múltiplos WED-flow, isolando-os em bases de dados distintas, o que possibilita compartimentar um sistema de acordo com a semântica do modelo de negócio.

Os demais elementos de um WED-flow são declarados em relação a seu escopo, ou seja, é preciso especificar em qual WED-flow serão executados os demais comandos. Isso é feito com a ajuda de um terminal de comandos WED-SQL 5.4. 


\section{REMOVE WED-FLOW <nome $>$}

Remove o WED-flow identificado por <nome $>$ e todas as suas instâncias e definições. Esse comando é especialmente útil para fins de testes em ambiente de desenvolvimento, podendo ser desabilitado em ambiente de produção.

\section{CREATE WED-ATTRIBUTE $<$ nome $>$ [DEFAULT VALUE $<$ valor $>$ ]}

Cria um novo WED-attribute identificado por $<$ nome $>$, opcionalmente, com o valor inicial padrão <valor $>$. Caso a cláusula DEFAULT VALUE seja omitida, o valor padrão desse WED-attribute será nulo. Os WED-attributes de um WED-flow precisam ser declarados antes de declarar-se as WED-conditions, uma vez que o ambiente de execução irá rejeitar predicados que contenham WED-attributes não declarados.

\section{CREATE WED-CONDITION $<$ nome $>$ AS $<$ predicado $>$}

Cria uma nova WED-condition identificada por $\langle$ nome $>$, com um predicado $<$ predicado $>$ sobre os WED-attributes. Esse predicado utiliza-se da mesma sintaxe de uma cláusula WHERE em SQL que nao contenha subconsultas. Ou seja, podem ser utilizados operadores booleanos (AND, OR, NOT), operadores de conjuntos (IN, ANY, ALL, etc ...) operadores de expressões regulares (LIKE, SIMILAR TO, etc ...), os operadores IS NULL e IS NOT NULL, além de funções agregadas nativas do SGBDR ou definidas pelo usuário.

\section{CREATE WED-TRANSITION $<$ nome $>$ [WITH TIMEOUT $<$ tempo limite $>$ ]}

Cria uma nova WED-transition identificada por $<$ nome $>$. Opcionalmente, pode-se especificar um tempo limítrofe para executar a transação que encapsula essa WED-transition. Efetivamente, esse comando apenas declara ao ambiente de execução o nome da WEDtransition que deverá ser executada, cuja implementação pode ser feita por meio de uma função agregada ou de um WED-worker. Os formatos válidos para expressar <tempo limite> são os mesmos aceitos para o tipo interval em SQL. Por exemplo, '5 01:10:15' significa cinco dias, uma hora, dez minutos e quinze segundos. 
CREATE WED-TRIGGER $<$ nome_da_trigger $>$ AS

$(<$ nome_da_condição $>[\mathrm{AS}<$ predicado $>]$,

$<$ nome_da_transição $>$ [WITH TIMEOUT $<t>])$

Cria uma nova WED-trigger, identificada por <nome_da_trigger $>$, que associa a WEDcondition identificada por <nome_da_condição $>$ à WED-transition identificada por $<$ nome_da_transition $>$. Caso as referidas WED-condition e a WED-transition foram definidas previamente, seus parâmetros opcionais não devem ser utilizados. Caso contrário, pode-se usar os respectivos parâmetros opcionais para criar-se a WED-condition ou a WEDtransition no momento de criação da WED-trigger.

\section{SET FINAL WED-CONDITION AS <predicado>}

Define a condição de parada do WED-flow. A sintaxe de um predicado válido é a mesma empregada na criação das demais WED-conditions. A WED-condition final é única e, diferentemente das demais, não deve ser associada a uma WED-transition. A mesma apenas determina quais estados de dados são aceitos como estados finais das instâncias. Pode ser redefinida por meio desse mesmo comando.

\subsubsection{Operações de Gerenciamento}

\section{CREATE INSTANCE AS DEFAULT VALUES}

Após definidos os elementos básicos de um WED-flow, por meio dos comandos anteriores, esse comando inicia uma nova instância utilizando os valores padrão definidos para os WED-attributes.

CREATE INSTANCE $\left(a_{1}, a_{2}, \ldots, a_{n}\right)$ VALUES $\left(v_{1}, v_{2}, \ldots, v_{n}\right)$

Inicia uma nova instância com valores específicos para cada WED-attribute $\left(a_{1}=^{\prime}\right.$ $\left.v_{1}^{\prime}, a_{2}=^{\prime} v_{2}^{\prime}, \ldots, a_{n}=^{\prime} v_{n}^{\prime}\right)$ utilizando uma sintaxe análoga a uma cláusula INSERT em SQL. 


\section{[ENABLE || DISABLE] WED-TRIGGER <nome $>$}

Habilita ou desabilita a WED-trigger identificada por <nome $>$. Esse comando é utilizado para modificar a sequência de execução de WED-transitions em um WED-flow em produção, seja para capturar e tratar exceções não previstas ou para incorporar ao sistema novas funcionalidades do modelo de negócio. No futuro, esta substituição de WED-triggers será feita de modo dinâmico por meio da definição de múltiplos esquemas de execução para um WED-flow (Veja 6.2.1).

\section{LIST WED-ATTRIBUTES}

Lista os WED-attributes e seus respectivos valores padrões.

\section{LIST WED-CONDITIONS}

Lista todas as WED-conditions e seus respectivos predicados.

\section{LIST WED-TRANSITIONS}

Lista as WED-transitions declaradas ao ambiente de execução e seus respectivos tempos limite de execução.

\section{LIST [ENABLED || DISABLED] WED-TRIGGERS}

Lista as WED-triggers, exibindo quais WED-conditions estão associadas a quais WEDtransitions. Os parâmetros opcionais ENABLED e DISABLED podem ser utilizados para mostrar apenas as WED-triggers que estão, respectivamente, habilitadas ou desabilitadas.

\section{LIST [TRANSACTIONING || INCONSISTENT || FINAL] INSTANCES}

Lista as instâncias de um WED-flow. Essa lista pode ser filtrada de acordo com o WEDstate atual de cada instância por meio dos parâmetros opcionais: TRANSACTIONING, se o estado atual é transação-consistente; INCONSISTENT, se o estado atual é inconsistente, indicando que essa instância precisa ser recuperada; FINAL, se a instância já atingiu um 
WED-state final e terminou sua execução. Caso nenhum parâmetro opcional seja informado, serão exibidos os estados de dados atuais de todas as instâncias.

\section{LIST TRANSACTIONING WED-TRANSITIONS [FOR $<$ wid $>$ ]}

Lista as WED-transitions em execução para a instância identificada por $\langle$ wid $>$ ou para todas elas caso esse parâmetro seja omitido. Após o disparo de uma WED-transition, sua execução será iniciada imediatamente caso a mesma esteja armazenada no ambiente de execução como um Procedimento Armazenado. No cenário em que essa WED-transition esteja implementada por meio de um WED-Worker, o início de sua execução poderá ser postergado por indisponibilidade do respectivo WED-Worker. De todo modo, o ambiente de execução detecta essa situação e informa se há WED-transitions aguardando para serem executadas como resultado complementar da execução desse comando. O parâmetro <wid $>$ pode ser obtido por meio do comando LIST INSTANCES.

\section{SHOW FINAL WED-CONDITION}

Exibe a condição de parada do WED-flow.

GET WED-TRACE FOR $<$ wid $>$

Exibe o histórico de execução da instância identificada por $<$ wid $>$.

\subsection{Descrição Formal}

Formalmente, a linguagem WED-SQL é gerada pela gramática livre de contexto (GLC) descrita no código 5.3. Nessa gramática, as palavras escritas em letras minúsculas são símbolos não terminais, as palavras escritas em letras maiúsculas são os símbolos terminais (tokens) e as palavras escritas entre aspas simples são literais, ou seja, palavras que estão em sua forma final. Uma regra de produção é composta, nessa ordem, por um símbolo não terminal seguido do caractere ":" seguido de uma sequencia de outros símbolos (terminais e ou não terminais) que definem quais são as substituições válidas para expandir essa regra. O caractere "l" indica alternância, ou seja, que uma regra pode ser expandida por mais de uma sequência de substituições válida. 
Analisando o código 5.3, as linhas 1 a 4 dizem que um programa escrito em WED-SQL (símbolo wsql) é uma lista de declarações separadas por ";". Por sua vez, uma declaração (símbolo stmt, linha 6) é uma das operações definidas sobre a estrutura de um modelo WED-flow 5.2. As regras de produção de todas as declarações válidas em WED-SQL estão descritas nas linhas 25 a 99. As linhas 100 a 112 descrevem, por meio de expressões regulares, os formatos válidos para os tokens definidos por essa gramática. Por exemplo, o token VALID_NAME descreve que um nome válido para uma WED-transition deve ser uma sequência não vazia que pode conter letras (de "a" a "z") maiúsculas ou minúsculas, números (de 0 a 9 ) e o caractere "_".

Com exceção dos comandos WED-SQL CREATE WED-FLOW ... e REMOVE WED$F L O W \ldots$, os quais operam sobre as metaestruturas de dados e estruturas de controle do Ambiente de Execução, os demais são traduzidos em código SQL. Desse modo, a GLC da WED-SQL não especifica como algumas estruturas comum às duas linguagens devem ser interpretadas, o que ficará a cargo do interpretador de SQL do SGBDR. Por exemplo, o token $S Q L \_S T M T$, empregado na declaração que define a criação de uma WED-condition, não define o que é um predicado válido uma vez que o mesmo é análogo a uma expressão válida de uma cláusula WHERE em SQL. Um outro exemplo é o token TIME_INTERVAL_STRING, o qual representa os formatos válidos para intervalo de tempo aceitos pelo SGBDR 5.2.1.

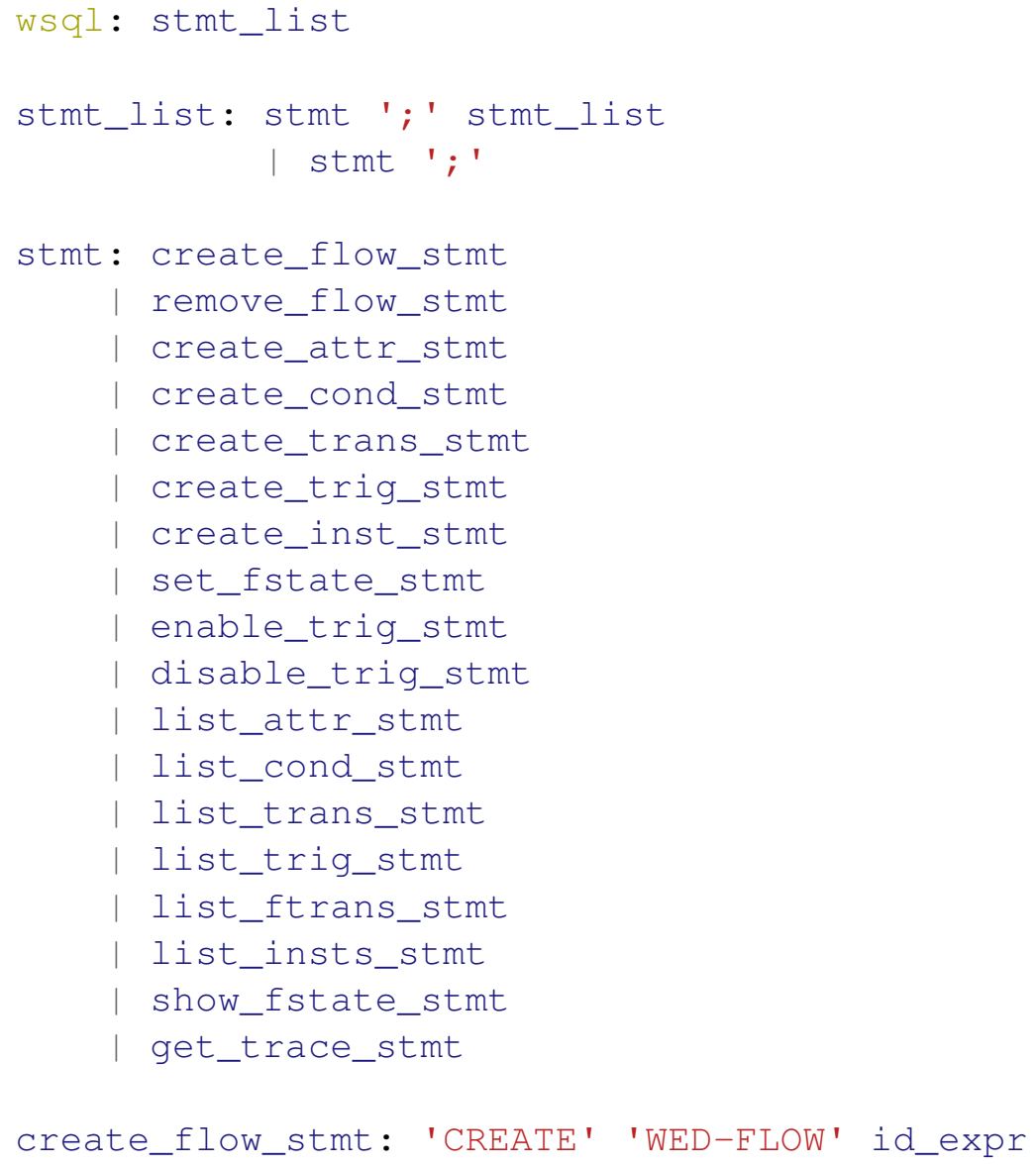




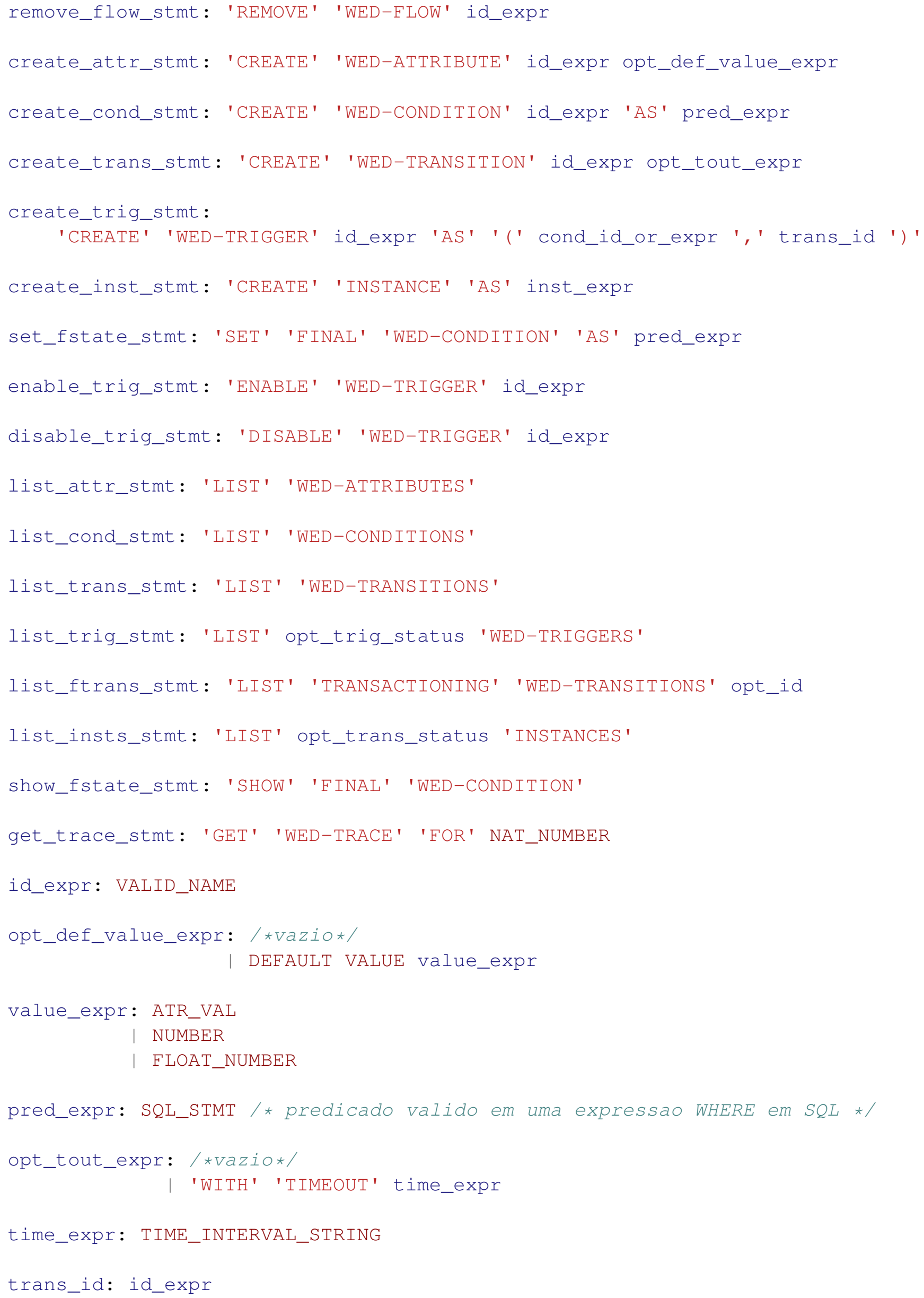




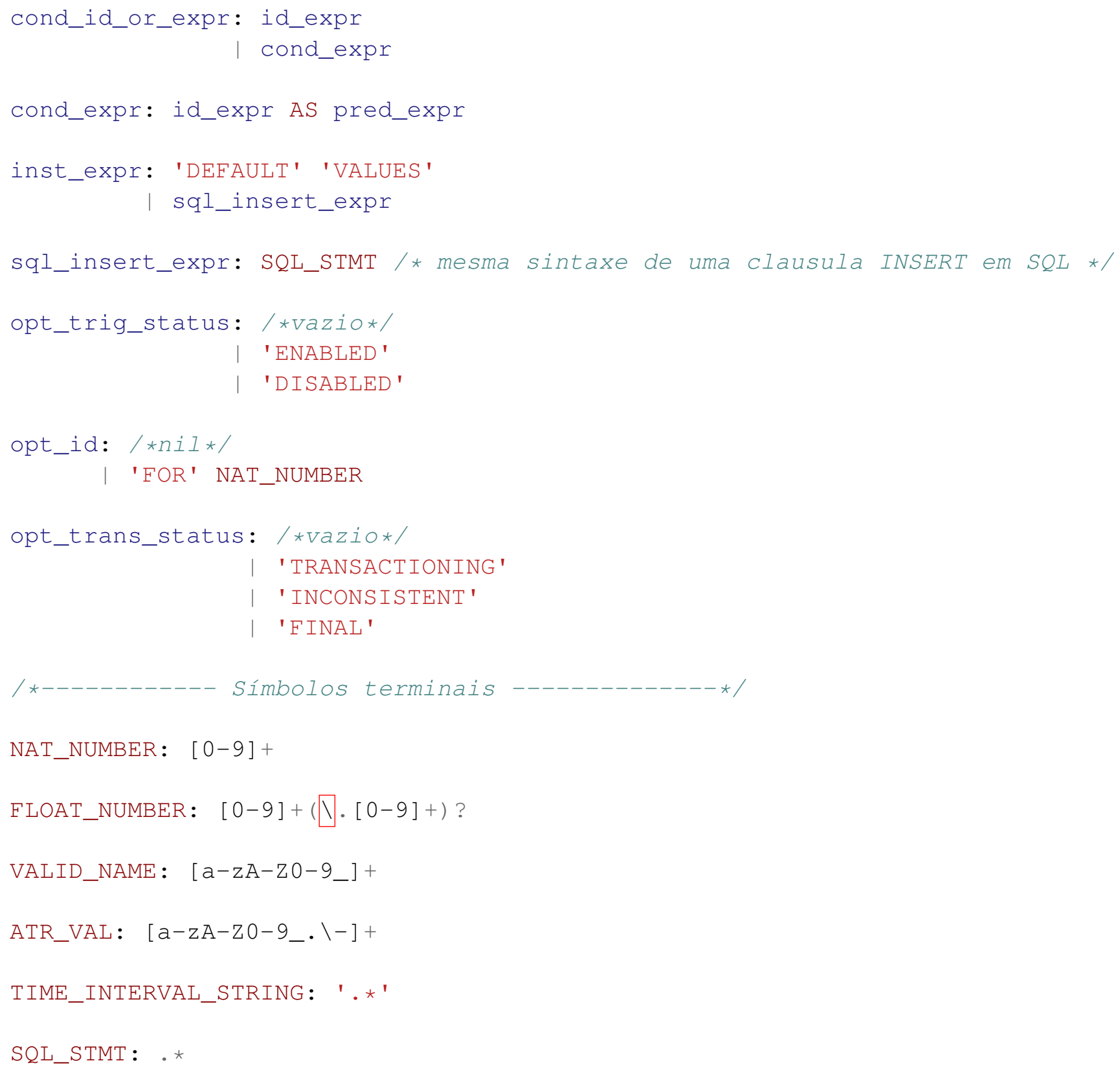

Código 5.3: Gramática Livre de Contexto que produz a linguagem WED-SQL

\subsection{Interpretador de Comandos}

Um interpretador de comandos é uma interface interativa capaz de executar um conjunto pré-definido de comandos e exibir ao usuário os resultados ou saída de cada comando executado. Esse tipo de software, também conhecido por Shell, é comumente empregado como ferramenta de acesso aos recursos disponibilizados por sistemas operacionais (e.g. GNU Bash para sistemas Linux), para gerenciar SGBDRs (e.g. psql para o Postgresql) além de servir 
como interface de programação interativa para diversas linguagens de programação (e.g. Python, Perl, SQL, etc ...). Assim, a fim de possibilitar o uso da linguagem WED-SQL em um ambiente dinâmico e interativo, tanto o processo de reconhecimento e interpretação da linguagem quanto o gerenciamento de seu ambiente de execução foram integrados em uma única ferramenta do tipo Shell : o WED-SQL Shell.

O WED-SQL Shell é um interpretador de comandos que reconhece tanto expressões da linguagem WED-SQL como expressões nativas de SQL, o que o torna apto a gerenciar o SGBDR além de inicializar e monitorar o ambiente de execução WED-SQL. Não obstante, há três comandos reconhecidos pelo WED-SQL Shell que não fazem parte nem da WED-SQL e nem de SQL. São eles:

- \lw: utilizado para listar quais WED-flows já foram declarados previamente;

- \cw: utilizado para conectar-se a um dos WED-flows listados por meio do comando lw;

- \q: caso esteja conectado a um WED-flow, desconecta-se e finaliza o Shell.

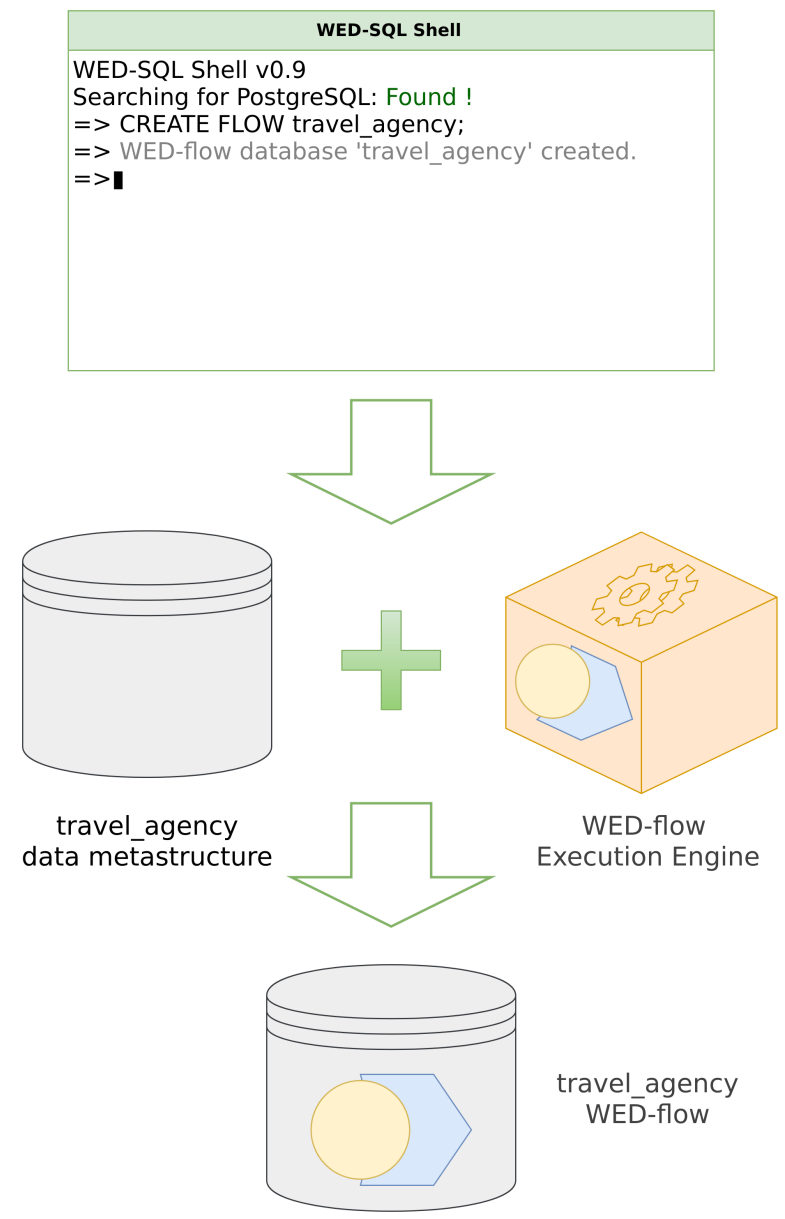

Figura 5.1: Inicializando um novo ambiente de execução para o WED-flow travel_agency 


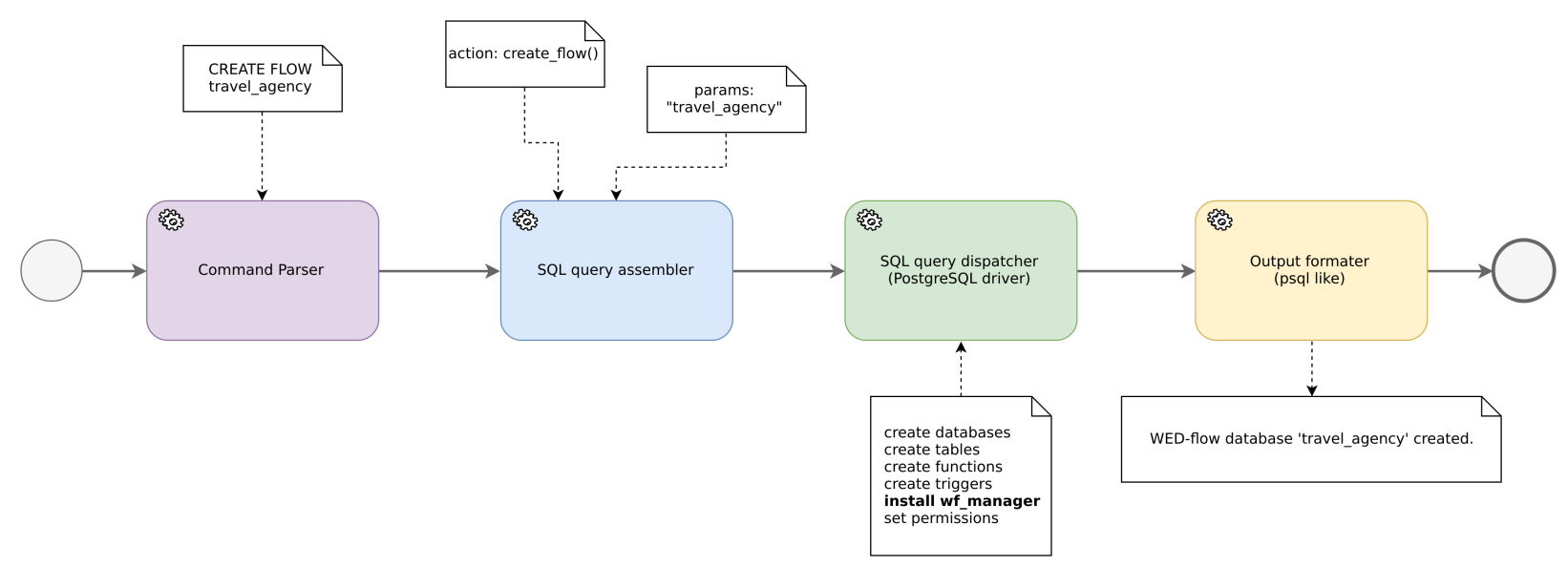

Figura 5.2: Diagrama de funcionamento do interpretador de comandos WED-SQL Shell

As figuras 5.1 e 5.2 ilustram o funcionamento do WED-SQL Shell por meio da declaração de um WED-flow denominado "travel_agency". Ao receber o comando WED-SQL CREATE FLOW travel_agency; (figura 5.1), será criado um banco de dados contendo a metaestrutura de dados necessária para armazenar os elementos desse WED-flow (capítulo 2). Além disso, as ferramentas de execução e controle transacional de WED-flows ( WED-flow Execution Engine) serão integradas a esse banco de dados transformando-o em um ambiente de execução desse WED-flow. Em seguida, o Shell exibe uma mensagem informando que o WED-flow travel_agency foi inicializado corretamente.

A figura 5.2 ilustra o funcionamento interno do WED-flow Shell para o mesmo exemplo. Ao receber um comando WED-SQL, o Shell invocará o interpretador de comandos WEDSQL 2 (Parser), o qual produzirá como resultado uma ação indicando qual operação deverá ser executada e seus respectivos parâmetros. Nesse exemplo, a ação produzida chama-se create_flow() e há um único parâmetro informando o nome do WED-flow que será criado ("travel_agency"). No passo seguinte (SQL Query Assembler), serão gerados os comandos SQL necessários para executar essa operação. Nesse caso, além dos comandos SQL para criar um novo banco de dados contendo as tabelas, funções agregadas e triggers que compõe a metaestrutura de dados, será necessário inicializar o ambiente de execução por meio da execução de um script de instalação. Nessa etapa, o Shell conecta-se ao SGBDR (SQL Query Dispatcher para executar essas operações. Em sua última etapa (Output Formater), o Shell exibe o resultado das operações executadas. Futuramente, os dois primeiros passos do processo de funcionamento do WED-SQL Shell serão substituídos por um Parser gerado por meio da ferramenta ANTLR (capítulo 2).

É importante notar que após a execução do comando CREATE FLOW travel_agency; é preciso conectar-se a esse WED-flow por meio do comando | cw travel_agency; para declarar os demais elementos desse WED-flow. Os comandos WED-SQL subsequentes para declarar WED-attributes, WED-conditions e etc ... somente serão aceitos caso o Shell esteja conectado a algum WED-flow. 


\subsection{Conclusão}

Uma boa modelagem do domínio de um problema é de vital importância para que se possa desenvolver um sistema computacional robusto, flexível, e que resolva o problema com eficiência. Com o crescente aumento da complexidade dos sistemas computacionais, ficou cada vez mais evidente a necessidade de se modelar um sistema em termos de abstrações. Essas abstrações aumentam a expressividade de um modelo e, com isso, ajudam não somente desenvolvedores mas também especialistas de negócio a compreender melhor o problema, resultando em um sistema mais bem projetado. Não obstante, pra que o poder das abstrações possa ser utilizado em sua plenitude no desenvolvimento de um sistema, é preciso que a linguagem de programação adotada para implementá-lo ofereça apoio adequado ao nível de abstração do modelo. Uma abordagem nova como a WED-flow, a qual propõe um modelo alternativo de computação, requer uma linguagem de programação construída especialmente para seu domínio de aplicação, uma linguagem na qual seja possível representar suas abstrações de modo natural e intuitivo. Nesse contexto, conjuntamente com o ambiente de execução WED-Engine, a linguagem WED-SQL, uma DSL declarativa e de sintaxe similar a linguagem SQL, foi cuidadosamente construída para ser a linguagem de programação da abordagem WED-FLOW. 


\section{Capítulo 6}

\section{Modelagem e Implementação}

Neste capítulo será apresentado um exemplo prático de como modelar e implementar um PAIS utilizando a linguagem WED-SQL e o ambiente de execução WED-Engine. Esse exemplo retrata, de modo simplificado, o funcionamento de uma agência de viagens a qual oferece serviços de reserva de hotéis, passagens aéreas e aluguel de carro a seus clientes os quais podem requisitar pacotes que incluam qualquer combinação dos serviços oferecidos. Ilustraremos em detalhes como a composição dos elementos da abordagem WED-flow captura com precisão e elegância as interações entre as atividades realizadas pelo processo de negócio desse sistema, além de ilustrar como essas interações conduzem o desenvolvimento de um modelo executável por meio da linguagem WED-SQL. Para finalizar, vamos modificar o sistema, inserindo uma nova funcionalidade, com o propósito de ilustrar o quão simples é evoluir um PAIS implementado em WED-SQL.

\subsection{Exemplo: Agência de Viagens}

A agência de viagens desse exemplo (figura 6.1) dispõe de três tipos de serviços de reserva: passagem aérea, automóvel e hotel. Esses serviços são oferecidos a seus clientes por meio de pacotes de viagem, os quais podem incluir qualquer combinação dos serviços disponíveis. Desse modo, um cliente inicia o processo de compra de um pacote informando à agência o destino e as datas da viagem, assim como quais reservas deseja adquirir. A agência, por sua vez, ao receber um novo pedido, entra em contato com suas empresas parceiras e efetua as reservas solicitadas, informando o resultado final ao cliente após o término dessa operação. Caso todas as reservas inclusas no pacote sejam efetuadas com sucesso, o cliente efetua o pagamento. Em seguida, a agência emite ao cliente os comprovantes das reservas e 


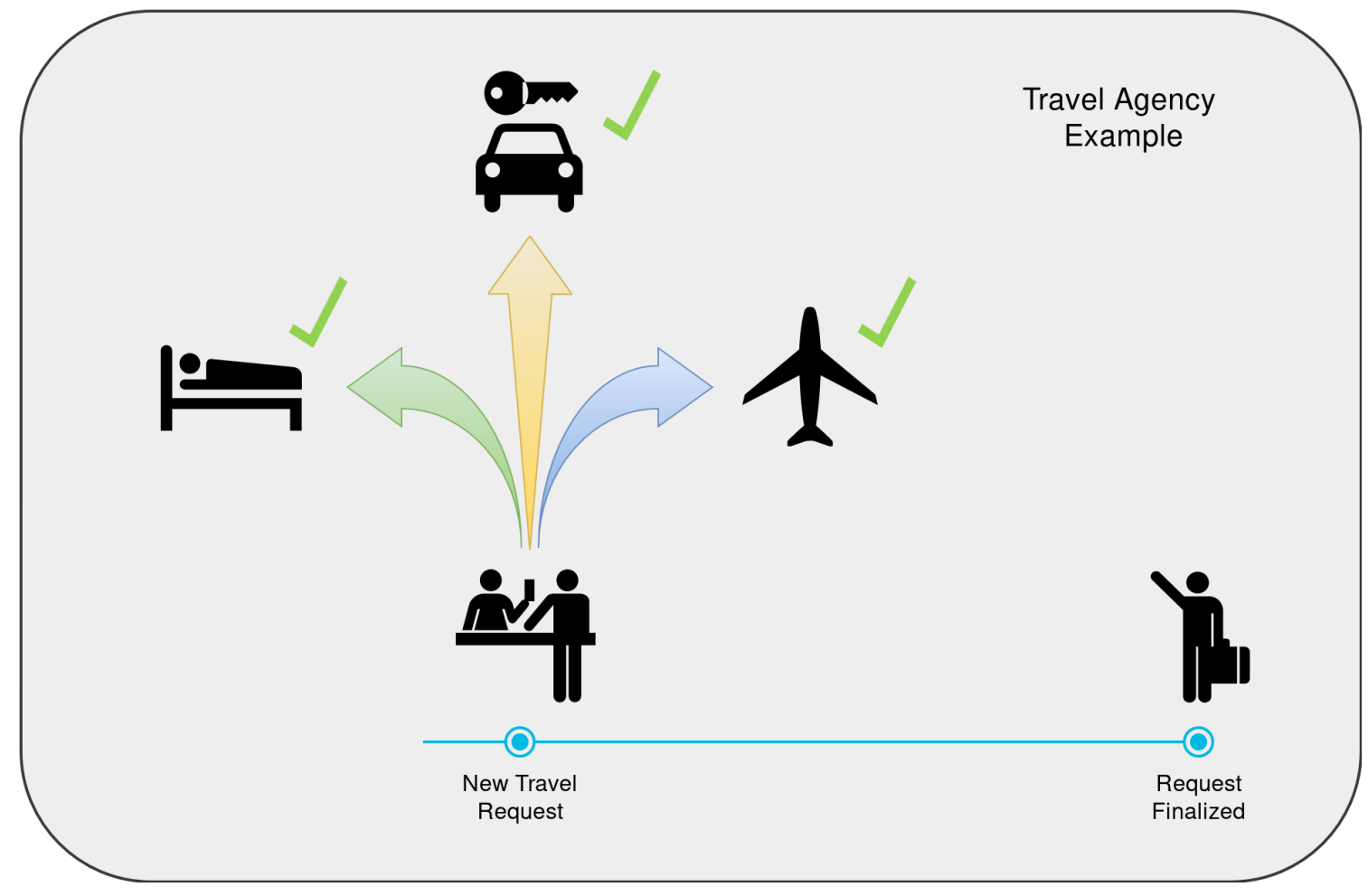

Figura 6.1: Exemplo do processo de negócio simplificado de uma agência de viagens

demais documentos, finalizando a instância.

Embora, a primeira vista, o exemplo apresentado possa parecer demasiado simples, o mesmo é adequado e suficiente não somente para expor as técnicas de modelagem mas também para discutir detalhes importantes da abordagem. Ao longo deste capítulo, à medida que as técnicas de modelagem forem sendo apresentadas, vamos indicar precisamente quando e como o exemplo poderia ser estendido de modo a torná-lo mais próximo de um processo de negócio do mundo real. Por exemplo, permitir que o cliente escolha datas distintas para as reservas solicitadas, ou ainda permitir que o cliente escolha um determinado modelo de carro assim como a categoria do hotel.

Vale notar que, cada instância de venda de um pacote de viagem possui apenas um único possível resultado final de sucesso. Ou seja, todas as etapas do processo de venda de de um pacote, o que inclui efetuar todas as reservas solicitadas por um cliente, devem ser bem sucedidas. A uma dada sequência de operações, ou passos, que compõe a execução de uma instância desde seu estado inicial até seu estado final denominamos um caminho. Um WED-flow pode ter mais de um caminho que conduza uma instância ao objetivo final. Nesse caso, dizemos que um caminho principal, ou caminho feliz, é aquele em que todos os passos de uma instância sejam executados com sucesso. Alternativamente, um caminho é dito alternativo quando, em decorrência de uma execução anômala de um ou mais de seus passos, uma instância atinge seu objetivo final por um caminho que desvie do caminho feliz. 
Uma aplicação prática do uso de caminhos alternativos em um WED-flow é permitir que uma instância termine com sucesso mesmo que apenas com algum resultado parcial. Por exemplo, suponha que um cliente requisitou um pacote que inclua reservas de passagem de avião, carro e hotel. No entanto, para a data informada, todos os hotéis estavam lotados. O cliente decide então que não deseja alterar a data de suas reservas, e aceita ficar somente com as reservas de passagem e automóvel. Nesse caso, o resultado parcial obtido é aceitável e a instância finaliza com sucesso. Ao final deste capítulo, será ilustrado como incorporar esse caminho alternativo à modelagem inicial.

Por mais que a abordagem WED-flow admita a modelagem de caminhos alternativos de execução no desenvolvimento de um PAIS, podem ocorrer eventos, geralmente não previstos na fase de modelagem, que impossibilitem uma instância de atingir seu objetivo final. Nesses cenários, dizemos que a instância entra em estado de exceção e sua execução é interrompida. O exemplo da agência de viagens, conforme apresentado anteriormente, admite apenas um único caminho de execução possível que é aceito como bem sucedido. Sendo assim, qualquer falha na execução de algum passo intermediário de uma instância implica no lançamento de uma exceção. Vale enfatizar que, ao contrário da abordagem transacional clássica, que na presença de falhas na execução de uma instância retorna-a a seu estado inicial desfazendo toda a computação realizada previamente, a abordagem WED-flow é capaz recuperar a execução de uma instância falha por meio dos mecanismos de compensação e recuperação propostos em [19]. Em outro trabalho, publicado mais recentemente, são propostos algoritmos mais avançados de recuperação baseados em um modelo de custos. Não obstante, no escopo deste trabalho, o WED-Engine limita-se a capturar exceções e interromper a execução da respectiva instância, deixando a recuperação a cargo de outras ferramentas externas ao ambiente de execução.

No restante deste capítulo, com base no exemplo da agência de viagens, serão apresentadas as técnicas de modelagem de um PAIS utilizando a abordagem WED-flow por meio da linguagem WED-SQL e o ambiente de execução WED-Engine. A metodologia adotada inclui técnicas para definir as atividades de um processo de negócio por meio de eventos; a parametrização desses eventos em eventos de dados; captura de eventos de dados e sua associação com as atividades; implementação das atividades em forma de WED-transitions. Após a modelagem do PN original, vamos estendê-lo adicionando um novo serviço oferecido pela agência de viagens.

\subsubsection{Identificando os Eventos}

Conforme mencionado anteriormente, a abordagem WED-flow é fundamentada na combinação de três elementos básicos onipresentes nos processos de negócio: workflow ou fluxo 
de trabalho, eventos e dataflow ou fluxo de dados. Não coincidentemente, na abordagem WED-flow, são esses mesmos elementos que guiam a modelagem de um sistema de gerenciamento dos processos de negócios. A abordagem sugere ainda que o primeiro passo da modelagem de um PN seja identificar seus eventos[20]. Essa diretriz baseia-se no fato de que a execução das atividades de um PN, caracterizada por meio das WED-transitions, está intimamente ligada a ocorrência de eventos. Tanto o início quanto o fim de uma atividade são marcados pela ocorrência de eventos.

No contexto da agência de viagens, podemos identificar os seguintes eventos:

- A agência recebe um novo pedido de um pacote de viagem;

- A agência solicita reserva de voo;

- A agência solicita reserva de hotel;

- A agência solicita reserva de automóvel;

- A agência finaliza o pedido;

Note que não é preciso identificar todos os eventos a priori, a abordagem WED-flow é suficientemente flexível para contemplar alterações futuras no modelo. A modelagem de muitos projetos se inicia sem uma definição clara e precisa de todos seus requisitos funcionais, os quais se manifestam e são incorporados naturalmente durante seu ciclo de vida. A WEDflow foi projetada desde o início para atender a essa evolução incremental inerente aos PAIS contemporâneos.

\subsubsection{Identificando as Atividades}

As principais notações para a modelagem de processos de negócio (e.g. Redes de Petri, BPMN, UML e etc ...) os caracterizam em termos de atividades [49]. Essas atividades, por sua vez, podem ser caracterizadas como unidades de trabalho cujo propósito é executar uma tarefa específica. No âmbito da WED-flow, uma atividade executa de forma atômica, como uma única transação de banco de dados, e recebe o nome de WED-transition.

Uma vez identificados os eventos, podemos derivar as WED-transitions relacionando a ocorrência de eventos às atividades que devem ser executadas. Desse modo, definimos por $\mathcal{T}$ $=\{$ inicia_pedido, reserva_voo, reserva_hotel, reserva_carro, finaliza_pedido $\}$ o conjunto das WED-transitions para o WED-flow da agência de viagens em que: 
- inicia_pedido: Ao receber um novo pedido de pacote de viagem, essa WED-transition é responsável por validar os dados iniciais fornecidos pelo cliente, como as datas da viagem e seu destino;

- reserva_voo: Caso o cliente tenha solicitado uma reserva de passagem aérea em seu pacote, essa WED-transitions encapsula os procedimentos para contatar as companhias aéreas parceiras da agência e efetuar a reserva;

- reserva_hotel: Caso o cliente tenha solicitado uma reserva de quarto de hotel em seu pacote, essa WED-transitions encapsula os procedimentos para contatar as redes hoteleiras conveniadas a agência e efetuar a reserva;

- reserva_carro: Caso o cliente tenha solicitado uma reserva de automóvel em seu pacote, essa WED-transitions encapsula os procedimentos para solicitar a reserva junto às locadoras de automóveis associadas à agência;

- finaliza_pedido: Uma vez concluídas todas as reservas solicitadas, essa WEDtransition executa as rotinas necessárias para finalizar o pedido, incluindo a confirmação final do cliente, pagamento e emissão dos recibos e outros documentos pertinentes ao pacote de viagem.

\subsubsection{Parametrizando Eventos}

Na abordagem WED-flow, os eventos de um PN são definidos na forma de estados de dados, que por sua vez são parametrizados com base em WED-attributes. Desse modo, seja $\mathcal{A}=\left\langle a_{1}, a_{2}, a_{3}, \ldots, a_{n}\right\rangle$ uma tupla, na qual cada $a_{i}$, tal que $1 \leq i \leq n$, representa um WEDattribute, dizemos que um estado de dados é uma valoração $\left\langle v_{1}, v_{2}, v_{3}, \ldots, v_{n}\right\rangle$ para $\mathcal{A}$ em que cada $v_{i}$, tal que $1 \leq i \leq n$, representa o valor do WED-attribute $a_{i}$. Vale lembrar que, conforme discutido no capítulo 4, o ambiente de execução da linguagem WED-SQL armazena os estados de dados de um WED-flow na tabela homônima de seu banco de dados. Ou seja, cada coluna (ou atributo) dessa tabela representa um WED-atributte, enquanto que cada linha contém o estado de dados atual de uma instância.

Embora os estados de dados sejam formalmente representados por tuplas contendo valorações para todos os WED-attributes definidos para uma aplicação WED-flow, na prática os eventos de interesse de cada WED-transition podem ser representados por um subconjunto desses WED-attributes. Por consequência, uma forma pragmática de se projetar os WEDattributes de um WED-flow é percorrer seu conjunto $\mathcal{T}$ das WED-transitions e identificar quais são os WED-attributes de interesse particular de cada WED-transition de acordo com seus requisitos de dados. 
Essa técnica de derivação dos WED-attributes de uma aplicação por meio de análises de requisitos de dados individuais para cada WED-transition nos permite construir a tupla $\mathrm{A}$ de maneira iterativa. No entanto, uma vez que na abordagem WED-flow o fluxo de trabalho de uma aplicação é determinado de modo implícito, exclusivamente por alguma sequência de estados de dados gerados pelas WED-transitions, a união dos WED-attributes de interesse de cada WED-transition deve necessariamente ser não disjunta. Em outras palavras, alguns dos WED-attributes deverão ser compartilhados entre duas ou mais WED-transitions. Essa condição é necessária para garantir que haja um fluxo de dados na aplicação. Ou seja, a menos do estado inicial, que é gerado por um evento externo, e do estado final, o qual finaliza a execução de uma instância, é esperado que sejam produzidos estados de dados que habilitem a execução de WED-transtions subsequentes.

De acordo com o conjunto $\mathcal{T}$ das WED-transitions da agência de viagens, podemos derivar os seguintes WED-attributes:

\section{1. inicia_pedido}

Para iniciar um pedido, o cliente deve informar previamente as datas de partida e de retorno, o destino e quais reservas devem ser inclusas em seu pacote. Para tal, vamos utilizar quatro WED-attributes:

- data_partida: data de início da viagem no formato AAAA-MM-DD;

- data_retorno: data de retorno da viagem no formato AAAA-MM-DD;

- destino: nome da cidade, estado e país de destino separados por vírgula;

- res_solicitadas: lista das reservas solicitadas pelo cliente. Pode conter apenas os valores 'voo', 'hotel' e 'carro'.

O resultado da execução da WED-transition inicia_pedido, por sua vez, será informado por meio de três WED-attributes:

- res_voo: indica se uma reserva de voo deverá ser inclusa nesse pacote;

- res_hotel: indica se uma reserva de hotel deverá ser inclusa nesse pacote;

- res_auto: indica se uma reserva de automóvel deverá ser inclusa nesse pacote;

- status: indica a situação atual do pedido. Os valores 'aberto' e 'fechado' indicam respectivamente que a instância está executando ou finalizada.

Os WED-attributes res_voo, res_hotel e res_auto podem assumir os valores 'requisitar' ou 'ignorar' para indicar se a respectiva reserva deverá ou não ser efetuada pelas WED-transitions responsáveis por cada uma delas. 
2. reserva_voo, reserva_hotel e reserva_carro

Os WED-attributes res_voo, res_hotel e res_auto também serão utilizados, respectivamente, para indicar o resultado da execução das WED-transitions reserva_voo, reserva_hotel e reserva_carro. Com isso, esses WED-attributes poderão, complementarmente, assumir o valor 'reservado', indicando que a respectiva reserva foi efetuada com sucesso, ou o valor 'erro', indicando que não foi possível efetuar a respectiva reserva.

\section{3. finaliza_pedido}

A WED-transition finaliza_pedido requer informação sobre a situação das reservas solicitadas, uma vez que o início de sua execução está condicionado ao termino das WED-transitions que realizam as reservas. Para tal, serão utilizados os mesmos WEDattributes res_voo, res_hotel e res_auto. Além disso, vamos utilizar o seguinte WEDattribute para representar o resultado da execução dessa WED-transition:

- status: o valor 'fechado' indica que a WED-transition finalizou com sucesso, enquanto que o valor 'erro' indica que houve algum problema durante sua execução.

Assim, $\mathcal{A}=\{$ data_partida, data_retorno, destino, reservas_solicitadas, res_voo, res_hotel, res_auto, status $\}$ é a tupla ordenada dos WED-attributes definidos para o WED-flow da agência de viagens.

\subsubsection{Capturando Eventos}

A etapa final da modelagem de uma aplicação WED-flow resume-se a modelagem de WED-conditions e a definição dos WED-triggers. Vale lembrar que os WED-triggers são estruturas de dados que associam uma WED-condition a uma WED-transition. As WEDconditions, por sua vez, são predicados definidos sobre os WED-attributes. Dizemos que um WED-trigger dispara uma WED-transition sempre que sua WED-condition associada for satisfeita. A modelagem das WED-conditions deve expressar precisamente quais são estados de dados de interesse de sua WED-transition associada. A figura 6.2 ilustra o conjunto $\mathcal{T}=$ \{TGi, TGv, TGh, TGa, TGf $\}$ das WED-triggers definidos para a agência de viagens.

A WED-trigger TGi dispara a WED-transition inicia_pedido quando ocorrer um estado de dados cujos WED-attributes data_partida, data_retorno, destino e reservas_solicitadas sejam não vazios. Ou seja, o cliente precisa necessariamente informar as datas da viagem, seu destino e ao menos um tipo de reserva, seja ela reserva de voo, hotel ou automóvel. Além disso, a data de partida deve obrigatoriamente ser inferior a data de retorno. Note que validar 


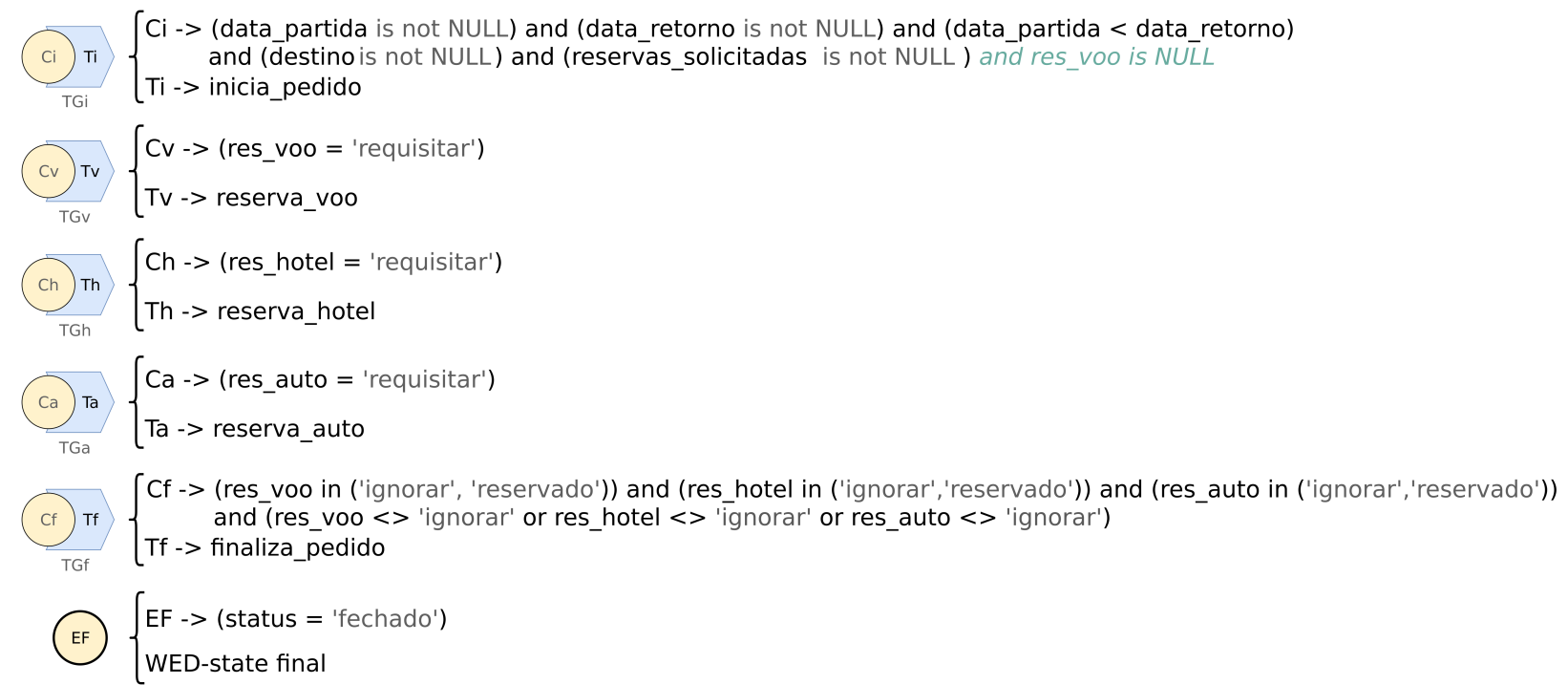

Figura 6.2: Notação WED-flow para a representação dos WED-triggers e WED-conditions projetados para a agência de viagens. Em WED-SQL, os predicados das WED-conditions são expressos utilizando-se da mesma sintaxe de uma cláusula WHERE em SQL.

as datas na WED-condition Ci ao invés de fazê-lo durante a execução da WED-transition inicia_pedido impede que uma instância seja criada apenas para entrar em um estado de exceção, caso o intervalo de datas informado seja inválido.

As WED-triggers TGv, TGh e TGa controlam, respectivamente, os disparos das WED-transitions reserva_voo, reserva_hotel e reserva_auto. Esses três disparos dependem exclusivamente do estado de dados gerado por inicia_pedido, o qual poderá conter os valores 'requisitar' ou 'ignorar' para cada um dos WED-attributes res_voo, res_hotel ou res_auto de acordo com as reservas solicitadas pelo cliente. Tanto os disparos quanto as execuções dessas três WED-transitions são concomitantes.

O disparo da WED-transition finaliza_pedido somente deverá ocorrer após a efetivação das reservas solicitadas. Além disso, é necessário que a instância contenha ao menos uma reserva, ou seja, uma instância que inicie com sua lista de reservas solicitadas vazia não irá conter um estado de dados que dispare finaliza_pedido, interrompendo seu processamento. Assim, a WED-condition Cf, associada a WED-trigger TGf, é a conjunção de três cláusulas que individualmente representam uma condição de espera para cada uma das WED-transitions que realizam reservas, além de uma quarta cláusula que representa a condição de que ao menos das reservas foi solicitada. Vale lembrar que as WED-transitions reserva_voo, reserva_hotel e reserva_auto escrevem, respectivamente, nos WED-attributes res_voo, res_hotel e res_auto, em que um valor 'ignorar' implica que a respectiva WEDtransition não foi disparada e, portanto, pode ser ignorada por Cf, já um valor 'solicitado' indica que a respectiva WED-transition terminou de executar.

Na figura 6.2, o círculo em negrito com a inscrição EF representa a condição de captura 
do evento de dados alvo das instâncias, que nada mais é do que uma classe de equivalência de estados de dados finais que devem ser alcançados por todas as instâncias de um WED-flow que seguiram seu "caminho feliz". Nesse exemplo, estados de dados cujo valor WED-attribute res_final seja "êxito"indicam que a WED-transition finaliza_pedido executou com sucesso e a instância foi concluída.

Note que cada WED-condition definida neste exemplo da agência de viagens emprega apenas um subconjunto dos WED-attributes definidos para esse sistema. Todavia, de acordo com a abordagem WED-flow, os estados de dados a que as WED-triggers são expostas são tuplas contendo valores para todos os WED-attributes em um WED-flow. Assim, ao omitir um WED-attribute de um predicado de uma WED-condition, estamos assumindo que qualquer valor para esse atributo é de interesse da WED-transition associada, o que deve ser feito meticulosamente a fim de evitar que ocorram disparos indevidos durante a execução de uma instância. Por exemplo, considere a WED-condition Ci, associada à WEDtransition inicia_pedido:

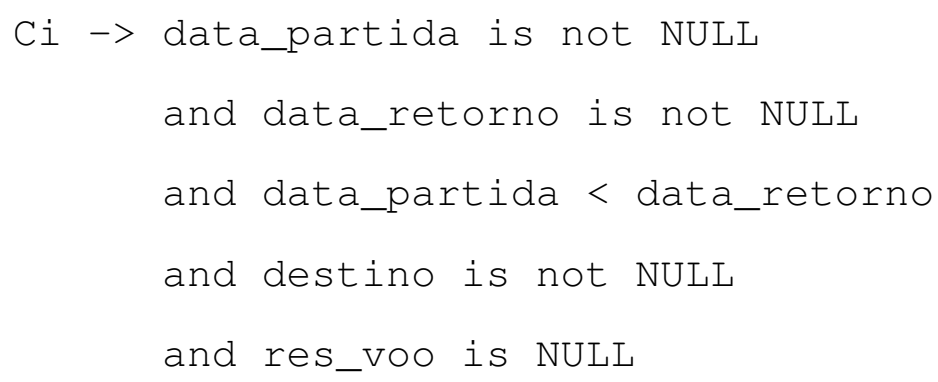

A clausula "and res_voo is $N U L L "$ em $\mathrm{Ci}$, embora à primeira vista não faça parte dos requisitos de dados de inicia_pedido, é necessária para evitar que os estados de dados gerados por uma execução prevista de WED-transitions subsequentes disparem novamente inicia_pedido como efeito colateral. Execução prevista de uma WED-transition é aquela que gera um estado de dados para o qual foi projetada uma WED-condition que capture esse evento. Para ilustrar esse efeito indesejado, vamos substituir $\mathrm{Ci}$ por $\mathrm{Ci}$ ' na WED-trigger TGi:

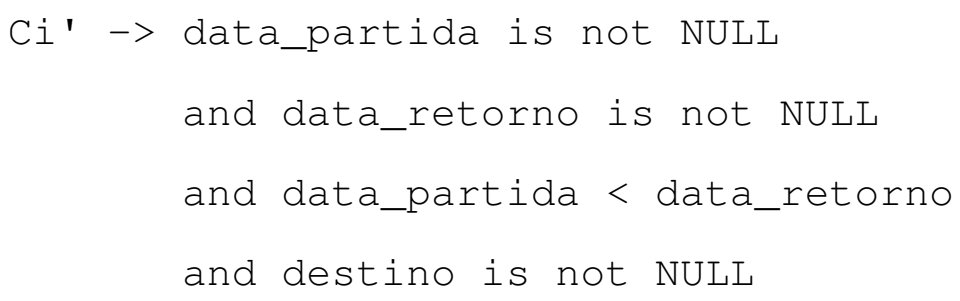

Do modo como o WED-flow da agência de viagens foi projetado, nenhum dos WEDattributes declarados no predicado de Ci’ será modificado durante a execução de uma instância. Logo, qualquer estado de dados gerado por qualquer WED-transition da agência 
de viagens, inclusive inicia_pedido, satisfaria $\mathrm{Ci}$, ocasionando o disparo de inicia_pedido múltiplas vezes. A presença da cláusula res_voo is NULL em Ci é suficiente para evitar esse problema, uma vez que após a execução de inicia_pedido, os valores possíveis para o WED-attribute res_voo, assim como res_hotel e res_auto, serão sempre diferentes de NULL. O mesmo fenômeno não se repete para as demais WED-transitions, dado que reserva_voo, reserva_hotel e reserva_auto alteram o valor dos WED-attributes responsáveis por seus disparos e finaliza_pedido gera um estado de dados final, o qual não dispara novas WED-transitions por definição.

Uma boa modelagem das WED-conditions é de fundamental importância para garantir a correta execução das instâncias de um WED-flow. São elas que, ainda que de modo implícito, determinam dinamicamente o workflow do sistema. Desse modo, ao modelar uma WEDcondition, devemos sempre examinar os possíveis estados de dados que podem ser gerados por todas as WED-transitions do sistema a fim de evitar disparos indevidos. Em seguida, vamos descrever o WED-flow da agência de viagens em WED-SQL.

\subsubsection{WED-SQL}

O código ilustrado na figura 6.1 representa a descrição do sistema WED-flow da agência de viagens em WED-SQL. O comando "CREATE WED-FLOW agência_de_viagens" (linha 1) é responsável pela inicialização da metaestrutura de dados que conterá os elementos desse WED-flow descritos nas linhas 4 a 35. Essa inicialização é necessária sempre que deseja-se declarar um novo WED-flow. Uma vez que o ambiente de execução é capaz de gerenciar múltiplos WED-flow, utiliza-se o comando " $\backslash c w "$ (linha 2) para selecionar em qual metaestrutura de dados serão executados os comandos WED-SQL subsequentes.

Vale lembrar que o comando CREATE WED-TRANSITION é utilizado apenas para declarar ao ambiente de execução os identificadores únicos das WED-transitions que deverão ser executadas na ocorrência dos eventos de dados de interesse. Nesse exemplo, cada WED-transition é identificada pelo seu próprio nome 6.1.2 (linhas 13 a 17). Efetivamente, a implementação das WED-transitions será discutida em sequência.

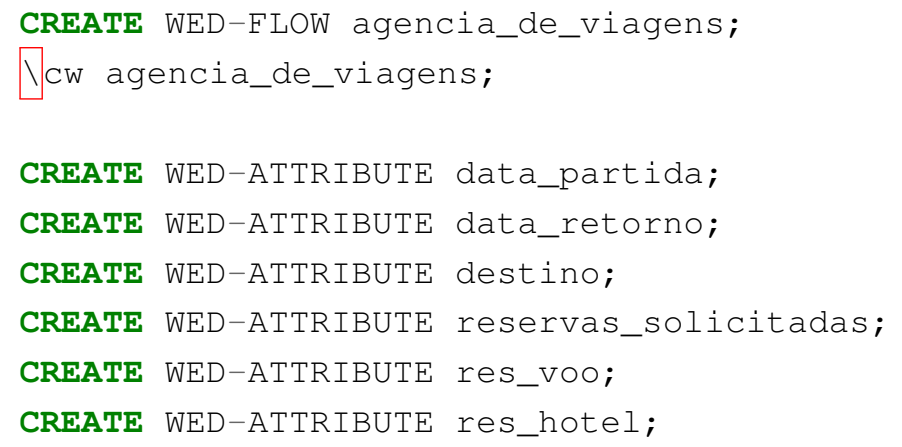




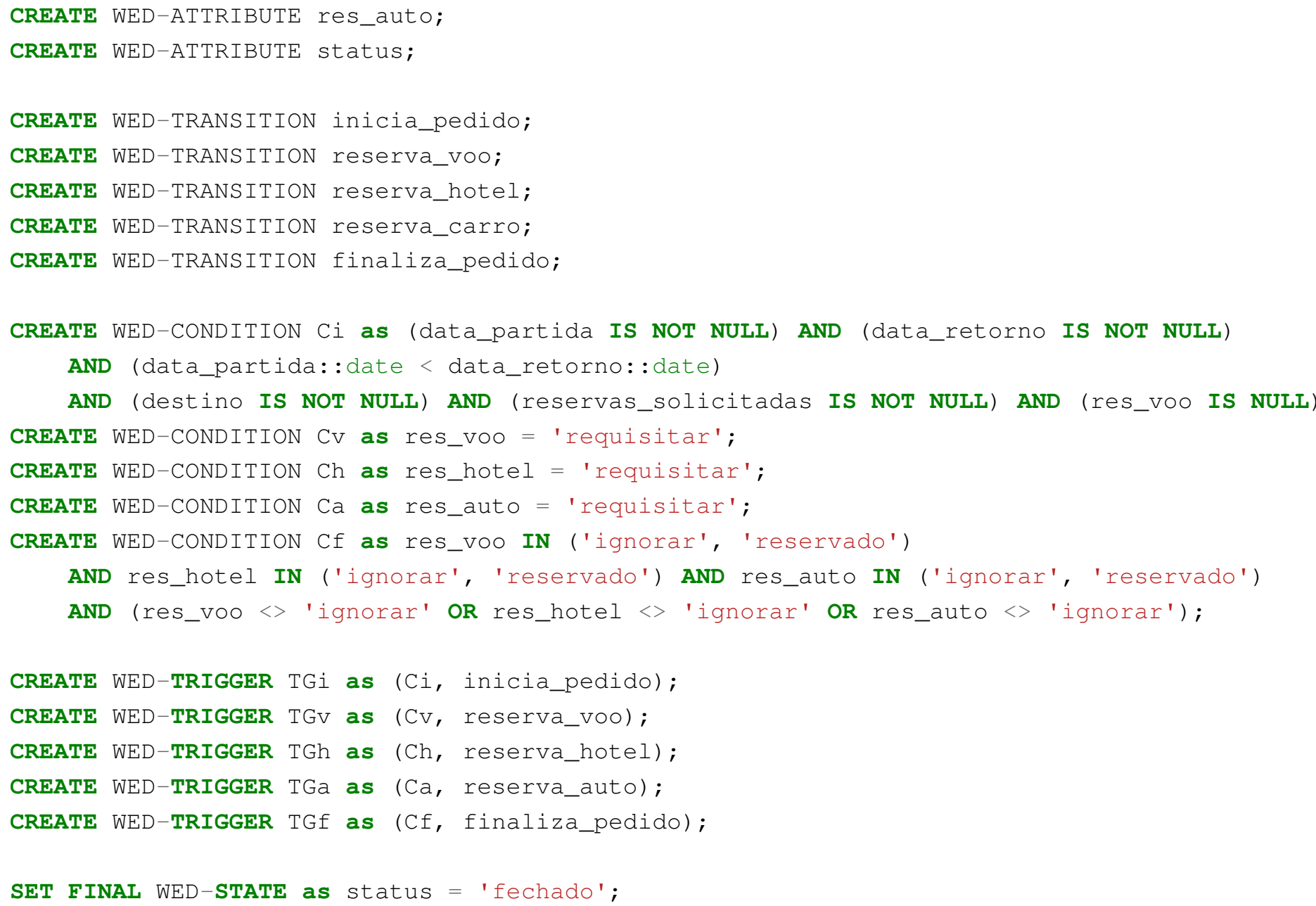

Código 6.1: Declaração do WED-flow da agência de viagens em WED-SQL

\subsubsection{Implementando as WED-transitions}

Conforme discutido no capítulo 4, WED-worker é uma interface de programação que encapsula o protocolo de comunicação com o ambiente de execução da linguagem WEDSQL. Com isso, permite que as WED-transitions sejam implementadas como processos do sistema operacional. Para a agência de viagens, haverá um WED-worker para cada WEDtransition. Por exemplo, o código 6.2 implementa o WED-worker que executa a WEDtransition inicia_pedido.

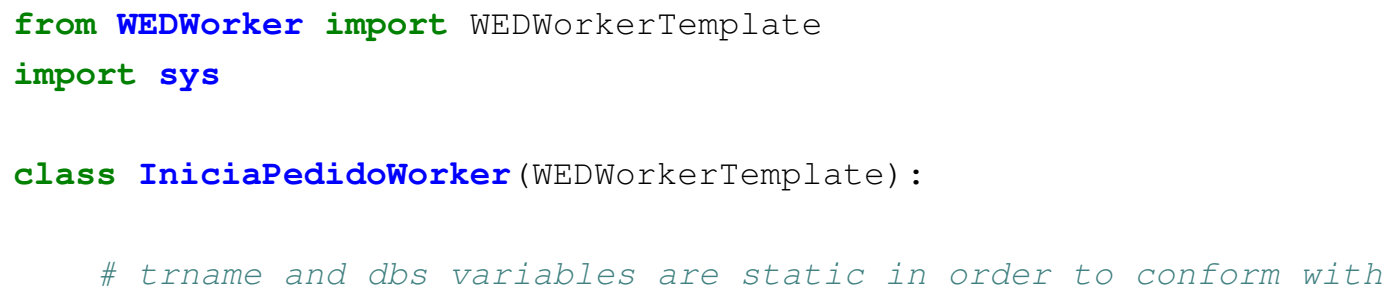




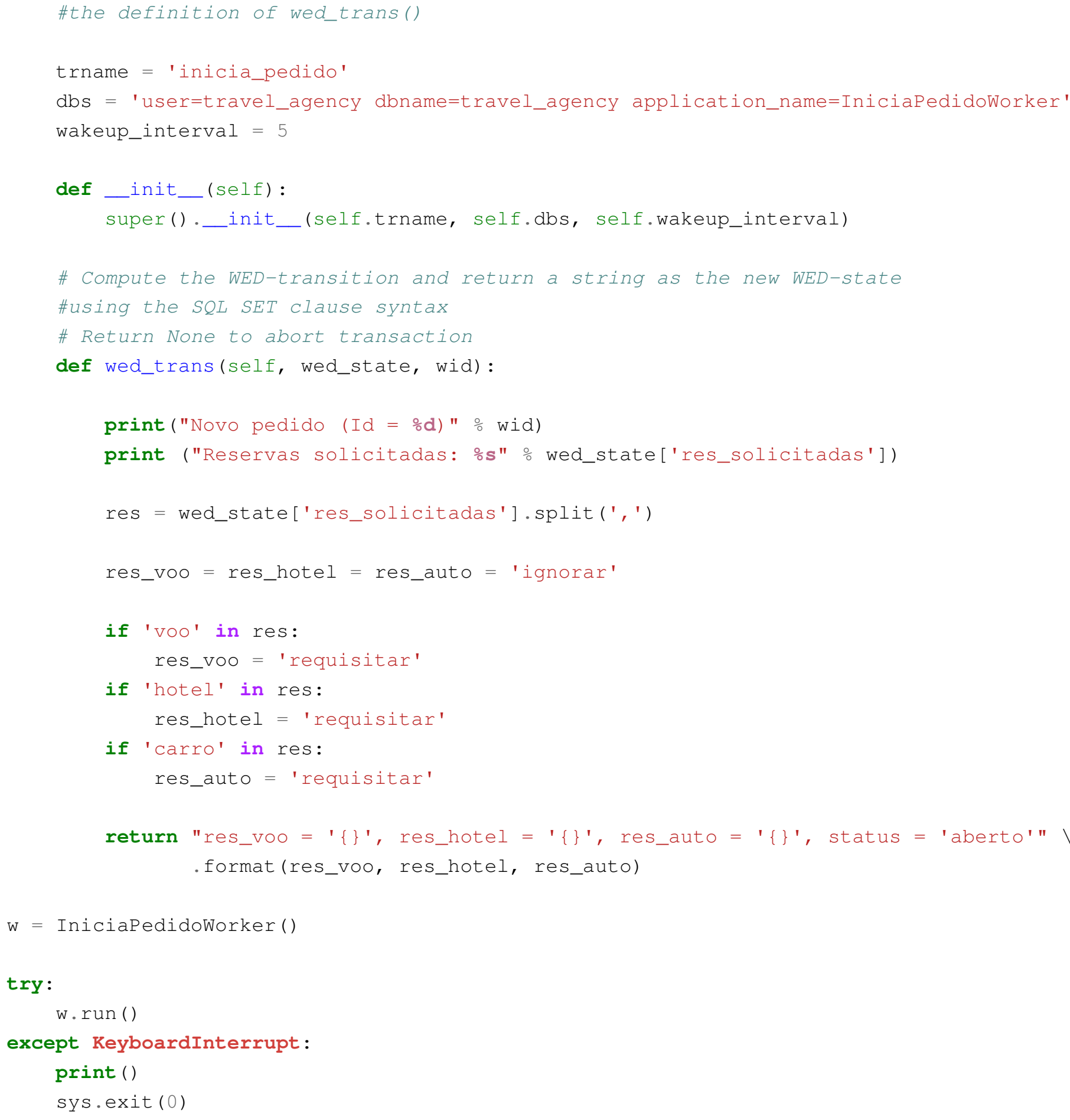

Código 6.2: WED-worker que executa a WED-transition inicia_pedido

A lógica de negócio de inicia_pedido está contida no método wed_trans(self, wed_state, wid) (linhas 19 a 36), o qual inspeciona o WED-attribute "res_solicitadas"(linha 24) a fim de determinar quais reservas deverão ser requisitadas para essa instância. $\mathrm{O}$ valor de retorno é um WED-state que, por meio dos WED-attriutes res_voo, res_hotel, res_auto e status, reflete o resultado da análise anterior. A atribuição do valor 'aberto' para o WED-attribute status nesse ponto de execução da instância tem efeito apenas cosmético, já que, de acordo 
com a condição final desse WED-flow (linha 35 do código 6.1) somente estados de dados cujo valor de status seja 'fechado' interessam para o WED-flow da agencia de viagens.

\subsubsection{Execução \& Análise de Resultados}

Uma vez definidos os elementos do WED-flow da agência de viagens, podemos instanciálo por intermédio do interpretador de comandos WED-SQL. Isso pode ser feito passandose um arquivo de texto contendo o código 6.1 como entrada do interpretador, ou ainda digitando-se os comandos um a um no próprio interpretador. Em seguida, é preciso inicializar a priori todos os WED-workers antes que o ambiente de execução comece a gerar as instância desse WED-flow, de modo a garantir que todo evento de dados modelado para esse sistema seja atendido e processado no menor intervalo de tempo possível. Vale lembrar que, conforme seu mecanismo de funcionamento, os WED-workers consomem pouquíssimos recursos computacionais quando estão ociosos, ou seja, enquanto não estão processando uma WED-transition.

Com o WED-flow instanciado e seus WED-workers prontos para executarem as WEDtransitions, vamos criar duas instâncias, $\alpha$ e $\beta$, e analisar seus históricos de execução. Para a instância $\alpha$, que simula uma reserva que inclui os três serviços fornecidos pela agencia, vamos utilizar o seguinte estado de dados inicial:

$$
\begin{gathered}
s_{0}=(\text { data_partida }=\text { '2018-01-02', data_retorno }=\text { '2018-02-11', } \\
\text { destino }=\text { 'Toronto', res_solicitadas }=\text { 'hotel,carro,voo' })
\end{gathered}
$$

Já a instância $\beta$, a qual requisita apenas reservas de voo e hotel, é inicializada pelo estado de dados:

$$
\begin{gathered}
s_{0}=(\text { data_partida }=\text { '2018-03-05', data_retorno }=\text { '2018-03-17', } \\
\text { destino }=\text { 'Vancouver', res_solicitadas }=\text { 'voo,hotel' })
\end{gathered}
$$

No interpretador, $\alpha$ e $\beta$ são criadas respectivamente com o seguinte comando WEDSQL:

CREATE INSTANCE WITH (data_partida, data_retorno, destino, res_solicitadas)

VALUES ('2018-01-02', '2018-02-11', 'Toronto', 'hotel,carro,voo');

CREATE INSTANCE WITH (data_partida, data_retorno, destino, res_solicitadas)

VALUES ('2018-03-05', '2018-03-17', 'Vancouver', 'voo, hotel'); 
Após criar uma instância, o ambiente de execução irá registrar, de modo incremental, todos os eventos capturados pelas WED-triggers e estados de dados gerados pelas WEDtransitions em seu histórico de execução. Ou seja, é possível acompanhar o progresso do processamento das instâncias em tempo real, o que inclui identificar prontamente se uma dada instância finalizou, foi interrompida como resultado de execução anômala de alguma WED-transition ou segue seu fluxo normal de acordo com a modelagem do WED-flow. A toda instância é atribuído um identificador universal (wid) no momento de sua criação, necessário e suficiente para identificar a qual instância pertencem os registros no histórico de execução. Nesse exemplo, a instância $\alpha$ é identificada pelo valor um (wid $=1$ ), enquanto a instância $\beta$ recebe o identificador dois $($ wid $=2$ ). Em WED-SQL, o histórico de execução de uma instância pode ser recuperado por meio do comando:

GET TRACE FOR <wid>;

O código 6.3 representa o histórico de execução total da instância $\alpha$ em ordem cronológica. Cada registro do histórico tem seis atributos:

- wid-> identificador da instância;

- trw-> WED-transition que gerou o estado de dados apontado por state;

- trf-> WED-transitions disparadas após a ocorrência do estado de dados apontado por state;

- status-> Indica a situação da instância:

- $R$ para execução conforme o previsto na modelagem;

- E para instância interrompida devido à ocorrência de um evento excepcional;

- F para indicar que o estado de dados apontado por state satisfaz a condição final;

- tstmp: Momento da ocorrência do evento;

- state: Estado de dados que gerou o evento;

Note que o atributo trw do primeiro registro contém o valor "_INIT". Esse valor é utilizado pelo ambiente de execução para indicar que o evento de dados registrado é proveniente de um estímulo externo ao sistema que deu origem à instância de que se trata, e não do resultado da execução de uma WED-transition. 

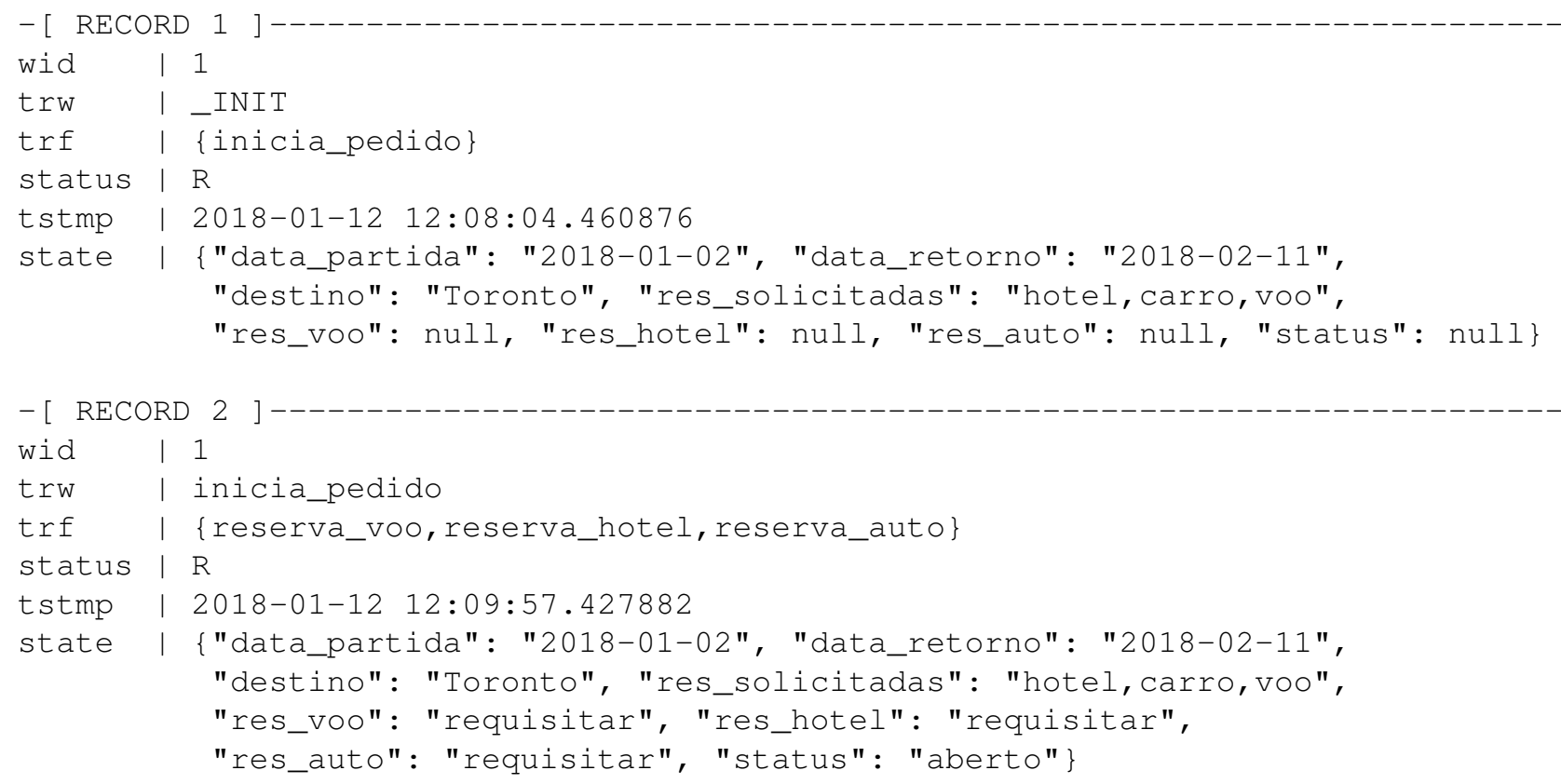

$-[$ RECORD 3 ]

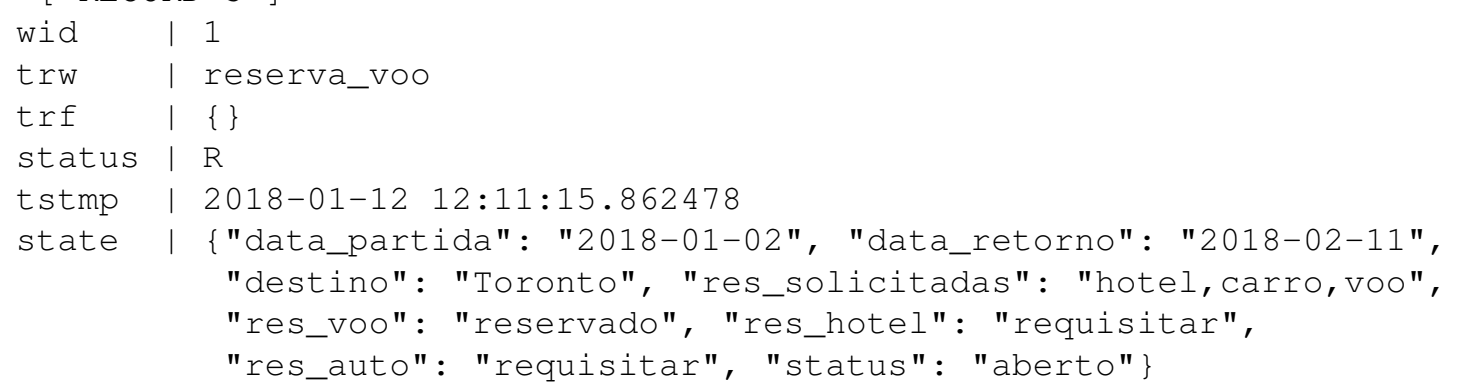




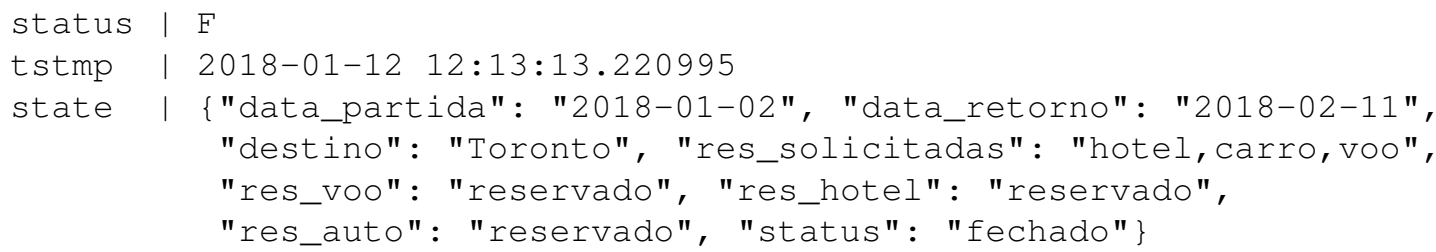

Código 6.3: Histórico de execução da instância $\alpha$

Analisando esse histórico em ordem cronológica da ocorrência dos eventos de dados, podemos compilar a tabela 6.1 associando os estados de dados ao disparo das WED-triggers. O estado s0 é capturado pela WED-trigger TGi, a qual dispara a WED-transition "inicia_pedido". O resultado da execução de "inicia_pedido" é o estado s1, que por sua vez é capturado por TGv, TGh e TGa e ocasiona o disparo simultâneo das WED-transitions "reserva_voo", "reserva_hotel" e "reserva_auto". Nesse exemplo em particular, a primeira WED-transition que termina de executar é "reserva_voo", a qual gera o estado de dados s2, seguida por "reserva_auto" e "reserva_hotel", as quais geram respectivamente os estados s3 e s4. Os estados de dados s2 e s3, denominados Transação Consistentes, apesar de não ocasionarem o disparo de nenhuma WED-transition são necessários para compor o estado s4 e dar continuidade ao fluxo de trabalho da instância. Ao seu término, a WED-transition "reserva_hotel" cria o estado s4. A WED-trigger TGf captura s4 e dispara a WED-transition "finaliza_pedido", a qual retorna o estado s5, que satisfaz a condição final.

\begin{tabular}{|c|c|c|c|c|c|c|c|c|}
\hline & depart & return & destination & reservations & res_flight & res_hotel & res_car & status \\
\hline 0 & 2018-01-02 & 2018-02-11 & Toronto & hotel,car,flight & - & - & - & - \\
\hline 1 & 2018-01-02 & 2018-02-11 & Toronto & hotel,car,flight & request & request & request & ongoing \\
\hline 2 & 2018-01-02 & 2018-02-11 & Toronto & hotel,car,flight & requested & request & request & ongoing \\
\hline 3 & 2018-01-02 & 2018-02-11 & Toronto & hotel,car,flight & requested & request & requested & ongoing \\
\hline 4 & 2018-01-02 & 2018-02-11 & Toronto & hotel,car,flight & requested & requested & requested & ongoing \\
\hline 55 & 2018-01-02 & 2018-02-11 & Toronto & hotel,car,flight & requested & requested & requested & done \\
\hline
\end{tabular}

Tabela 6.1: Sequência de disparo de WED-triggers para a instância $\alpha$

Ao analisar o histórico de execução da instância $\beta$, ilustrado no Código 6.4, a qual solicita apenas as reservas de vôo e hotel, podemos confirmar que o ambiente de execução realmente não ativa a WED-transition "reserva_auto". O registro 2 do histórico mostra que o estado de dados retornado pela WED-transition "inicia_pedido" ocasiona o disparo apenas 
das WED-transitions "reserva_voo" e "reserva_hotel". De maneira intuitiva, a tabela 6.2 compila os estados de dados envolvidos no processamento da instância $\beta$ afim de ilustrar a captura de eventos pelas WED-triggers.

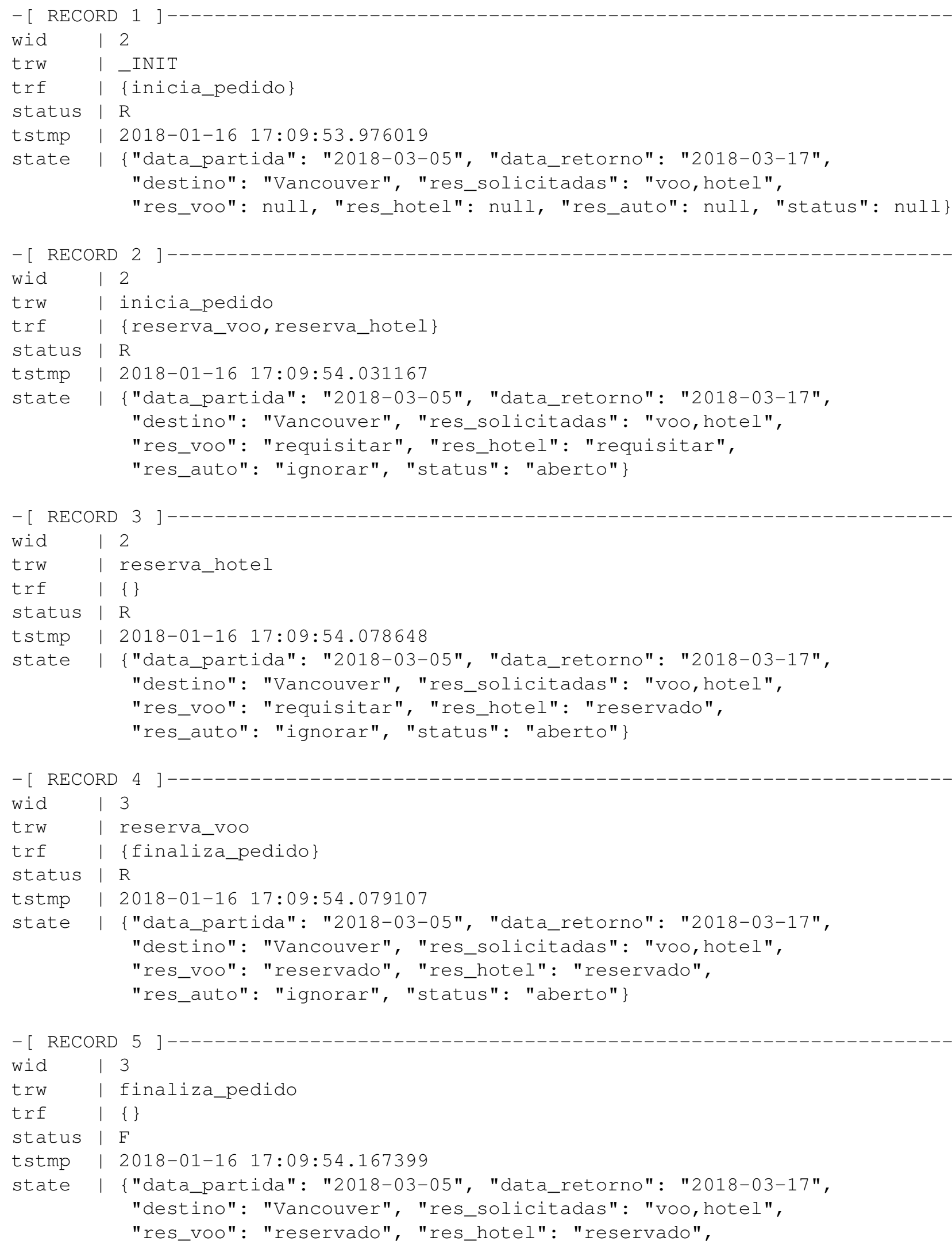


"res_auto": "ignorar", "status": "fechado"

Código 6.4: Histórico de execução da instância $\beta$

Na tabela 6.2, o estado de dados $s 0$, o qual inicia a instância, é capturado pela WEDtrigger TGi e acarreta no disparo da WED-transition "inicia_pedido". Diferentemente da instância $\alpha$, o estado de dados s1, gerado por "inicia_pedido", da instância $\beta$ contém o valor 'ignorar' para o WED-attribute "res_auto". Com isso, apenas as WED-triggers TGv e TGh capturam $s 1$ e disparam, respectivamente e simultaneamente, as WED-transitions "res_voo" e "res_hotel". O estado de dados s2, resultante da execução de "res_voo", embora não seja capturado por nenhuma WED-trigger é necessário para compor o estado de dados s3, o qual implica no disparo da WED-transition "finaliza_pedido". O estado de dados s4, gerado por "finaliza_pedido", satisfaz a condição final do WED-flow e finaliza a instância.

\begin{tabular}{|c|c|c|c|c|c|c|c|c|}
\hline & depart & return & destination & reservations & res_flight & res_hotel & res_car & status \\
\hline 80 & 2018-03-05 & 2018-03-17 & Vancouver & flight,hotel & - & - & - & - \\
\hline s1 & 2018-03-05 & 2018-03-17 & Vancouver & flight,hotel & request & request & ignore & ongoing \\
\hline 82 & 2018-03-05 & 2018-03-17 & Vancouver & flight,hotel & requested & request & ignore & ongoing \\
\hline 83 & 2018-03-05 & 2018-03-17 & Vancouver & flight,hotel & requested & requested & ignore & ongoing \\
\hline 84 & 2018-03-05 & 2018-03-17 & Vancouver & flight,hotel & requested & requested & ignore & done \\
\hline
\end{tabular}

Tabela 6.2: Sequência de disparo de WED-triggers para a instância $\beta$

\subsection{Estendendo o Exemplo}

Um avanço consideravelmente importante, proveniente da adoção da abordagem WEDflow na modelagem e implementação de processos de negócio $(\mathrm{PN})$ frente às abordagens mais tradicionais, é a naturalidade com que mudanças recorrentes no modelo de negócio, cada vez mais frequentes e em volume crescente em um mundo cada vez mais conectado, podem ser dinamicamente incorporadas ao sistema de software que implementa esse PN. Como consequência direta, a versatilidade da WED-flow nos permite construir sistemas que se adaptam as necessidades do PN modernos sem abrir mão de uma implementação robusta ou de uma modelagem bem estruturada. Alem do mais, por manter uma relação intima entre implementação e modelo, a WED-flow otimiza a manutenibilidade do sistema. 
Para exemplificar a flexibilidade de um sistema WED-flow, vamos incrementar o modelo da agência de viagens adicionando um novo tipo de serviço: reserva de passeios turísticos. Assim, os clientes terão a opção de incluir em seu pacote de viagem, além das reservas de voo, carro e hotel, uma reserva de um pacote de passeios turísticos disponíveis para o destino escolhido. Além dessa nova funcionalidade, vamos permitir também que os clientes possam decidir se aceitam resultados parcialmente bem sucedidos das reservas requisitadas. Por exemplo, ao requisitar reservas de voo e hotel o cliente descobre que para o destino e datas informados não existe disponibilidade de quartos de hotel. Não obstante, o cliente não deseja alterar nem as datas nem o destino escolhidos, mas decide fechar o pacote apenas com a reserva de voo. Na nova versão do sistema, esse desvio do fluxo de execução previsto das instâncias, outrora não permitido, nao mais necessariamente implica na interrupção imediata do processamento da instância.

Seguindo a metodologia de modelagem desenvolvida ao longo deste capítulo, ao adicionar a reserva de passeios na agência de viagens podemos identificar o seguinte evento de interesse:

- A agência solicita reserva de passeio.

Desse novo evento, derivamos a WED-transition "reserva_passeio". Com a finalidade de manter o exemplo simples, assim como feito para as demais WED-transitions, vamos assumir que "reserva_passeio" simplesmente inclui um único passeio, composto essencialmente por um tour pela cidade destino. Assim, temos que:

- reserva_passeio: Caso o cliente opte por incluir em seu pacote uma reserva de passeio turístico na cidade destino ou arredores, essa WED-transition é responsável por contatar as agências de turismo locais e agendar o passeio pela cidade.

De maneira análoga às WED-transitions que executam as demais reservas, será necessário criar um novo WED-attribute para contemplar os estados de dados envolvidos tanto no disparo quanto no resultado da execução de "reserva_passeio". Esse WED-attribute, denominado res_tour, pode assumir os seguintes valores: 'requisitar', 'ignorar', 'reservado' e 'erro'. Os valores 'requisitar' e 'ignorar' são atribuídos pela WED-transition inicia_pedido respectivamente quando o cliente optar por incluir ou não o passeio no pacote. Já os valores 'reservado' e 'erro' representam o resultado da execução de "reserva_passeio".

Na sequência, devemos parametrizar o evento de dados e associá-lo à WED-transition "reserva_passeio". Para tal, vamos definir a WED-condition "Cp" e a WED-trigger "TGp" como ilustrado na figura 6.3. Entretanto, a simples inclusão dessa WED-trigger no sistema 


$$
\underbrace{}_{T G p} T p\left\{\begin{array}{l}
C p->\text { (res_tour }=\text { 'requisitar') } \\
T p->\text { reserva_passeio }
\end{array}\right.
$$

Figura 6.3: WED-trigger que incrementa o WED-flow da agência de viagens adicionando o serviço de reserva de passeio turístico

não é suficiente para definir o fluxo de trabalho pretendido, é preciso modificar tanto a WEDtrigger "TGi", a qual dispara a WED-transition "inicia_pedido", quanto a WED-trigger "TGf", que dispara a WED-transition "finaliza_pedido".

A WED-transition "inicia_pedido" é responsável por gerar os eventos de interesse das WED-transitions que efetuam as reservas de vôo, carro e hotel. Desse modo, ao incluir o serviço de reserva de passeio turístico na agência de viagens, a mesma deverá ser capaz de, complementarmente, gerar o evento de dados de interesse da reserva de passeio. Essa modificação é basicamente verificar, além das demais reservas, se o cliente solicitou a reserva de passeio e escrever o resultado no WED-attribute res_tour. O código 6.5 ilustra como WED-worker que implementa "inicia_pedido" (código 6.2) deve ser alterado para incorporar essa nova lógica de negócio. A nova versão de "inicia_pedido" recebe o nome de "inicia_pedido_v2"

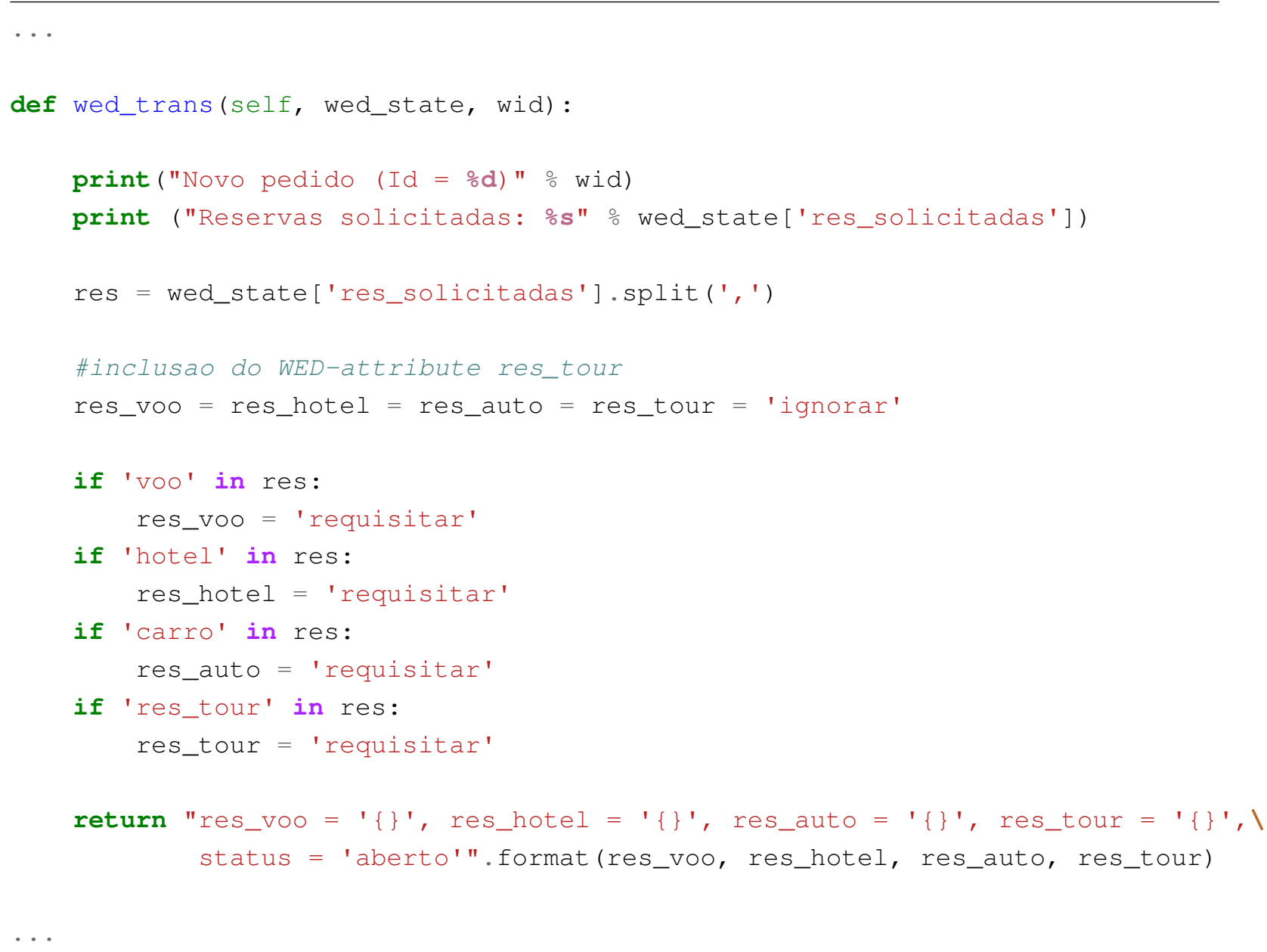


Código 6.5: Extensão da WED-transition inicia_pedido para incluir reserva de passeios

Supondo-se uma sequência prevista de disparos de WED-triggers ao longo do processamento de uma instância, a execução da WED-transition "finaliza_pedido" deve ocorrer somente após todas as WED-transitions que realizam as reservas solicitadas terminem de executar. Sendo assim, é preciso modificar sua WED-condition associada de modo que seu disparo esteja condicionado complementarmente à possível requisição de uma reserva de passeio. Para implementar a outra proposta de modificação incremental do WED-flow da agência de viagens, a qual permite, conforme discutido anteriormente, que o cliente que requisitou um pacote de viagem possa decidir se aceita ou não que algumas, mas não todas, reservas solicitadas não puderam ser efetivadas para as datas e destino escolhidos, também será necessário modificar a WED-condition associada à WED-transition "finaliza_pedido". Com isso, definimos por Cfv2 essa nova WED-condition que captura ambas modificações da seguinte maneira:

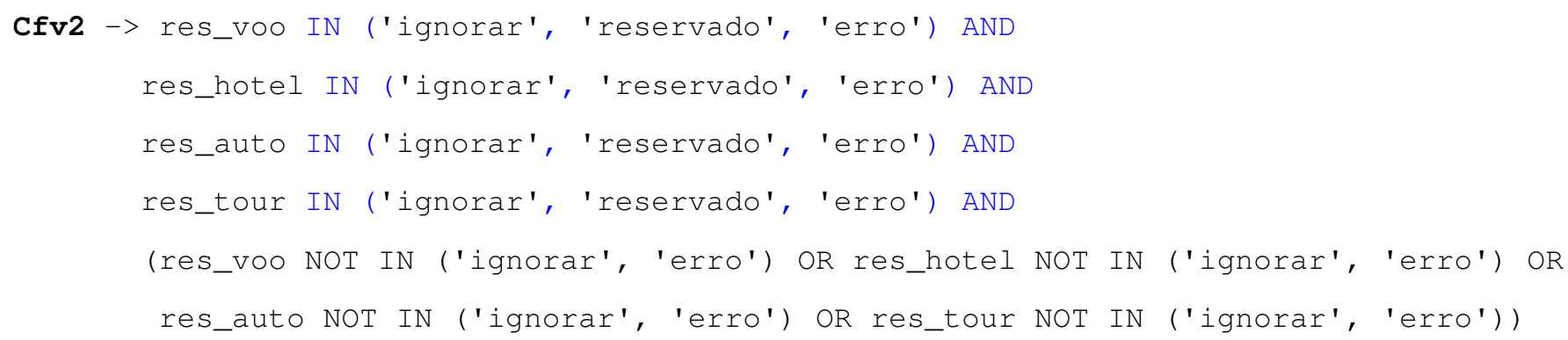

Além disso, também será preciso modificar a WED-transition "finaliza_pedido", a qual precisará permitir que o cliente decida se um resultado parcial é aceitável ou não. À nova versão de "finaliza_pedido" daremos o nome de "finaliza_pedido_v2" .Caso o cliente opte por não aceitar o resultado parcial, "finaliza_pedido_v2" deverá gerar um estado de dados que interrompa a execução da instância, ou seja, esse estado de dados que a princípio não é capturado por nenhuma das WED-conditions da agência de viagens coloca a instância em estado de exceção. Por outro lado, caso o cliente aceite o resultado parcial a instância finaliza com sucesso, todavia por um caminho alternativo. Desse modo, o WED-attribute status, que efetivamente representa o resultado da execução de "finaliza_pedido_v2", poderá assumir os seguintes valores:

- 'fechado': assim como no exemplo original, indica que a instância executou com sucesso seguindo o caminho previsto; 
- 'fechado_alt': indica que a instância executou com sucesso seguindo o caminho alternativo no caso em que o cliente aceita um resultado parcial;

- 'recusado': indica que o cliente recusou o resultado parcial oferecido a ele.

Por consequência, os estados de dados aceitos como finais nesse novo exemplo (EFv2) são capturados pelo predicado:

EFv2 -> status IN ('fechado', 'fechado_alt')

Note que, de acordo com EFv2, apenas estados de dados cujo WED-attribute status contenha ou o valor 'fechado' ou o valor 'fechado_alt' são aceitos como estados finais. Logo, caso a WED-transition "finaliza_pedido" gere um estado de dados cujo WED-attribute status contenha o valor 'recusado', nem a condição de parada sera satisfeita e nenhuma WED-transition será disparada, interrompendo assim a execução da instância. Diante disso, a abordagem WED-flow provê diversos mecanismos de recuperação de exceção, conforme publicado em [19], para auxiliar o projetista do sistema a desenvolver os procedimentos necessários para desfazer ou compensar os efeitos da execução das WED-transitions de acordo com alguma semântica de recuperação. Do ponto de vista de implementação, o processo de recuperação compreende basicamente o desenvolvimento de novas WED-triggers, WEDconditions e WED-transitions para capturar os eventos de exceção e gerar novos estados de dados capazes de levar a instância novamente a um estado consistente. Neste exemplo em que um cliente se recusa a aceitar um resultado parcial, os procedimentos de recuperação envolveriam desfazer as reservas já efetuadas e possivelmente requisitar ao cliente novas datas ou até mesmo um novo destino. O tratamento de exceções no entanto foge ao escopo deste trabalho e não será abordado no exemplo da agência de viagens.

\subsubsection{Implementação em WED-SQL}

Tanto a linguagem WED-SQL quanto seu ambiente de execução permitem que um WED-flow seja modificado em tempo de execução. Novos WED-attributes, WED-conditions e WED-transitions podem ser criados em qualquer momento do seu ciclo de vida, uma vez que adicionar tais elementos a um WED-flow operando em produção não altera seu fluxo de trabalho e tampouco exercem qualquer influência sobre o processamento de suas instâncias. No entanto, é preciso ter cuidado ao adicionar novas WED-triggers a um sistema em produção já que seu efeito sobre as instâncias em processamento dependerá do progresso 
atual de cada instância. Ou seja, dependendo da complexidade do WED-flow e também da quantidade de instâncias em processamento, pode ser inviável tentar prever todos os efeitos da inserção de uma nova WED-trigger. Nesse caso, é mais seguro criar um novo WED-flow que contenha as modificações necessárias para receber as novas instâncias. De fato, estamos criando uma nova versão do WED-flow anterior.

Em [46], é proposta uma extensão da abordagem WED-flow na qual é possível definir múltiplas versões, ou esquemas, para um dado WED-flow baseando-se em um conceito de validade temporal de seus elementos. Com isso, é possível definir, por exemplo, instantes no tempo que determinem a validade de uma WED-trigger. Em outras palavras, uma WED-trigger terá um marco temporal a partir do qual estará ativa e, possivelmente, um outro marco temporal que determine sua desativação. Além disso, também é possível definir políticas de migração para as instâncias, por exemplo, obrigando uma instância a executar completamente no esquema em que foi criada ou ainda fazê-la migrar para o esquema mais atual caso seja complacente. A implementação atual da WED-SQL não contempla essa extensão da abordagem, que será integrada em uma versão futura.

O código 6.6 representa a nova versão do WED-flow da agência de viagens. Embora estejamos efetivamente criando um novo WED-flow, vamos copiar a metaestrutura de dados da versão anterior e inserir as modificações propostas. Desse modo, além do novo WEDattribute 'res_tour', todos os demais WED-attributes declarados anteriormente e seus respectivos domínios serão reutilizados (linhas 4 a 12). Com exceção às WED-transitions 'inicia_pedido_v2' (linha 14), 'finaliza_pedido_v2' (linha 19) e 'reserva_passeio' (linha 18), as demais são exatamente as mesmas do exemplo original. Em relação às WED-conditions, foi introduzida a WED-condition Cp (linha 27), enquanto que a WED-condition Cf do exemplo original deu lugar à Cfv2 (linha 28). Em sequência, as WED-triggers TGv, TGa e TGh (linhas 36 a 38) permaneceram inalteradas, enquanto que as demais são responsáveis por disparar as novas WED-transitions.

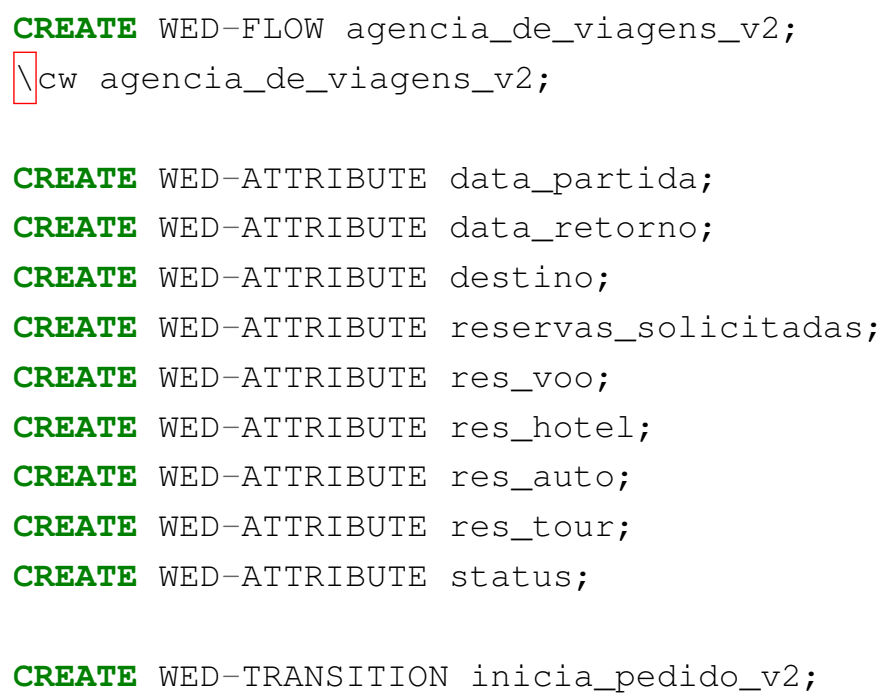




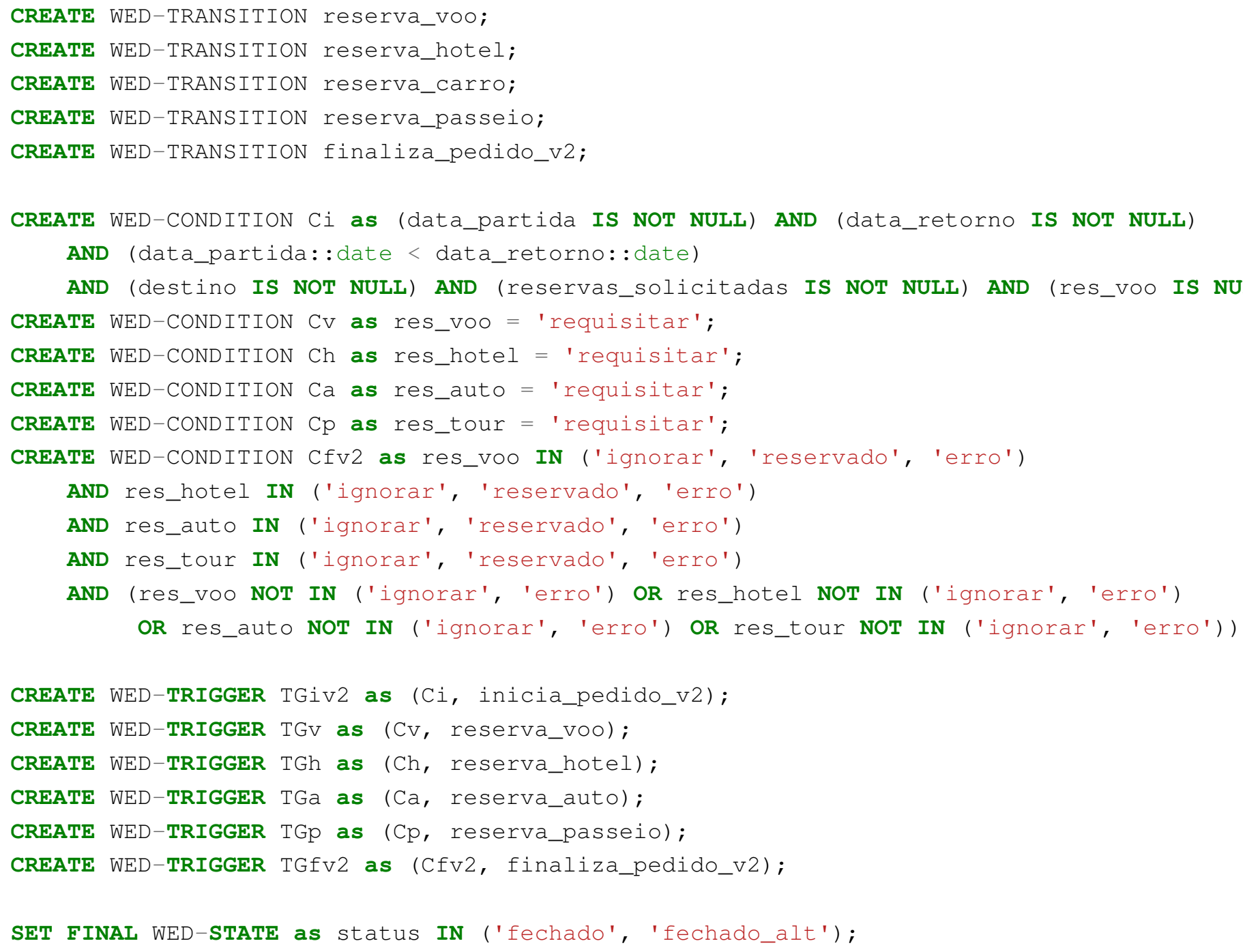

Código 6.6: WED-flow da agência de viagens em WED-SQL contendo os incrementos funcionais propostos

\subsection{Conclusão}

O exemplo da agência de viagens apresenta um método pragmático de se projetar um sistema WED-flow utilizando a linguagem WED-SQL e o ambiente de execução WED-Engine. Foram apresentadas as principais técnicas de modelagem, as limitações atuais da abordagem nos quesitos de recuperação de falhas e da migração de instância em PAIS multiesquema, além de uma análise de detalhes importantes de modelagem e implementação de PAIS utilizando a abordagem WED-flow. Este exemplo ilustrou a eficácia da abordagem WED-flow em modelar e implementar PAIS cuja ordem de execução de processos é determinada em tempo de execução por meio de WED-conditions e de estados de dados. Em outras palavras, o fluxo de trabalho de um PAIS WED-flow é determinado implicitamente por meio 
de dependências de dados. Sempre que não houver conflito entre as dependências de dados para a execução de dois ou mais processos, o WED-Engine irá habilitá-los para executar em paralelo, o que ocorre com as reservas de voo, carro e hotel. Para os demais processos, a execução será sequencial. Esse dinamismo na execução de processos coloca a abordagem WED-flow a frente das demais abordagens como uma solução mais versátil e eficiente para a construção dos PAIS contemporâneos. A abordagem WED-flow está em continua evolução, suas limitações aqui apresentadas serão suplantadas em breve. Resultados recentes, frutos de pesquisas em andamento que ainda serão publicados, contribuem de modo significativo para melhorar e estender a abordagem WED-flow e serão contemplados em versões futuras tanto da linguagem WED-SQL quanto do ambiente de execução WED-Engine. 


\section{Capítulo 7}

\section{Conclusão}

Avanços tecnológicos nas áreas de Tecnologia da Informação, como o aumento da capacidade de comunicação e de processamento e armazenamento de dados, fizeram surgir uma demanda crescente por PAIS cada vez mais complexos e que sejam suficientemente flexíveis para implementar modelos de processos de negócio dinâmicos os quais evoluem ao longo do tempo. Conforme discutido no capítulo 3, a rigidez estrutural imposta por abordagens clássicas para a modelagem e implementação de PAIS não atende a esses novos requisitos de flexibilidade e dinamicidade. Por outro lado, ao integrar os paradigmas de dados, processos e eventos, a abordagem WED-flow emerge como uma alternativa mais robusta e flexível tanto para a modelagem quanto para a implementação dessa nova geração de PAIS. Não obstante, a abordagem WED-flow foi apresentada inicialmente como um conceito teórico, necessitando portanto do apoio de um arcabouço de implementação e de uma linguagem concreta de especificação. A fim de suprir essa necessidade, neste trabalho foram propostas duas contribuições: o ambiente de execução WED-flow denominado WED-Engine e a linguagem declarativa de especificação WED-SQL.

A primeira contribuição deste trabalho, publicada em [40], é o ambiente de execução WED-Engine, um arcabouço transacional cujo propósito é gerenciar a execução de sistemas WED-flow especificados por meio da linguagem SQL. Sua construção foi fundamentada no SGBDR PostgreSQL, o qual oferece ferramentas de implementação por meio das quais é possível estender suas funcionalidades para incorporar novas estruturas de dados e mecanismos de gerenciamento transacional. O WED-Engine é capaz de escalonar dinamicamente a execução das WED-transitions de acordo com sua dependência de dados, ou seja, WEDtransitions não codependentes executam em paralelo, enquanto que as demais executam de modo sequencial. Além disso, o WED-Engine é adequado para executar em ambientes distribuídos uma vez que as WED-transitions são implementadas por meio de serviços externos ao SGBDR. 
A segunda contribuição deste trabalho, publicada em [39], é a linguagem WED-SQL, uma linguagem declarativa, de sintaxe similar à linguagem SQL, cujo propósito é servir como uma linguagem de especificação intermediária entre a notação matemática originalmente empregada para descrever os elementos de um modelo WED-flow e a linguagem SQL utilizada pelo WED-Engine. No contexto da abordagem WED-flow, a linguagem WED-SQL é uma linguagem específica de domínio desenvolvida para representar fielmente os elementos da WED-flow de modo simples e intuitivo, simplificando o desenvolvimento desses sistemas. A WED-SQL é definida formalmente por meio de uma gramática livre de contexto, a qual é utilizada por um interpretador de comandos para traduzir suas operações para comandos SQL e enviá-los ao WED-Engine. Além disso, dada sua definição formal, a WED-SQL pode mais facilmente ser estendida para contemplar novas operações decorrentes da evolução da abordagem WED-flow.

A linguagem WED-SQL e o ambiente de execução WED-Engine provém a infraestrutura de software necessária à implementação eficiente de PAIS modelados sob os conceitos da abordagem WED-flow. Essas ferramentas de software foram empregadas no desenvolvimento do sistema SISAUT [18], um PAIS para o gerenciamento de autópsias e coleta de materiais para experimentos científicos cujas dependências de dados entre processos é inerentemente complexa. Os resultados desse experimento comprovam não apenas os benefícios oriundos de utilizar-se a abordagem WED-flow para a modelagem de PAIS adequados para gerenciar um alto nível de interdependência de dados entre processos, como também a eficácia da linguagem WED-SQL e do ambiente de execução WED-Engine.

Nossa pesquisa em andamento inclui o desenvolvimento de um mecanismo de adaptação que tem como principal sustentação os aspectos temporais. Mais concretamente, o tempo de validade, o tempo de transação e o tempo de execução da transação serão incorporados às estruturas do WED-flow. Essa evolução na representação de aspectos temporais proporcionará a execução de PAIS adaptativos e suas respectivas validações formais de terminação. Além disso, temos esforços contínuos para garantir propriedades de correção em modelos de fluxo WED que são capazes de evitar anomalias no momento da criação. Em relação ao tratamento de exceção, estamos estudando alternativas de otimização introduzindo funções de custo. Adicionalmente, estamos criando um ambiente para predição ou redefinição de processos com base no histórico de execução. 


\section{Referências Bibliográficas}

[1] W. M. P. Aalst, A. H. M. Hofstede, B. Kiepuszewski, and A. Barros. Workflow patterns. In Distributed and Parallel Databases, vol. 14, no. 1, pages 5-51, Jul. 2003. 20

[2] Alfred V. Aho, Monica S. Lam, Ravi Sethi, and Jeffrey D. Ullman. Compilers: Principles, Techniques, and Tools. Addison-Wesley, ISBN-13: 978-0321486813, 2nd edition, 2006. 12,16

[3] N. Alexopoulou, M. Nikolaidou, D. Anagnostopoulos, and D. Martakos. An eventdriven modeling approach for dynamic human-intensive business processes. In Business Process Management Workshops, BPM 2009 International Workshops, Ulm, Germany, pages 393-404, 2009. 21

[4] Andrew W. Appel. Modern Compiler Implementation in C. Cambridge University Press, ISBN-10: 0-521-60765-5, 1st edition, 1998. 12, 16

[5] J. A. Bergstra, A. Ponse, , and S. A. Smolka. Handbook of process algebra. Elsevier, ISBN: 9780080533674, 2001. 1, 20

[6] K. Bhattacharya, N. S. Caswell, S. Kumaran, A. Nigam, and F. Y. Wu. Artifactcentered operational modeling: Lessons from customer engagements. In IBM Systems Journal, vol. 46, no. 4, pages 703-721, 2007. 22

[7] K. Bhattacharya, C. Gerede, R. Hull, and J. Su. Towards formal analysis of artifactcentric business process models. In Proceedings of the 5th international conference on Business information systems, pages 288-304, 2007. 22

[8] Antonio Brogi and Razvan Popescu. From bpel processes to yawl workflows. In WS-FM 2006: Web Services and Formal Methods, pages 107-122, 2006. 20

[9] F. Bry, M. Eckert, P. L. Patranjan, and I. Romanenko. Realizing business processes with eca rules: Benefits, challenges, limits. In Proceedings of the 4 th International Conference on Principles and Practice of Semantic Web Reasoning, pages 48-62, 2006. 21

[10] F. Bry and P. L. Patranjan. Reactivity on the web: paradigms and applications of the language xchange. In Proceedings of the 2005 ACM symposium on Applied computing, pages $1645-1649,2005.21$

[11] F. Casati, S. Castano, M. Fugini, I. Mirbel, and B. Pernici. Using patterns to design rules in workflows. In IEEE Transactions on Software Engineering, Volume 26 Issue 8, August 2000, pages 760-785, 2000. 21

[12] Robert Corbett. Gnu bison. https://www.gnu.org/software/bison/. 2014. 16 
[13] B. Curtis, M. I. Kellner, and J. Over. Process modeling. In Communications of the ACM - Special issue on analysis and modeling in software development, Volume 35 Issue 9, pages 75-90, Sep. 1992. 19

[14] Umeshwar Dayal. Active Database Systems: Triggers and Rules for Advanced Database Processing. Morgan Kaufmann Publishers Inc. San Francisco, CA, USA. ISSN: 1558603042, 1st edition, 1994. 2, 21

[15] Marlon Dumas, Wil van der Aalst, and H. M. ter Hofstede Arthur. Process-Aware Information Systems: Bridging People and Software through Process Technology. Willey,New York, NY, USA. ISBN: 978-0-471-66306-5, 1st edition, September 2005. 1, 20

[16] Héctor García-Molina e Kenneth Salem. Sagas. In SIGMOD '87 Proceedings of the 1987 ACM SIGMOD international conference on Management of data, pages 249-259, 1987. 2

[17] Ahmed K. Elmagarmid. Database Transaction Models for Advanced Applications. Morgan Kaufmann Publishers Inc. San Francisco, CA, USA. ISSN: 1558602143, 1st edition, April 1992. 2, 9, 41

[18] Joao Eduardo Ferreira, Pedro Losco Takecian, Leonardo Tadashi Kamaura, Bruno Padilha, and Calton $\mathrm{Pu}$. Dependency management with wed-flow techniques and tools: A case study. In 2017 IEEE 3rd International Conference on Collaboration and Internet Computing (CIC), California, USA, ISBN-13: 978-1-5386-2565-1, 2017. 80

[19] João Eduardo Ferreira, Kelly Rosa Braghetto, Osvaldo Kotaro Takai, and Calton Pu. Transactional recovery support for robust exception handling in business process services. In ICWS '12 Proceedings of the 2012 IEEE 19th International Conference on Web Services, pages 303-310, 2012. 3, 6, 22, 34, 41, 55, 74

[20] João Eduardo Ferreira, Osvaldo Kotaro Takai, Simon Malkowski, and Calton Pu. Reducing exception handling complexity in business process modeling and implementation:the wed-flow approach. In Proceedings of the 2010 international conference on On the move to meaningful internet systems - Volume Part I, pages 150-167. SpringerVerlag, 2010, 2010. 56

[21] Martin Fowler. Domain Specific Languages. Addison-Wesley Professional, ISBN-13: 978-0321712943, 1st edition, 2010. 4, 40

[22] C. E. Gerede, K. Bhattacharya, and J. Su. Static analysis of business artifact-centric operational models. In Proceedings of the IEEE International Conference on ServiceOriented Computing and Applications, ser. SOCA 'O'7, pages 133-140, 2007. 22

[23] Jim Gray. The transaction concept: Virtues and limitations. In Proceedings of the 7th International Conference on Very Large Data Bases, volume 7 of VLDB, pages 144-154, 1981. 2,34

[24] The PostgreSQL Global Development Group. Postgresql: The world's most advanced open source relational database. https://www.postgresql.org/. 2017. 9, 35

[25] Steve Heath. Microprocessor Architectures, Second Edition: RISC, CISC and DSP. Newnes; 2 edition (May 10, 1995), ISBN-13 978-0750623032, 1995. 13 
[26] S. Jablonski and C. Bussler. Workflow Management: Modeling Concepts, Architecture, and Implementation. International Thomson Computer Press, London, UK, 1996. 19

[27] John Levine. Flex Ef Bison. O'Reilly, ISBN-13: 978-0596155971, 1st edition, 2009. 16

[28] R. Lu and S. Sadiq. A survey of comparative business process modeling approaches. In Proceedings of the 5th international conference on Business information systems, pages 82-94, 2007. 1, 20

[29] D. Luckham. The Power of Events: An Introduction to Complex Event Processing in Distributed Enterprise Systems. Addison-Wesley Professional, ISBN:0201727897, 2001. 21

[30] Marco Montali. The condec language. In Specification and Verification of Declarative Open Interaction Models. Lecture Notes in Business Information Processing, vol 56. Springer, Berlin, Heidelberg, pages 47-75, 2010. 21

[31] T. Murata. Petri nets: Properties, analysis and applications. In Proceedings of the IEEE, vol. 77, no. 4. IEEE Computer Society, pages 541-580, 1989. 1, 20

[32] D. Müller, M. Reichert, and J. Herbst. Data-driven modeling and coordination of large process structures. In On the Move to Meaningful Internet Systems200\%: CoopIS, DOA, ODBASE, GADA, and IS. OTM 200\%. Lecture Notes in Computer Science, vol 4803. Springer, Berlin, Heidelberg, pages 131-149, 2007. 21

[33] D. Müller, M. Reichert, and J. Herbst. A new paradigm for the enactment and dynamic adaptation of data-driven process structures. In Advanced Information Systems Engineering. CAiSE 2008. Lecture Notes in Computer Science, vol 5074. Springer, Berlin, Heidelberg, pages 48-63, 2008. 21

[34] D. Müller, M. Reichert, J. Herbst, D. Köntges, and A. Neubert. Corepro sim: A tool for modeling, simulating and adapting data-driven process structures. In 6th Int'l Conf. on Business Process Management (BPM'08 Demonstrations), Milan, Italy, pages 394-397, 2008. 21

[35] A. Nigam and N. S. Caswell. Business artifacts: An approach to operational specification. In IBM Systems Journal, vol. 42, no. 3, pages 428-445, 2003. 22

[36] OASIS. Web services business process execution language version 2.0. http://docs. oasis-open.org/wsbpel/2.0/wsbpel-v2.0.html. 2007. 20

[37] OASIS. Web services business process execution language version 2.0 (wsbpel). http: //docs.oasis-open.org/wsbpel/2.0/OS/wsbpel-v2.0-OS.html. 2007. 1

[38] OMG. Business process model and notation 2.0 (bpmn). http://www.omg.org/spec/ $\mathrm{BPMN} / 2.0 / .2011 .1,20$

[39] Bruno Padilha, Rafael Liberato Roberto, André Luis Schwerz, Calton Pu, and João Eduardo Ferreira. Wed-sql: An intermediate declarative language for pais execution. In 2018 International Conference on Web Services (ICWS), Seattle, USA, ISBN-13: 978-3-31994289-6, 2018. 80 
[40] Bruno Padilha, André Luis Schwerz, and Rafael Liberato Roberto. A relational framework for design and implementation of process-aware information systems. In 2017 IEEE 37th International Conference on Distributed Computing Systems Workshops (ICDCSW), Atlanta, USA, ISBN-13:978-1-5386-3292-5, 2017. 79

[41] Terence Parr. Antlr (another tool for language recognition). http://www.antlr.org/. 2018. 16

[42] Terence Parr and Kathleen Shanahan Fisher. $\operatorname{Ll}\left({ }^{*}\right)$ : the foundation of the antlr parser generator. In ACM SIGPLAN Notices (PLDI 2011), DOI: 10.1145/1993316.1993548, 2011. 16

[43] Terrence Parr. The Definitive Antlr 4 Reference. Pragmatic Bookshelf, ISBN-13: 9781934356999, 2nd edition, 2013. 16

[44] Maja Pesic, Helen Schonenberg, and Wil. M. P. van der Aalst. Declare: Full support for loosely-structured processes. In Enterprise Distributed Object Computing Conference, 200\%. EDOC 200\%. 11th IEEE International, page 287, 2007. 21

[45] Eric S. Raymond. The Art of UNIX Programming, Chapter 8: Minilanguages. AddisonWesley Professional, ISBN-13: 978-0-13-142901-7, 1st edition, 2003. 40

[46] R. L. Roberto. Aumentando a Migração de Instâncias Não Complacentes em Sistemas de Informação Cientes de Processos. PhD thesis, Instituto de Matemática e Estatística, Universidade de São Paulo, Brasil, Dezembro 2016. 22, 75

[47] A. L. Schwerz. Sistemas de Informação Cientes de Processos, Robustos e Confiáveis. PhD thesis, Instituto de Matemática e Estatística, Universidade de São Paulo, Brasil, Dezembro 2016. 22

[48] Wil. M. P. van der Aalst. Process-aware information systems: Lessons to be learned from process mining. In Wil. M. P. van der Aalst Kurt Jensen, editor, Transactions on Petri Nets and Other Models of Concurrency II, pages 1-26. primeira edition, 2009. 23

[49] Wil. M. P. van der Aalst. Business Process Management: A Comprehensive Survey. ISRN Software Engineering, 2013(507984):37, 2013. 56

[50] Wil. M. P. van der Aalst and Maja Pesic. Decserflow: Towards a truly declarative service flow language. In Web Services and Formal Methods. WS-FM 2006, pages 1-23, 2006. 21

[51] W.M.P. van der Aalst, A.H.M. ter Hofstede, and M.H. Weske. Business process management: a survey. In Business Process Management, International Conference, BPM 2003, Eindhoven, The Netherlands, pages 1-12, Jun. 2003. 1, 20

[52] Matthias Weidlich, Gero Decker, Alexander Großkopf, and Mathias Weske. Bpel to bpmn: The myth of a straight-forward mapping. In On the Move to Meaningful Internet Systems: OTM 2008, pages 265-282, 2008. 2, 20

[53] WfMC. Workflow management coalition. http://www.wfmc.org. 2018. 19

[54] M. Pesic e H. Schonenberg Wil. M. P. van der Aalst. Declarative workflows: Balancing between flexibility and support. Comp. Sci. Res. Dev, 23(2):99-113, May 2009. 2, 20 
[55] P. Wohed, W. M. P. van der Aalst, M. Dumas, A. H. M. ter Hofstede, and N. Russell. On the suitability of bpmn for business process modelling. In Business Process Management. BPM 2006, pages 161-176, 2006. 1

[56] Michael zur Muehlen. Workflow-based Process Controlling: Foundation, Design,and Application of workflow-driven Process Information Systems. Logos Berlin (Verlag), ISBN: 978-3-8325-0388-8, 1st edition, 2004. 1, 19 